\title{
Factors Promoting \\ Coexistence between \\ Endemic Ants and \\ Invasive Wasps
}

by

\section{Catherine Duthie}

\author{
A thesis submitted to \\ Victoria University of Wellington \\ in fulfilment of the requirements for the degree of \\ Doctor of Philosophy in Ecology and Biodiversity \\ Victoria University of Wellington \\ 2011
}




\section{Abstract}

Invasive animals can alter the community composition of native ecosystems by means of competition and predation. In this study I investigated the factors that may facilitate coexistence between endemic ants and invasive wasps. Previous research has shown that entire communities can be impacted by invasions. Endemic species subject to pressure from invasive species may undergo a niche shift to enable coexistence and minimise the impact of this pressure. The invertebrate community composition of Nothofagus forests in the South Island of New Zealand has been altered by predation from Invasive Vespula wasps. Ants and wasps in this ecosystem coexist on the same trophic level; they simultaneously fill multiple trophic roles as primary predators, secondary predators, and primary consumers. The outcome of competition between species such as ants and wasps is not easy to predict, and may vary in different communities and with different densities of competitors.

In this dissertation I aimed to determine the extent to which competition occurs between native ants and invasive Vespula wasps, and to investigate the impacts of invasion on the native invertebrate community. I quantified the invertebrate community composition of Nothofagus forests and then experimentally reduced wasp numbers to investigate any changes as a result of a reduction in predation or competition.

The observed changes in community composition were as a result of differing abundances of taxonomic groups within my study sites. In order to more robustly determine the community effects of wasp removal it may be necessary to reduce wasp numbers by up to $90 \%$ for many years. Even under these conditions, species that are particularly vulnerable to wasp predation or competition may have already been permanently excluded from this system. 
I then investigated temporal niche shifts by native ants when faced with reduced competition for food resources from invasive wasps. There was an increase in the numbers of ants foraging on honeydew when I experimentally reduced wasp numbers. This increase may be due to increases in both the quantity and quality of the available honeydew. When densities of wasps were substantially reduced there was a difference in the foraging abundances of ants and wasps; however, there was no change in the overall temporal foraging pattern of ants.

Isotope ratios and consequently trophic levels of native competitors may change in response to the removal of an invasive species. To test this I examined changes in isotope ratios as a result of removal of wasps. The observed changes in the trophic levels of both ants and wasps appear to be a result of natural seasonal variation in consumption related to the nutritional requirements of the colony.

Finally, I examined behavioral interactions between native ants and invasive wasps during foraging. This study has indicated that wasps may find and access resources more readily when ants are present. Native ants may facilitate foraging by wasps, as demonstrated by the increase in wasp numbers when foraging in the presence of ants. Additionally, the impact of competition between wasps and ants is likely to be density dependant.

Co-occurrence between endemic and invasive competitors is possible through two important mechanisms, niche separation and behavioural adaptations. Native ants in this system are able to forage in different temporal niches than invasive wasps, and their dominant behaviour serves to diminish competitive interactions. These findings have implications for the ecology of these forests in understanding the considerable impact that invasive species may have on native ecosystems and particularly those species which have similar resource requirements. 


\section{Acknowledgments}

This dissertation is the culmination of ten years of university study. Starting as a mature undergraduate in 2000 once I developed a taste for biology there was no looking back. My interest and enthusiasm has been fostered by so many inspirational people within the School of Biological Sciences at Victoria University of Wellington.

In particular I thank my primary supervisor, Associate Professor Phil Lester; his guidance has been invaluable and I will always appreciate his calm manner and superb organisational skills. Dr Angela Moles, my secondary supervisor, was of great help during the initial stages of this degree. Allan Burne has been of particular support; it has been of immense help to have someone to throw ideas at who has some idea what I am talking about. Additionally all the members of Bug Club have been of great assistance over the years from developing the proposal, to the many stages of data collection and writing.

I thank all my field assistants: Laura Warman, Oren Werker, John Searle, Ilse Corkery, Zak Murdoch, Paul Marsden, Allan Burne, Julien Grangier and Laura Bass. Without them the data collection would have been near impossible and not nearly so much fun. Thanks also go to all the administrative staff within the School of Biological Sciences; particularly Patricia Stein. The job of a graduate administrator is often an unenviable one, but her ability to materialise resources out of thin air, with such good humour, is nothing short of miraculous.

Financial support was generously provided by a grant from the Royal Society of New Zealand Marsden Fund and a Victoria University of Wellington PhD scholarship. Without this support the project would not have been possible. Thanks to the Department of Conservation in Nelson Lakes National Park and to the Tasman District Council, particularly the caretakers at the Maitai and Roding waterworks, for access to land. Thanks 
also to Richard Toft and Jo Rees formerly of LandCare research in Nelson for help with the poisoning operation.

With so many people to thank I am sure to have unintentionally overlooked some, I sincerely apologise for this.

Finally I would like to thank my family. My parents, Ian and Barbara Duthie, have been hugely supportive all throughout this degree, and the two preceding ones. Their encouragement and faith in me has made all the difference to this journey, they gave me the confidence to proceed when it all seemed too much. I also thank my sisters, Sarah and Jane, and my brother-in-law, Chamsy, for their support and interest. Thanks also to my lovely son, Zak Murdoch; it is he who provides the inspiration for so much that I do. No parent could wish for a better son. My partner, John Searle, has been wonderful. The support and encouragement and the many fun and interesting things we have done together over the past three years have helped keep this degree in perspective and shown me a side to life that in the past I only dreamed of. 


\section{Contents}

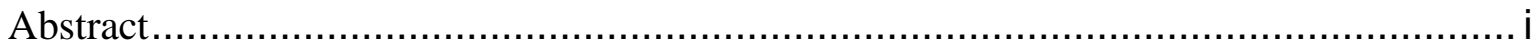

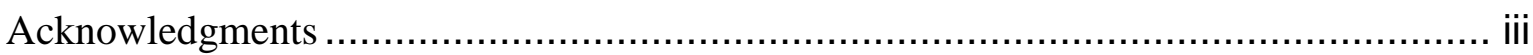

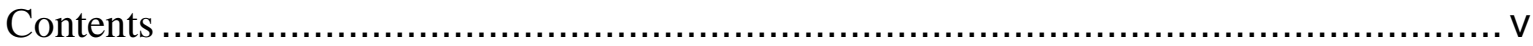

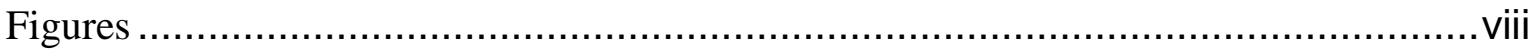

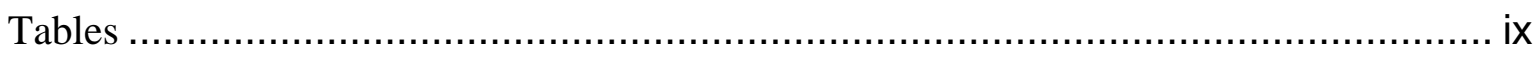

$1 \quad$ Chapter One General Introduction ........................................................ 1

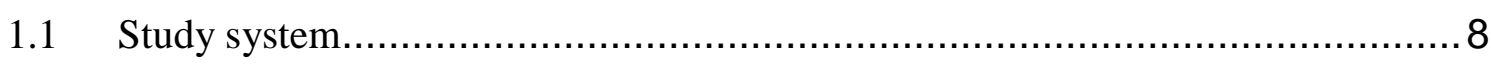

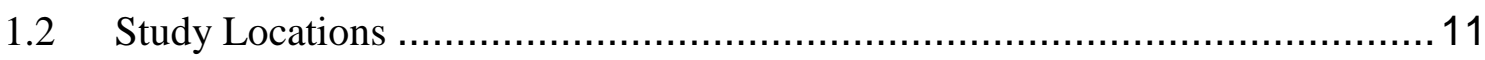

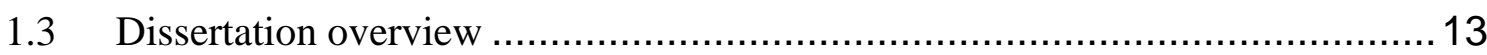

1.3.1 Chapter Two-Invertebrate community composition of Nothofagus forests is impacted by the presence of the invasive wasp Vespula vulgaris............................13

1.3.2 Chapter Three - Temporal patterns of honeydew foraging by an endemic ant and a competing invasive wasp .................................................................. 14

1.3.3 Chapter Four - The trophic level of native ants changes in response to the removal of an invasive competitor ................................................................ 14

1.3.4 Chapter Five - Density-dependent behavioural plasticity in competitive interactions between native ants and invasive wasps.

1.3.5 Chapter Six - General discussion .............................................. 15

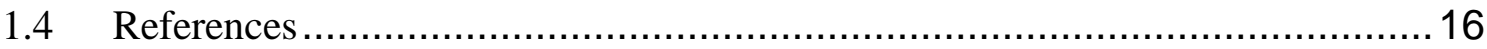

2 Chapter Two Invertebrate Community Composition of Nothofagus Forests is Impacted by the Presence of the Invasive Wasp Vespula vulgaris ...............................21

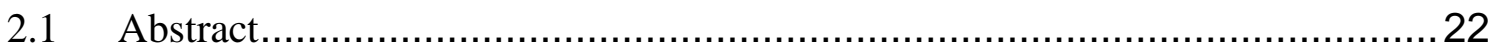

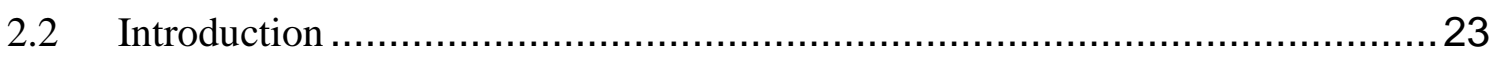

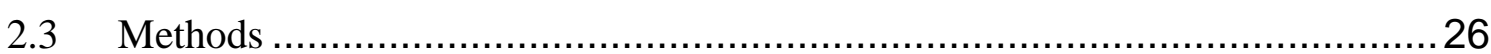

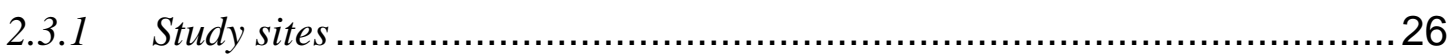

2.3.2 Pitfall and Malaise trapping .......................................................27

2.3.3 Data analysis of invertebrate community composition ..........................28

2.3.4 Vegetation sampling and honeydew abundance ..................................29

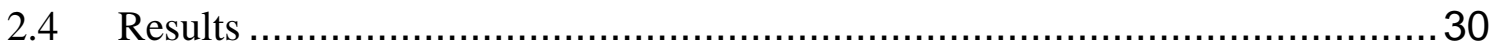

2.4.1 Honeydew abundance and vegetation community composition.................30

2.4.2 Wasp abundance ........................................................... 33

2.4.3 Invertebrate community composition............................................ 34

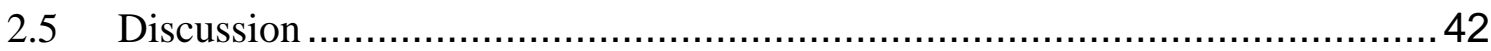

2.5.1 The influence of forest structure and honeydew abundance on community composition ......................................................................................... 42

2.5.2 Changes in community composition following wasp poisoning ................42 
2.5.3 Changes in ant abundance following common wasp poisoning ................46 46

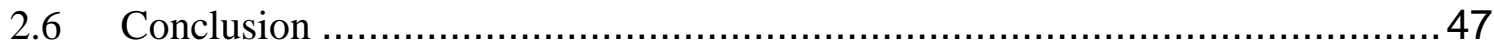

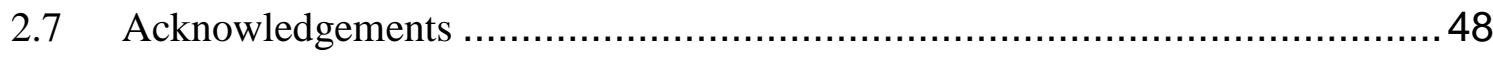

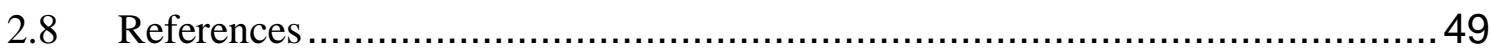

3 Chapter Three Temporal Patterns of Honeydew Foraging by an Endemic Ant and a

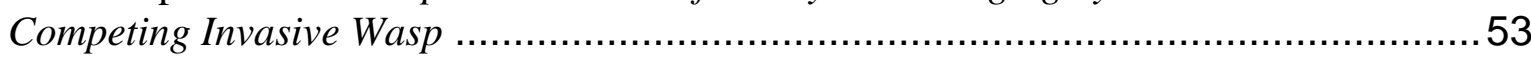

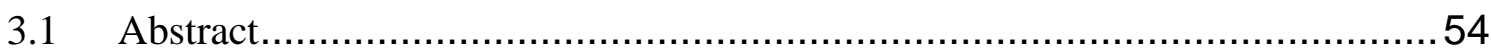

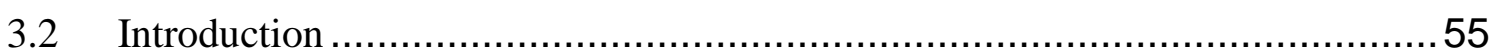

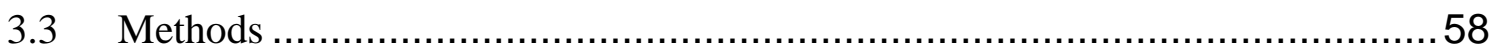

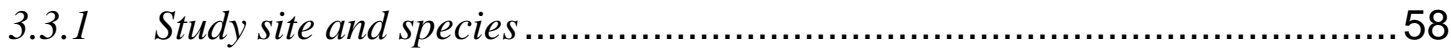

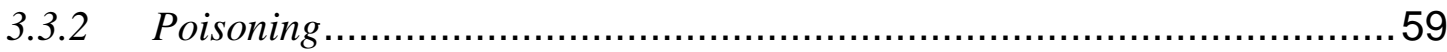

3.3.3 24 Hour observations of foraging ............................................... 59

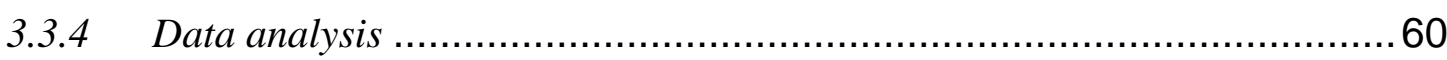

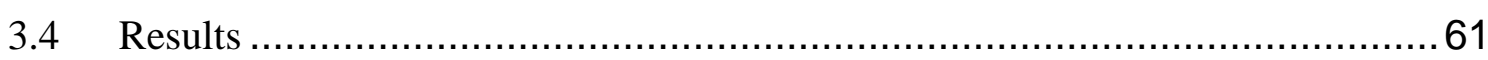

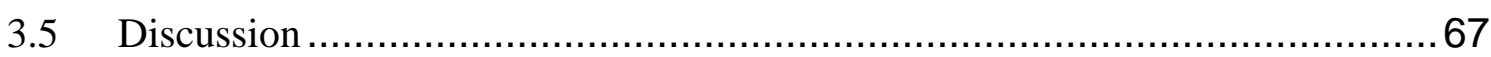

3.5.1 Ant foraging in relation to common wasp abundance ...........................6. 67

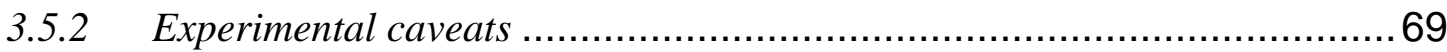

3.5.3 Temporal partitioning of the honeydew resource .................................70

3.6 Conclusion .............................................................................. 71

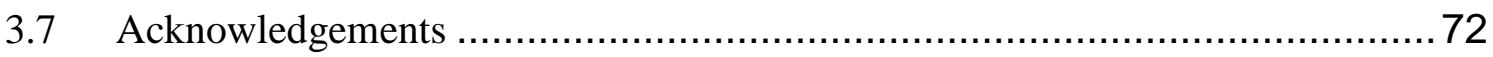

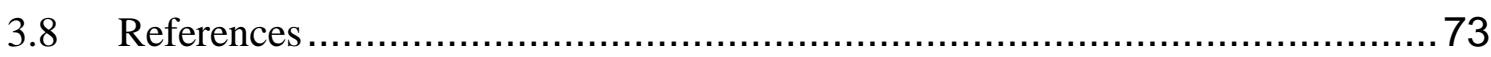

4 Chapter Four The Trophic Level of Native Ants Changes in Response to the Removal of an Invasive Competitor .......................................................... 78

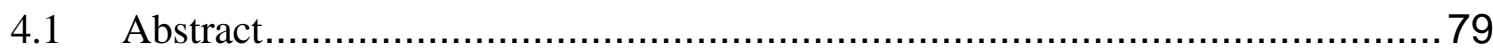

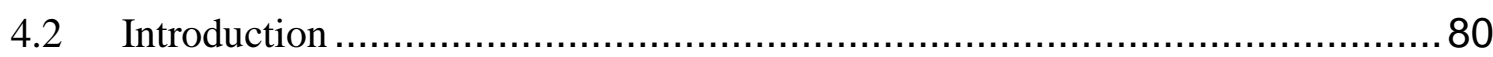

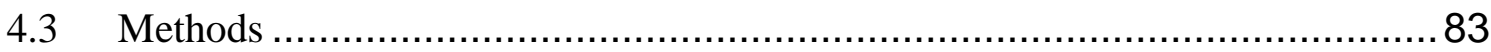

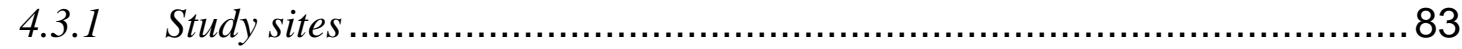

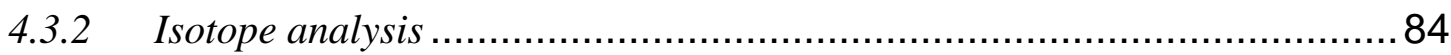

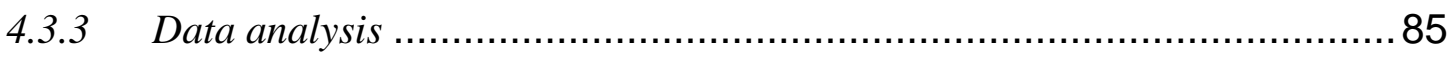

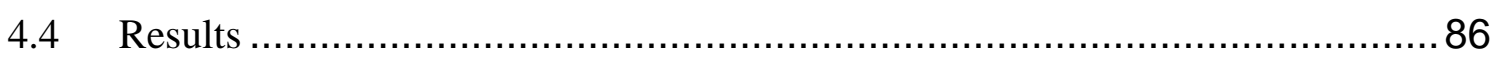

4.4.1 Do the isotope ratios of native species change after the removal of an invasive competitor? ...................................................................... 87

4.4.2 Do trophic positions change after the removal of an invasive competitor? .90

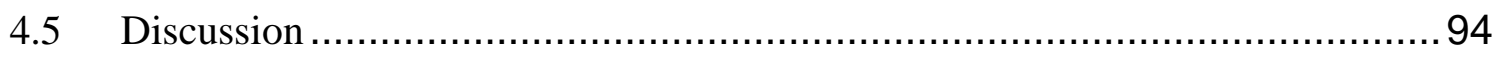

4.5.1 Do the isotope ratios of native species change after the reduction in number of an invasive competitor? ................................................................. 95

4.5.2 Do trophic positions change after the reduction in number of an invasive competitor? 


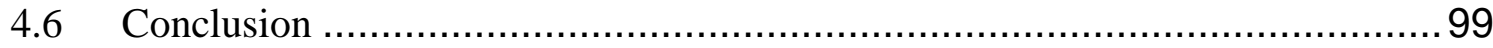

$4.7 \quad$ Acknowledgements ........................................................................ 100

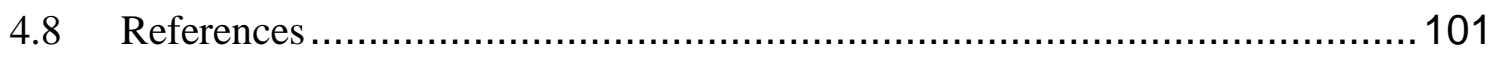

5 Chapter Five Density-Dependent Behavioural Plasticity in Competitive Interactions between Native Ants and Invasive Wasps. ..................................................... 106

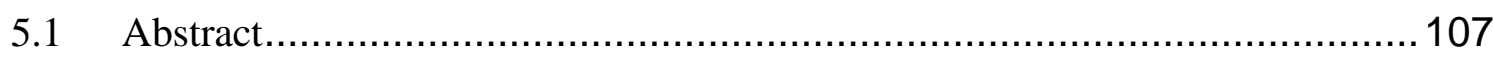

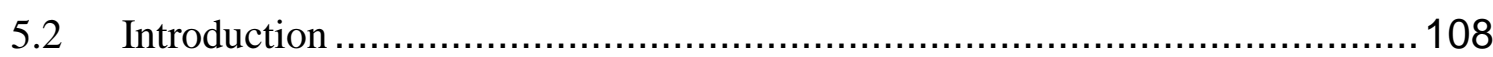

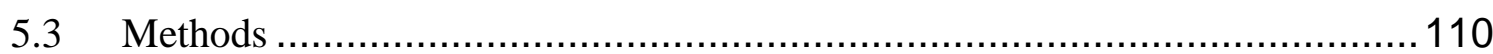

5.3.1 Study site ............................................................................... 110

5.3.2 Wasp or ant exclusion experiments ............................................. 110

5.3.3 Resource dominance on a natural food ........................................... 112

5.3.4 Food collection experiments ...................................................... 112

5.3.5 Behavioural interactions between common wasps and ants ..................113

5.3.6 Forager abundance ............................................................... 114

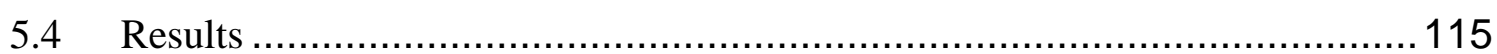

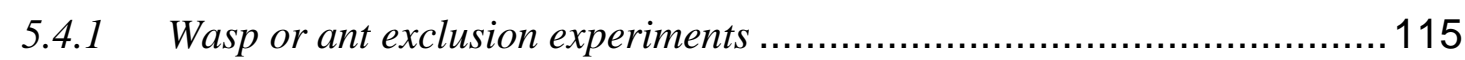

5.4.2 Resource dominance on a natural food .............................................118

5.4.3 Food collection experiments ........................................................ 119

5.4.4 Behavioural interactions between common wasps and ants .................. 121

5.4.5 Forager abundance .............................................................. 123

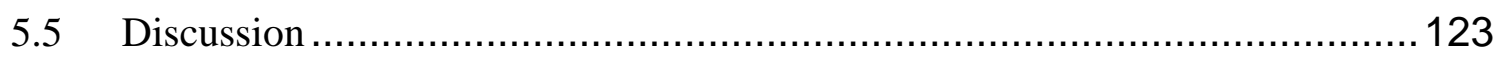

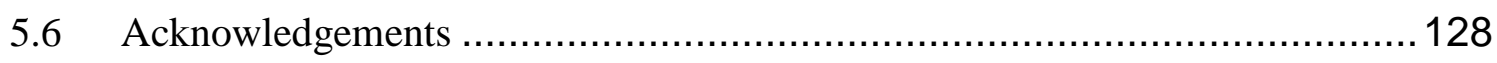

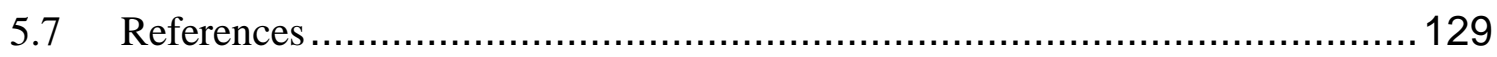

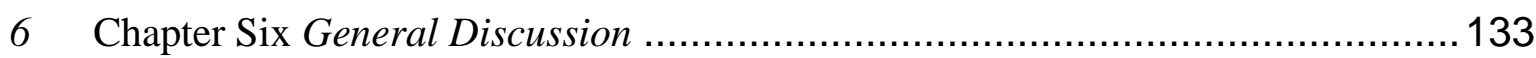

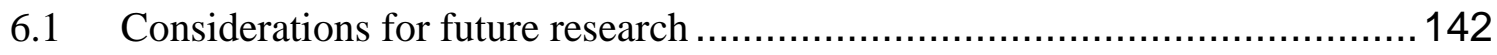

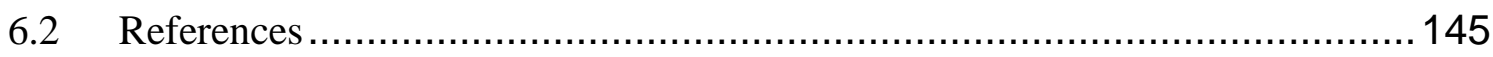




\section{Figures}

Figure 1.1 Location of the three study sites in the Nelson region in the northern South

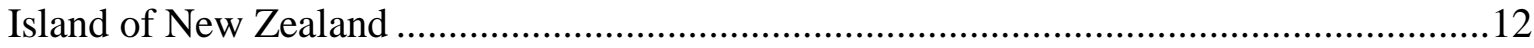

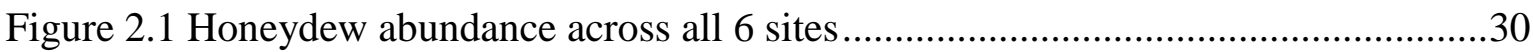

Figure 2.2 Honeydew producing Nothofagus abundance across all 6 sites ........................31

Figure 2.3 MDS plot of vegetation community composition across all six sites..................32

Figure 2.4 Numbers of common wasps caught in Malaise traps ........................................34

Figure 2.5 Mean number of individuals and taxonomic groups collected in Malaise traps 35

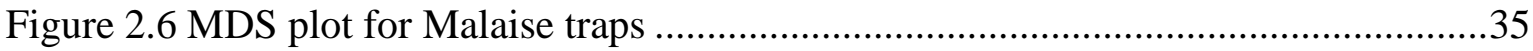

Figure 2.7 Mean number of individuals and taxonomic groups collected in pitfall traps ...38

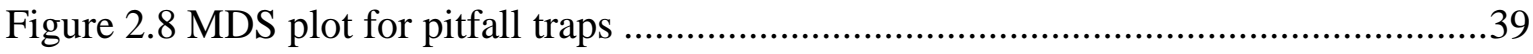

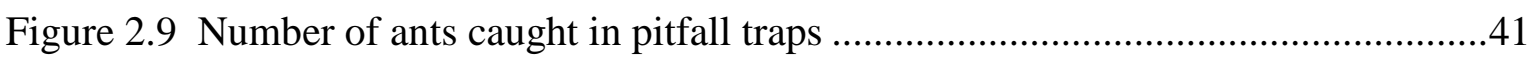

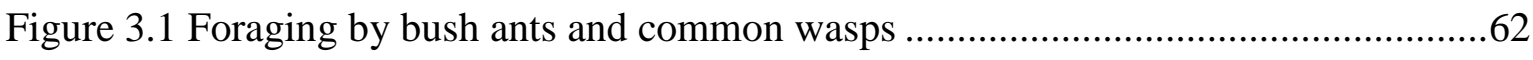

Figure 3.2 twenty-four hour foraging by bush ants and common wasps ...........................63

Figure 3.3 Relationship between foraging bush ants and common wasps..........................65

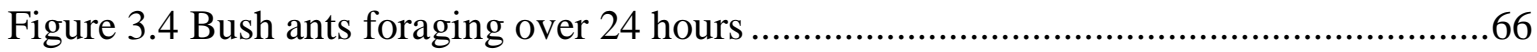

Figure 4.1 Reduction in common wasp numbers after poisoning at the different treatment sites.

Figure 4.2 Isotope changes in bush ants and common wasps pre- and post-poisoning ........88

Figure 4.3 Isotope changes in spiders and Carabidae pre- and post-poisoning ..................89

Figure 4.4 Mean trophic levels of common wasps and bush ants.....................................91

Figure 4.5 Mean trophic level of spiders and Carabidae …….........................................93

Figure 5.1 Recruitment of Huberia brounii, Prolasius advenus and Vespula vulgaris to

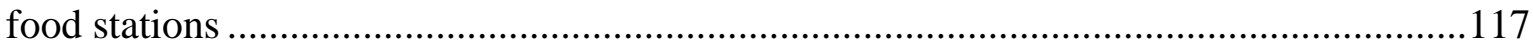

Figure 5.2 Recruitment of Huberia brounii, Prolasius advenus and Vespula vulgaris to

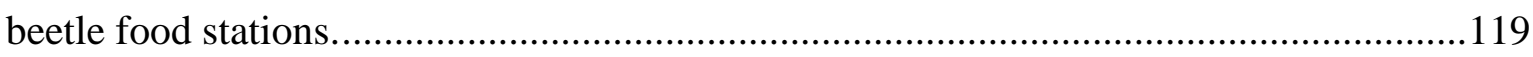

Figure 5.3 Food collected by ants and common wasps after 3 hours. ............................120 Figure 5.4 Behavioural interactions between two species of native ants (Prolasius advenus and Huberia brounii) and the invasive common wasp Vespula vulgaris. 


\section{Tables}

Table 2.1 PERMANOVA table of results for plant communities .....................................32

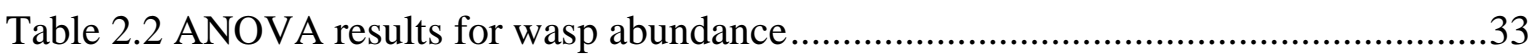

Table 2.3 PERMANOVA table of results for invertebrate community composition ...........36

Table 2.4 ANOSIM table of results for pitfall and Malaise traps .......................................37

Table 3.1 Results for ANOVA analysis of day-time foraging ..........................................61

Table 3.2 Results for repeated measures ANOVA analysis of 24 hour foraging. ..............64

Table 3.3 Results for ANOVA analysis of ant foraging over 24 hours. ...........................67

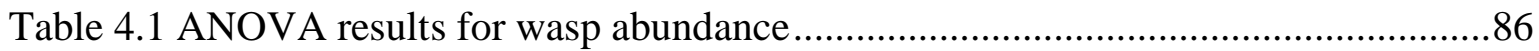

Table 4.2 ANOVA results for changes in trophic position...............................................90

Table 4.3 ANOVA results for changes in trophic position of spiders and Carabidae .........92

Table 5.1 Results for repeated-measures ANOVA analysis of exclusion experiments.....118 


\section{Chapter One}

\section{General Introduction}

In many ecological systems, introduced or invasive animals alter the community composition of native ecosystems by means of competition and predation (Human and Gordon 1999, Snyder and Evans 2006, Rowles and O'Dowd 2007, Bøhn et al. 2008). Invasive species may have superior abilities to exploit resources in their new environment, compared to local species, enabling them to expand rapidly into the new environment and outcompete native species (Sakai et al. 2001, Amarasekare 2002, Tillman 2004). Native species impacted by invasive organisms may continue to persist by altering the way in which they use shared resources. It is possible that behavioural adaptations by native species to dominant invaders may enable species co-occurrence in the face of competition for resources (Mooney and Cleland 2001). 
When species exploit common resources the species that can maintain positive growth at the lowest resource level will drive other species extinct

Competition is one of the central concepts in ecology and is defined by Welden and Slauson (1986) as "the induction of strain in one organism as a direct result of the use of resource items by another organism”. Strain in this context refers to a suboptimal physiological state. The impact of competition on an organism is proportional to the degree to which it decreases growth rate, fecundity, survival or fitness below the organism's optimal condition (Welden and Slauson 1986). In natural environments there are two conditions necessary for interspecific competition; 1 ) resource use by the competing species must overlap and 2) the resource availability to one species must be reduced by either interference or exploitation (Bonesi et al. 2004). When organisms are negatively impacted by competition, individual level effects such as decreased growth, decreased reproduction or increased mortality, and consequently population level effects, may also be negatively impacted. If physiological strain results in lower individual fitness within populations, selection pressure acting towards new optimal states can be expected resulting in long term evolutionary change (Welden and Slauson 1986).

Competition between species for a food resource can be a driving force structuring ecosystems (Brown and Davidson 1977, Chase et al. 2002). The intensity of this competition is a function of the degree to which two organisms require the same resources and may be measured by the amount of decrease in growth rate, fecundity, size or fitness of an individual, or population, independent of the decrease caused by other factors (Abrams 1980, Welden and Slauson 1986). Species diversity in an ecosystem may be maintained by interspecific trade-offs in colonisation, competition, fecundity and dispersal, thereby reducing the impacts of interspecific competition (Palmer et al. 2003). 
Furthermore, the availability of resources and consequently the outcome of competition may be influenced by environmental variation over space and time (Apps et al. 2006).

Competitive exclusion of inferior competitors has the potential to reduce species richness in an environment. By mechanisms including resource partitioning coexistence and diversity may be maintained. Thus the effects of competition depend on the initial degree of niche overlap and the competitive abilities of each species (Munday et al. 2001, Schmitt and Holbrook 2003). Environmental variability may also increase the potential for co-occurrence of two competing species. Both spatial and temporal variability can enable competing species to partition resources, avoiding resource competition and maintaining populations that in a homogeneous environment would lead to the competitive exclusion of one of the species (Connell 1980, Bonesi and Macdonald 2004).

\section{Coexistence requires species to be different in the way they affect, and are affected by,} resources

There is an assumption that competition by two species for a single resource in a stable environment will result in competitive exclusion of the weaker competitor. However, competition for resources associated with space, such as food or nest sites, is influenced by the spatial structure of the environment. Both resources and individuals within a population may be either aggregated or diffuse. This variation serves to enable competing species to coexist in a spatially heterogeneous or patchy resource environment (Abrams and Wilson 2004). In addition to spatial heterogeneity, temporal heterogeneity may also contribute to niche partitioning. Tradeoffs along these two environmental axes allow species to coexist with each species utilising different points along each axis (Palmer et al. 2003). 
The fundamental niche of a species relates to the range of environmental variables and ecological factors which would enable the species to persist indefinitely. However, the concept of the fundamental niche also requires information on species interactions as no species exists in isolation. In any environment several co-occurring species are likely to require similar environmental and ecological conditions. The dynamics of competition can serve to reduce the fundamental niche to a set of conditions which is a subset of the species' optimal niche space, termed the realised niche (Hutchinson 1957, Hubbell 2005). Niche overlap between species is a measure of similarity in resource requirements and refers to the types of resources needed rather than the resources themselves. Therefore, two organisms may have identical niches but not compete if they obtain the resources differently either spatially or temporally, or if the resource is in sufficient abundance to be used by both organisms at the same time. Niche overlap provides a measure of the intensity of competition and may also be an indication of past competition (Welden and Slauson 1986).

Niche shifts can result from competitive pressure and the ecological differences that result from niche partitioning can occur in three different ways. First, different species may specialise on different resources. This is the classical definition of resource partitioning (MacArthur and Levins 1967). Second, organisms may partition resources temporally. These species may be limited by the same resource but differ in terms of when they exploit this resource. And finally, species may differ in terms of where they experience limiting resources, which can lead to spatial niche partitioning (Amarasekare 2003). 


\section{Coexistence requires some form of niche partitioning}

Understanding resource partitioning is fundamental to understanding strategies of resource use, effects of competition and mechanisms of coexistence (Abrams 1980).

Resource partitioning can arise through competitive interactions with most resources commonly partitioned spatially. This occurs at a range of scales and is correlated with the size and abundance of competitors (Apps et al. 2006). Resources are not often partitioned temporally as this leads to an overall reduction in the resource (Schoener 1974). However resources may be partitioned temporally on a seasonal basis as nutritional requirements may vary with different life stages. For example, social Hymenoptera typically feed larvae a protein rich diet and therefore require a larger supply of protein during times of larval development (Beggs 2001).

Patterns of biodiversity may be shaped by the mechanisms that promote coexistence. Spatial variation in resources and differing strategies of resource use enable species to coexist in the presence of limiting resources (Schmitt and Holbrook 2003, Chase 2005). In the presence of ongoing competition and population interactions species evolve strategies that promote specialisation and partition niche space (Ricklefs 2004).

\section{The differences between species that allow coexistence are thought of as species' niches}

If two species exist in a homogeneous resource environment one species may become locally extinct if there is no mechanism for coexistence. Coexistence is only possible when species use this resource in different manners; this is the fundamental principle of niche differentiation (Hutchinson 1957). Two organisms may occupy the same niche but not compete if the required resources are abundant or able to be obtained from different locations. Resource partitioning may result in differential rates of use; this may allow competing species to coexist, or if they are unable to partition the resource it will 
lead to competitive exclusion with one species dominating the resource to the detriment of the other.

Competitive exclusion may occur in a system where a new species has invaded and there has not been sufficient time for niche differentiation to occur (Gurnell et al. 2004). For example, Sanders et al. (2003) found that invasion by the Argentine ant, Linepithema humile, caused changes in the organisation of native ant communities and a loss of native species through the mechanisms of superior resource exploitation and interference competition by the Argentine ant. Niche divergence, competitive exclusion and habitat shifts serve to reduce or eliminate the detrimental effects of competition. In these cases the process of competition is often inferred by its absence (Welden and Slauson 1986). Species' traits are meaningful only in an environmental context and therefore diversity patterns in a spatial context are reflections of niche differences exhibited as trade-offs among species (Kneitel and Chase 2004).

Competition operates on more than one timescale and the effects vary depending on the scale of interest. The shortest timescale encompasses the lifespan of the individual, and its interactions with competitors and the environment and are reflected in behavioural and developmental responses. The intermediate timescale spans a few generations and is seen in spatial patterns such as territory sizes, species composition of communities and distribution of species on environmental gradients. It can be reflected in reduced fitness and the resulting selection pressures. The longest timescale affects the evolutionary processes that underlie competition such as niche separation, habitat shift and territorial behaviour (Welden and Slauson 1986).

Species that compete are subject to both evolutionary and ecological pressure that can result in niche differentiation. This differentiation can underlie the mechanisms that maintain ecological differences between species and promote coexistence. Niche 
differentiation can also significantly contribute to community assembly (Tillman 1994). Coexistence is possible through niche differentiation. However when an invasive species enters an ecosystem there may not be sufficient evolutionary time for differentiation, so competitive exclusion of the weaker species may occur instead (Gurnell et al. 2004). There has been an abundance of theory over the past 50 years to explain competitive coexistence; however, there is far less empirical evidence. Competition for the abundant honeydew and protein resources in the Nothofagus forests of the Nelson region of New Zealand provides an ideal opportunity to investigate mechanisms of coexistence between an invasive wasp and resident endemic ants.

\section{Mechanisms of coexistence are important in determining the fate of a species under pressure from an invasive species}

The overall goal of this dissertation is to investigate the factors which may promote coexistence between an endemic and an invasive species. When faced with predation or competition pressure from an invasive species many resident species are forced to alter the ways in which they use resources. If species are unable to partition resources effectively then the resident population will decline in number, which may lead to localised extinctions. Resources are not uniform and vary in abundance and quality both temporally and spatially. An endemic species subject to pressure from an invasive species may undergo a niche shift to enable coexistence and minimise the impact of this pressure. 


\subsection{Study system}

Nothofagus (southern beech) forests have a wide distribution in New Zealand, from the central North Island to the southern South Island; they are the predominant forest type in the northwest of the South Island of New Zealand (Stewart and Rose 1990, Wardle 1970). Nothofagus have a wide tolerance to conditions of low rainfall and soil fertility, high altitude and poor soil drainage (Leathwick 1998, Wardle 1970). Nothofagus forests in much of the South Island are infested with the sooty beech scale insect (Ultracoelostoma spp) which produces copious amounts of honeydew as a waste product (Morales et al. 1988). The vegetation of Nothofagus forests is simple in structure with the canopy dominated by mature beech trees. The understory consists primarily of shrubs and small trees including Pseudopanax spp., Coprosma spp., Cyathodes juniperina, Leucopogon fasciculatus, Griselinia littoralis and juvenile Nothofagus. Moss commonly grows on fallen trees, and ferns are often present in the understory.

Honeydew is an important resource driving ecological interactions in Nothofagus forests (Morales et al. 1988). The sooty beech scale insect infests the trunks and branches of black beech (Nothofagus solandri var. solandri), mountain beech (N. solandri var. cliffortioides), hard beech (N. truncata), and red beech (N. fusca) but rarely silver beech (N. menziesii) (Beggs 2001). It feeds on the sap and excretes excess carbohydrate from its waxy anal filament in the form of honeydew. Sooty beech scale is found in Nothofagus forests throughout New Zealand with the highest densities occurring in the northern half of the South Island (Morales et al. 1988).

Honeydew is an important food source for birds, lizards and invertebrates, along with the black sooty mould also characteristic of these Nothofagus forests, which in turn is a food source for invertebrates (Morales et al. 1988, Markwell et al. 1993, Ewers 2002). 
Honeydew production varies spatially and temporally within the forest in response to altitude, sunlight, tree age and species (Ewers 2002). The production of honeydew declines from late spring to summer relating to both fluctuations in the populations of scale insects and the increase in common wasp numbers. When common wasps harvest honeydew they nibble the end of the anal tube, gradually shortening it and sometimes removing it altogether, contributing to a decline in honeydew production over the summer months (Moller and Tilley 1989).

In other systems with honeydew producing insects, invertebrates are known to consume the honeydew, with ants forming the dominant group of consumers (Carroll and Janzen 1973, Stadler and Dixon 1999, Mailleux et al. 2003). Many ants have coevolved with these specific food sources and may be highly territorial of the host plant. Almost all groups of ants harvest honeydew to some degree (Carroll and Janzen 1973, Buckley 1987). There are limited published studies of invertebrates feeding on honeydew in New Zealand Nothofagus forests. While ants have been observed feeding on the honeydew, particularly honeydew spilled on the bark (Moller and Tilley 1989), this resource utilisation by ants has never been studied.

Prolasius advenus (Linnaeus), commonly referred to as the New Zealand bush ant, is the predominant ant species in New Zealand Nothofagus forests (McColl 1975). Despite its abundance very little is known about this species. In the Nothofagus forests of the Nelson area the bush ant is a generalist forager and has been observed feeding on honeydew produced by the sooty beech scale insect. Additionally, bush ants prey on small invertebrates and forage for larger, already dead, invertebrates (C. Duthie Pers. obs.). Huberia brounii Forel is a second endemic ant species that inhabits native forests and is common in leaf litter. Like the bush ant, the biology of this species is not well known (Don 2007). Huberia is a genus endemic to New Zealand while bush ants belong to a genus with 
all other representatives in Australia (Shuttack 2000). In addition to bush ants and $H$. brounii there are other ant species associated with Nothofagus forests; these include Huberia striata and Discothyrea antarctica (Don 2007).

The German wasp (Vespula germanica) established in New Zealand in the 1940s. The common wasp (V. vulgaris) became established in the 1980s and has largely replaced the German wasp in dominating the Nothofagus forests (Harris 1991). Introduced Vespula wasps have successfully established in Nothofagus forests and by collecting the carbohydrate rich honeydew resource have reached extremely high densities (Beggs et al. 1998, Beggs 2001). Left unchecked the common wasp biomass may exceed the total biomass of all birds plus introduced mammals (Thomas et al. 1990). Common wasps forage for protein in the form of animal prey to feed their developing larvae and they use carbohydrates, such as honeydew, for their own energy requirements (Harris 1991). For five months of the year common wasps reduce the standing crop of honeydew by more than $92 \%$ impacting honey-eating native birds such as kaka, tui and bellbirds, forcing a switch to an alternative food source or provoking a reduction in reproductive output (Beggs et al. 1998). Native insects are subject to predation by common wasps, which in turn may affect numbers of insectivorous birds. The prey biomass consumed by common wasps has been estimated to be similar to the prey biomass consumed by the entire bird fauna (Harris 1991). Studies have also shown that native ants make up around $30 \%$ of the diet of both common and German wasps (Moller and Tilley 1989, Harris 1991). 


\subsection{Study Locations}

This study encompasses three locations in the Nelson area in the northern South Island of New Zealand ( $\left.41^{\circ} 18^{\prime} \mathrm{S}, 173^{\circ} 16^{\prime} \mathrm{E}\right)$ (Fig 1.1). One pair of experimental sites was established in each location. Each pair of sites consisted of a control site (waspsmaintained) in which common wasps remained at natural levels and a treatment site (wasps-controlled) where common wasps were poisoned. At each location the vegetation was similar with the canopy dominated by the mature beech trees Nothofagus solandri and N. menziesii. The understory consisted primarily of Pseudopanax spp., Coprosma spp., Cyathodes juniperina, Leucopogon fasciculatus, Griselinia littoralis and juvenile Nothofagus.

The Rotoiti Nature Recovery Project funded by the Department of Conservation (DOC) was established as a 'mainland island' in 1995 with a core management area of 825 ha. Introduced animal pests are being intensively controlled by the use of poisoning and trapping grids established throughout the area. The goal statement of DOC in the Rotoiti area is "Restoration of a beech forest community with emphasis on the honeydew cycle" (DOC 2000). Both common wasp numbers and honeydew levels are monitored in order to gauge progress in relation to this goal. Common wasps have been successfully controlled in Rotoiti for the first time in such a large area. Ecological responses to pest control have included successful fledging of kaka where previously few were surviving (Saunders and Norton 2001). Two areas adjacent to the mainland island have been designated as 'control' areas. No trapping or poisoning has taken place in these areas and regular monitoring gives an indication as to the levels of introduced pests in the absence of common wasp poisoning and predator trapping (DOC 2000). 
A further two locations with both common wasp poison and control sites were established in December 2007 to provide replicates for this study. These locations were owned by the Tasman District Council and both were catchment areas supplying water to the Nelson region. The Maitai Valley is located east of Nelson City and is a 10,000 ha reserve dominated by Nothofagus forest. The Roding Waterworks Reserve is located south-east of Nelson City and is also dominated by Nothofagus. There is currently no ongoing common wasp treatment in these areas and they both have significant common wasp populations which have been monitored by LandCare Research.

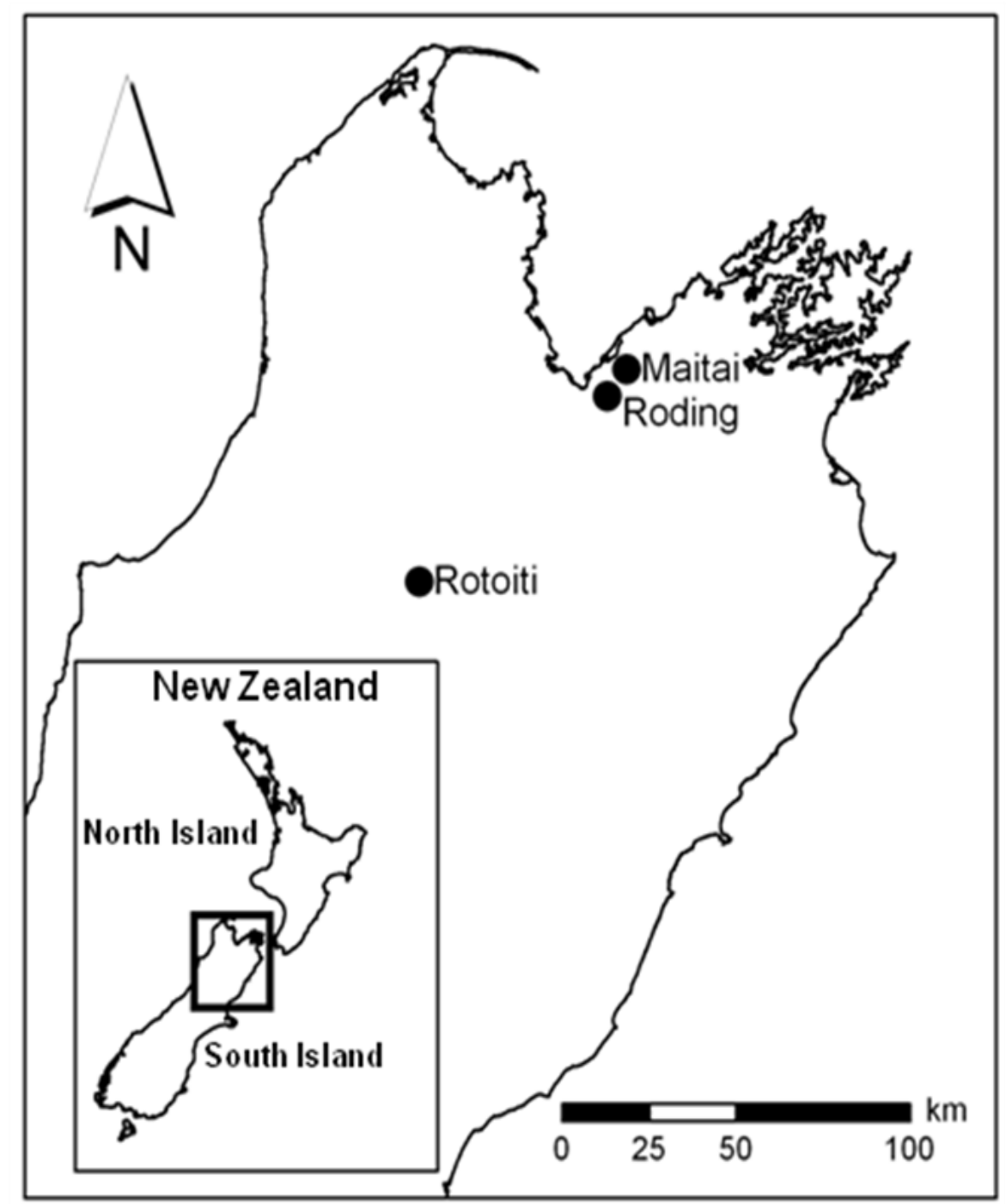

Figure 1.1 Location of the three study sites in the Nelson region in the northern South Island of New Zealand 


\subsection{Dissertation overview}

Little is currently known about the ecology and life history of Prolasius advenus and Huberia brounii in Nothofagus forests, or their potential for competitive interactions with Vespula vulgaris. In this dissertation I aimed to determine the extent to which competition occurs between these native ants and invasive common wasps, and to investigate the impacts of wasp invasion on the native invertebrate community. Because mechanisms of coexistence are fundamentally important in determining the fate of a community under pressure from an invasive species I aimed to investigate how coexistence is achieved in the face of competition through changes in resource use.

Chapters two, three, four and five are intended for publication and therefore I use the term 'we' to acknowledge the role of my supervisor during the research process. This in no way detracts from the fact that this thesis is the outcome of my own original work. All those who helped and advised me are listed in the acknowledgements sections in each chapter.

\subsubsection{Chapter Two - Invertebrate community composition of Nothofagus forests is impacted by the presence of the invasive wasp Vespula vulgaris}

In chapter two I investigated community level effects of common wasp removal. Because of the documented effects of common wasp predation I predicted that a reduction in common wasp numbers would result in a change in the overall diversity and community composition and an increase in the number of native invertebrate species. Native ant species may be particularly impacted so I assessed the effect of common wasp removal on two native ant species Prolasius advenus and Huberia brounii. As variation in the 
honeydew resource and composition of the vegetation community may affect the community composition of invertebrates I assessed the honeydew abundance and community composition of vegetation for variation between sites.

\subsubsection{Chapter Three - Temporal patterns of honeydew foraging by an endemic ant and a competing invasive wasp}

In chapter three I investigated possible temporal niche shifts by bush ants in response to the presence of common wasps. In the face of a dominant invasive species the native ants in Nothofagus forests may have adjusted their pattern of resource use to avoid interspecific aggression or exclusion from resources. Because both bush ants and common wasps compete for similar food resources I predicted that I would see fewer bush ants foraging in areas of higher common wasp abundance. Additionally, it is possible that bush ants and common wasps may have partitioned the honeydew resource temporally to avoid direct competition. As bush ants have been observed foraging nocturnally, I expected to see proportionally more bush ants foraging at night in areas of higher common wasp abundance. In order to better understand patterns of resource use I experimentally reduced common wasp numbers. I predicted that this removal of a dominant competitor may allow an increase in the number of bush ants foraging during the day, and reduce any difference between the numbers of bush ants foraging both diurnally and nocturnally.

\subsubsection{Chapter Four - The trophic level of native ants changes in response to the removal of an invasive competitor}

In chapter four I examined the effect of an invasive species on the trophic level of native competitors, using the native ants Prolasius advenus and the invasive wasps 
Vespula vulgaris. I asked if the isotope ratios and trophic level of native competitors change in response to the removal of this invasive species. Additionally, as heavy predation and competition pressure from an invasive species may impact populations of other predators I asked if the trophic positions and isotope ratios of these other predators change in response to the removal of an invasive species.

\subsubsection{Chapter Five-Density-dependent behavioural plasticity in competitive interactions between native ants and invasive wasps.}

In chapter five I examined interactions between the native ants Prolasius advenus and Huberia brounii and invasive common wasps during foraging. My specific goal was to determine whether the presence of exotic common wasps influenced the foraging success of native ants. I aimed to determine if the amount of food taken by native ants and common wasps differed when each species foraged individually or together. I tested if aggressive behaviour of common wasps or native ants was density-dependent. Additionally I assessed whether numerical dominance corresponds to behavioural dominance at food resources.

\subsubsection{Chapter Six - General discussion}

Chapter six summarises the findings of the previous four data chapters and presents an overall conclusion. I discuss the results obtained in relation to my overall thesis questions. I also discuss the relevance of my research in the context of invasion ecology. I conclude by discussing considerations for further research. 


\subsection{References}

Abrams, P. 1980. Some comments on measuring niche overlap. Ecology 61:44-49.

Abrams, P. A. and W. G. Wilson. 2004. Coexistence of competitors in metacommunities due to spatial variation in resource growth rates; does $R^{*}$ predict the outcome of competition? Ecology Letters 7:929-940.

Amarasekare, P. 2002. Interference competition and species coexistence. Proceedings of the Royal Society of London B 269:2541-2550.

Amarasekare, P. 2003. Competitive coexistence in spatially structured environments: a synthesis. Ecology Letters 6:1109-1122.

Apps, C. D., B. N. McLellan, and J. G. Woods. 2006. Landscape partitioning and spatial inferences of competition between black and grizzly bears. Ecography 29:561-572.

Beggs, J. 2001. The ecological consequences of social wasps (Vespula spp.) invading an ecosystem that has an abundant carbohydrate resource. Biological Conservation 99:17-28.

Beggs, J., R. J. Toft, J. P. Malham, J. S. Rees, J. A. V. Tilley, H. Moller, and P. Alspach. 1998. The difficulty of reducing introduced wasp (Vespula vulgaris) populations for conservation gains. New Zealand Journal of Ecology 22:55-63.

Blüthgen, N. and C. Fiedler. 2004. Competition for composition: lessons from nectarfeeding ant communities. Ecology 85:1479-1485.

Bøhn, T., P. Amundsen, and A. Sparrow. 2008. Competitive exclusion after invasion? Biological Invasions 10:359-368.

Bonesi, L., P. Chanin, and D. W. Macdonald. 2004. Competition between Eurasian otter Lutra lutra and American mink Mustela vison probed by niche shift. Oikos 106:1926.

Bonesi, L. and D. W. Macdonald. 2004. Differential habitat use promotes sustainable coexistence between the specialist otter and the generalist mink. Oikos 106:509519.

Brown, J. H. and D. W. Davidson. 1977. Competition between seed-eating rodents and ants in desert ecosystems. Science 196:880-882.

Buckley, R. C. 1987. Interactions involving plants, homoptera, and ants. Annual Review of Ecology and Systematics 18:111-135. 
Carroll, C. R. and D. H. Janzen. 1973. Ecology of foraging by ants. Annual Review of Ecology and Systematics 4:231-257.

Chase, J. M. 2005. Towards a really unified theory for metacommunities. Functional Ecology 19:182-186.

Chase, J. M., P. A. Abrams, J. P. Grover, S. Diehl, P. Chesson, R. D. Holt, S. A. Richards, R. M. Nisbet, and T. J. Case. 2002. The interaction between predation and competition: a review and synthesis. Ecology Letters 5.

Connell, J. H. 1980. Diversity and the coevolution of competitors, or the ghost of competition past. Oikos 35:131-138.

DOC. 2000. Rotoiti nature recovery project annual report 1997-1998. Department of Conservation.

Ewers, R. 2002. The influence of honeydew on arthropod community composition in a New Zealand beech forest. New Zealand Journal of Ecology 26:23-29.

Gurnell, J., L. A. Wauters, P. W. Lurz, and G. Tosi. 2004. Alien species and interspecific competition: effects of introduced eastern grey squirrels on red squirrel population dynamics. Journal of Animal Ecology 73:26-35.

Harris, R. J. 1991. Diet of the wasps Vespula vulgaris and V. germanica in honeydew beech forest of the South Island, New Zealand. New Zealand Journal of Zoology 18:159-169.

Hubbell, S. P. 2005. Neutral theory in community ecology and the hypothesis of functional equivalence. Functional Ecology 19:166-172.

Human, K. G. and D. M. Gordon. 1999. Behavioural interactions of the invasive Argentine ant with native ant species. Insectes Sociaux 46:159 - 163.

Hutchinson, G. E. 1957. Concluding remarks. Cold Springs Symposia on Quantitative Biology 22:415-427.

Kneitel, J. M. and J. M. Chase. 2004. Trade-offs in community ecology: linking spatial scales and species coexistence. Ecology Letters 7:69-80.

Leathwick, J. R. 1998. Are New Zealand's Nothofagus species in equilibrium with their environment? Journal of Vegetation Science 9:719-732.

MacArthur, R. and R. Levins. 1967. The limiting similarity, convergence, and divergence of coexisting species. The American Naturalist 101:377-385.

Mailleux, A., J. Deneubourg, and C. Detrain. 2003. Regulation of ants' foraging to resource productivity. Proceedings of the Royal Society of London 270:1609-1616. 
Markwell, T. J., D. Kelly, and K. W. Duncan. 1993. Competition between honey bees (Apis mellifera) and wasps (Vespula spp.) in honeydew beech (Nothofagus solandri var. solandri) forest. New Zealand Journal of Ecology 17:85-93.

McColl, H. P. 1975. The invertebrate fauna of the litter surface of a Nothofagus truncata forest floor, and the effect of microclimate on activity. New Zealand Journal of Ecology 2:15-34.

Moller, H. and J. A. V. Tilley. 1989. Beech honeydew: seasonal variation and use by wasps, honey Bees, and other insects. New Zealand Journal of Zoology 16:289302.

Mooney, H. A. and E. E. Cleland. 2001. The evolutionary impact of invasive species. Proceedings of the National Academy of Sciences 98:5446-5451.

Morales, C. F., M. G. Hill, and A. K. Walker. 1988. Life history of the sooty beech scale (Ultracoelostoma assimile) (Maskell), (Hemiptera: Margodidae) in New Zealand Nothofagus forests. New Zealand Entomologist 11:24-38.

Munday, P. L., G. P. Jones, and M. J. Caley. 2001. Interspecific competition and coexistence in a guild of coral-dwelling fishes. Ecology 82:2177-2189.

Palmer, T. M., M. L. Stanton, and T. P. Young. 2003. Competition and coexistence: exploring mechanisms that restrict and maintain diversity within mutualist guilds. The American Naturalist 162:S63-S79.

Ricklefs, R. E. 2004. A comprehensive framework for global patterns in biodiversity. Ecology Letters 7:1-15.

Rowles, A. D. and D. J. O'Dowd. 2007. Interference competition by Argentine ants displaces native ants: implications for biotic resistance to invasion. Biological Invasions 9:73-85.

Sakai, A. K., F. W. Allendorf, J. S. Holt, D. M. Lodge, J. Molofsky, K. A. With, S. Baughman, R. J. Cabin, J. E. Cohen, N. C. Ellstrand, D. E. McCauley, P. O'Neil, I. M. Parker, J. N. Thompson, and S. G. Weller. 2001. Population biology of invasive species. Annual Review of Ecology, Evolution, and Systematics 32:305-332.

Sanders, N. J., N. J. Gotelli, N. E. Heller, and D. M. Gordon. 2003. Community disassembly by an invasive species. Proceedings of the National Academy of Sciences 100:2474-2477.

Saunders, A. and D. A. Norton. 2001. Ecological restoration at mainland islands in New Zealand. Biological Conservation 99:109-119. 
Schmitt, R. J. and S. J. Holbrook. 2003. Mutualism can mediate competition and promote coexistence. Ecology Letters 6:898-902.

Schoener, T. W. 1974. The compression hypothesis and temporal resource partitioning. Proceedings of the National Academy of Sciences 71:4169-4172.

Shuttack, S. O. 2000. Australian ants: their biology and identification. CSIRO Publishing, Collingwood, VIC.

Snyder, W. E. and E. W. Evans. 2006. Ecological effects of invasive arthropod generalist predators. Annual Review of Ecology, Evolution, and Systematics 37:95-122.

Stadler, B. and A. F. G. Dixon. 1999. Ant attendance in aphids: why different degrees of myrmecophily? Ecological Entomology 24:363-369.

Stewart, G. H. and A. B. Rose. 1990. The significance of life history strategies in the developmental history of mixed beech (Nothofagus) forests, New Zealand. Vegetatio 87:101-114.

Thomas, C. D., H. Moller, G. M. Plunkett, and R. J. Harris. 1990. The prevalence of introduced Vespula vulgaris wasps in a New Zealand beech forest community. New Zealand Journal of Ecology 13:63-72.

Tillman, D. 1994. Competition and biodiversity in spatially structured habitats. Ecology 75:2-16.

Tillman, D. 2004. Niche tradeoffs, neutrality, and community structure: A stochastic theory of resource competition, invasion, and community assembly. Proceedings of the National Academy of Sciences 101:10854-10861.

Wardle, J. 1970. The Ecology of Nothofagus Solandri 1. The distribution and relationship with other major forest and scrub species. New Zealand Journal of Botany 8:494531.

Welden, C. W. and W. L. Slauson. 1986. The intensity of competition versus its importance: an overlooked distinction and some implications. The Quarterly Review of Biology 61:23-44. 


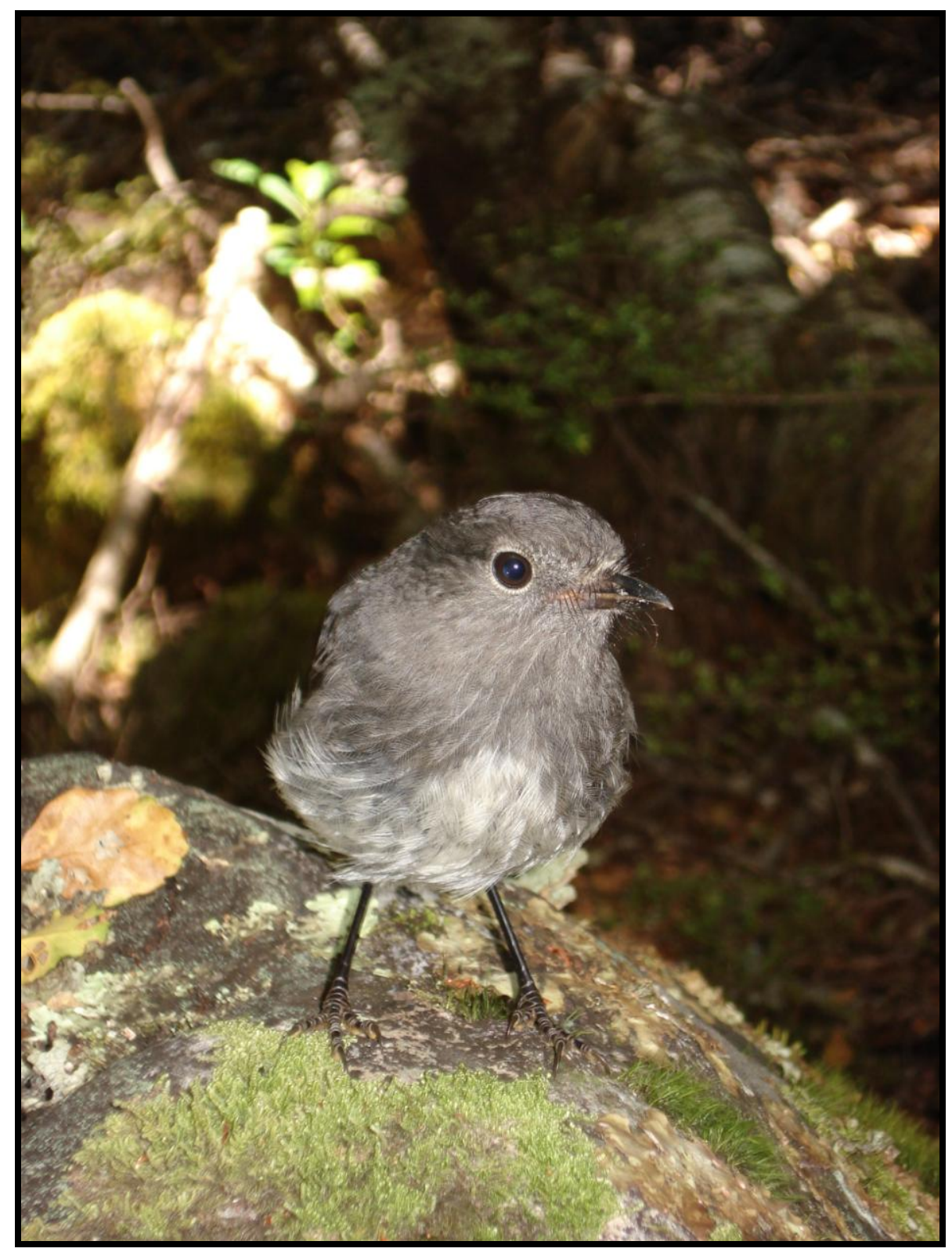

Petroica australis australis my constant field companion 


\section{Chapter Two}

Invertebrate Community

Composition of Nothofagus

Forests is Impacted by the

Presence of the Invasive Wasp

Vespula vulgaris 


\subsection{Abstract}

Invasive animals can alter the community composition of native ecosystems by means of competition and predation. Vespula vulgaris (common wasps) are significant predators of invertebrates in the Nothofagus forests of the South Island of New Zealand. Previous work has shown that common wasp numbers peak between January and May and consequently numbers of other invertebrates decline. We predicted that a reduction in common wasp numbers would result in an increase in the number, overall diversity and community composition of native invertebrate species, in particular native ants. Three pairs of experimental sites were established in different locations in the Nelson region. Each pair of sites consisted of a control site (wasps-maintained) in which common wasps remained at natural levels and a treatment site (wasps-controlled) where common wasps were poisoned. Invertebrate communities as all sites were sampled by pitfall and Malaise trapping both before and after the application of poison. Results indicated a significant difference in community composition caught in pitfall traps between sampling periods and between sites, and a significant effect of common wasp control. The community composition of invertebrates caught in Malaise traps was significantly different between sampling periods however; there was no difference between treatments or locations. Regardless, native ants are abundant in this forest system and seem to be unaffected by common wasp densities. Species that are vulnerable to common wasp predation may have already become scarce in areas with high common wasp abundance such as these Nothofagus forests, and are not recovering after such a short duration of common wasp reduction. There are several other hypotheses to explain our findings; however, the most parsimonious explanation for our results is that we may not have reduced common wasp numbers sufficiently to see a recovery in the community. 


\subsection{Introduction}

In many ecological systems introduced or invasive animals alter the community composition of native ecosystems by means of competition and predation (Human and Gordon 1999, Snyder and Evans 2006, Rowles and O'Dowd 2007, Bøhn et al. 2008). For example, Human and Gordon (1999) showed that due to a superior ability at interference competition introduced Argentine ants are able to displace native ants at resources, leading to a reduction in diversity of native species. Predation can also influence the community composition of an invaded ecosystem. For example, an increase in the abundance of an invasive mantid species in the South-Eastern United States has reduced the abundance of other generalist predators and as a result of this decline the abundance of Hemiptera has increased (Fagan et al. 2002). Communities may also be structured through more complex mechanisms such as apparent competition. This may occur when the presence of one species indirectly decreases the fitness of another through the presence of a shared enemy (Holt 1977, van Veen et al. 2006).

Honeydew is an important resource driving ecological interactions in many of the Nothofagus forests of New Zealand (Morales et al. 1988). The sooty beech scale insect (Ultracoelostoma spp.) infests the trunks and branches of Nothofagus trees; it feeds on the sap and excretes excess carbohydrate from its waxy anal filament in the form of honeydew. Sooty beech scale is found in Nothofagus forests throughout New Zealand with the highest densities occurring in the Northern half of the South Island (Morales et al. 1988). In other systems with honeydew producing insects, invertebrates are known to consume the honeydew, with ants forming the dominant group of consumers (Carroll and Janzen 1973, Buckley 1987, Stadler and Dixon 1999, Mailleux et al. 2003). Introduced common wasps (Vespula spp.) have successfully established in these Nothofagus forests and by collecting 
the carbohydrate rich honeydew resource have reached extremely high densities (Beggs et al. 1998, Beggs 2001). The common wasp (Vespula vulgaris) (Linnaeus) became established in New Zealand in the 1980s and is now a dominant species in Nothofagus forests (Harris 1991, Beggs 2001). The abundant carbohydrate resource in the form of honeydew is the primary source of energy for common wasps enabling them to forage for protein in the form of animal prey to feed their developing larvae (Harris 1991). Access to persistent honeydew resources is also thought to be essential for behavioural and ecological dominance within hymenopteran communities (Way 1963, Room 1975).

Common wasps are major predators of invertebrates in many of the Nothofagus forests of the South Island of New Zealand. Common wasp numbers peak between January and May and consequently numbers of other invertebrates decline as a result of strong competitive interactions and predation pressure (Moller and Tilley 1989, Beggs et al. 1998, Beggs 2001). The prey biomass consumed by common wasps has been estimated to be similar to the prey biomass consumed by the entire bird fauna, with spiders, lepidopteran larvae and Diptera making up the majority of the common wasp diet in the early summer months (Harris 1991). The probability of orb-wed spiders (Eriophora pustulosa) surviving the summer in areas where common wasps are abundant has been estimated to be almost nil $\left(5.08 \times 10^{-18}\right)$ (Toft and Rees 1998). Similarly the chance of caterpillars (Kowhai moth, Urisephita polygonalis maorialis) surviving in areas of high common wasp abundance was estimated at only 10\% (Beggs and Rees 1999).

The relative biomass of common wasps has been estimated to be greater than that of any other predator, introduced or native, in the Nothofagus forests (Thomas et al. 1990). The abundance of common wasps appears likely to have the potential to restructure both predator and prey communities. Common wasps not only impact communities through predation pressure but also have the potential to restructure communities through the 
mechanisms of competition (Beggs 2001, Beggs and Wardle 2006). Common wasps compete for honeydew with feral honey bees (Apis mellifera), and consume so much of the honeydew it becomes uneconomical for bees to forage at times of high common wasp abundance (Moller and Tilley 1989). In Patagonia invasive Vespula wasps compete with native ants for protein (Masciocchi et al. 2009); however, there have been no similar published studies to determine the impact of competition on other Hymenoptera in New Zealand Nothofagus forests.

Because of the documented effects of common wasps consuming native invertebrates (Harris 1991) we predicted that a reduction in common wasp numbers would result in an increase in the number, overall diversity and community composition of native invertebrate species. Due to similar diet and foraging patterns (Don 2007), some native ant species may be particularly impacted by common wasp predation and competition, hence we assessed the impact of common wasp removal on two common native ant species, the New Zealand bush ant (Prolasius advenus) and Huberia brounii. As variation in the composition of the vegetation community may affect the community composition of invertebrates, we assessed the community composition of vegetation for variation between sites. Variation in the honeydew resource also has the potential to affect the numbers of common wasps so we compared the abundance of honeydew between sites. 


\subsection{Methods}

\subsubsection{Study sites}

One pair of experimental sites was set up in each of three different locations in the Nelson region of the South Island of New Zealand. The locations were in the Nature Recovery Area of Nelson Lakes National Park $\left(41^{\circ} 48^{\prime} \mathrm{S}, 172^{\circ} 50^{\prime} \mathrm{E}\right.$ at $630 \mathrm{~m}$ and $41^{\circ} 49^{\prime}$ $\mathrm{S}, 172^{\circ} 50^{\prime} \mathrm{E}$ at $\left.630 \mathrm{~m}\right)$, Maitai Valley east of Nelson city $\left(41^{\circ} 17^{\prime} \mathrm{S}, 173^{\circ} 21^{\prime} \mathrm{E}\right.$ at $160 \mathrm{~m}$ and $41^{\circ} 18^{\prime} \mathrm{S}, 173^{\circ} 22^{\prime} \mathrm{E}$ at $265 \mathrm{~m}$ ) and the Roding Valley south-east of Nelson city $\left(42^{\circ} 21^{\prime} \mathrm{S}, 173^{\circ} 16^{\prime} \mathrm{E}\right.$ at $220 \mathrm{~m}$ and $41^{\circ} 21^{\prime} \mathrm{S}, 173^{\circ} 17^{\prime} \mathrm{E}$ at $\left.270 \mathrm{~m}\right)$. At each location the vegetation was simple in structure with the canopy dominated by the mature beech trees Nothofagus solandri and N. menziesii. The understory consisted primarily of Pseudopanax spp., Coprosma spp., Cyathodes juniperina, Leucopogon fasciculatus, Griselinia littoralis and juvenile Nothofagus. Each pair of sites consisted of a control site (wasps-maintained) in which common wasps remained at natural levels and a treatment site (wasps-controlled) where common wasps were poisoned. Each site in the pair was separated by no less than $1.5 \mathrm{~km}$. During February of 2008 and 2009 common wasps were poisoned at the three wasps-controlled sites. This was achieved by the placement of bait stations containing Xstinguish ${ }^{\mathrm{TM}}$ bait (active ingredient fipronil at $0.1 \mathrm{~g} / \mathrm{kg}$ ). Bait stations were attached to trees in a $50 \times 200 \mathrm{~m}$ grid pattern covering $1 \mathrm{~km}^{2}$ surrounding each study site. Except for Nelson Lakes National Park where due to an existing pest control programme over the last 10 years, an $8.25 \mathrm{~km}^{2}$ area was poisoned. Any uneaten bait was removed from bait stations after 48 hours. The effect of poisoning was monitored by Malaise trapping (detailed below). The mean numbers of common wasps caught in traps in both wasps-controlled and wasps-maintained sites were compared between the pre- and post-poisoning periods. 


\subsubsection{Pitfall and Malaise trapping}

All six sites were sampled in December of 2007 and 2008 and January, February and March of 2008 and 2009. This trapping regime encompassed two Southern Hemisphere summers. Two 20 x 20 m quadrats were established in each experimental site. Malaise traps were used to intercept flying insects. These traps consisted of a mesh tentlike structure with a collection jar at the apex, and are useful for collecting a large number of specimens. One Malaise trap was placed in the centre of each quadrat. The collection jar in each Malaise trap was $1 / 3$ filled with water with the addition of a drop of detergent to break the surface tension. Pitfall traps are designed to opportunistically collect ground dwelling invertebrates. These traps are dug into the ground with the trap entrance flush with the soil surface. In this study pitfall traps were plastic cups with a diameter of $70 \mathrm{~mm}$ and volume of $250 \mathrm{ml}$; they were $1 / 3$ filled with water with the addition of a drop of detergent to break the surface tension. Twenty pitfall traps were placed haphazardly within each quadrat no closer than two metres to any other pitfall trap. The three locations were trapped concurrently each month. Traps remained in place for four days at each site. At the end of each trapping period all traps were collected and sieved into $70 \%$ ethanol to preserve the samples. Samples were taken back to the laboratory and individuals were identified to family where possible, except for all common wasps and ants which were identified to species.

Differences in the numbers of common wasps caught in Malaise traps in both wasps-maintained and wasps-controlled sites both pre- and post-poisoning was analysed using ANOVA with number of common wasps as the dependant variable and time (pre- or post-poisoning), treatment (wasps-maintained or wasps-controlled) and location (Maitai, Roding or Rotoiti) as fixed factors. Differences in the numbers of Huberia brounii and bush ants caught in pitfall traps in wasps-maintained and wasps-controlled sites both pre- 
and post-poisoning were analysed using ANOVA with number of individuals as the dependant variable and time (pre- or post-poisoning), treatment (wasps-maintained or wasps-controlled) and location (Maitai, Roding or Rotoiti) as fixed factors. Data for this analysis were $\log 10$ transformed and met assumptions of normality and homoscedacity. A post-hoc LSD test was used to determine individual differences between sites. All ANOVA and T-test analyses in this chapter were performed in SPSS 16.0 (2008).

\subsubsection{Data analysis of invertebrate community composition}

Patterns of change in community structure before and after poisoning and between sites were assessed using species abundances collected from pitfall and Malaise traps from each site. Data were analysed in PRIMER v6 (Clarke and Gorley 2006). Abundances contained many zero counts making parametric analysis (which assumes statistical normality) unsuitable. Therefore, we used PERMANOVA (Permutational Multivariate Analysis of Variance) to test for differences between pre- and post-sampling periods before and after common wasp poisoning. PERMANOVA uses permutation procedures to obtain $P$-values thus avoiding the usual normality assumptions of ANOVA. Data were fourth root transformed to reduce dominance by more abundant species. The Bray-Curtis measure of similarity was used to perform a non-metric multidimensional scaling ordination (MDS) (Anderson 2005). Tests for significant differences in Malaise trap data between sampling periods were assessed using Analysis of Similarity (ANOSIM). The samples used for analyses were the numbers of individuals from each family in each site. The similarities percentages procedure (SIMPER) was used to calculate those families that contributed the most to dissimilarities between sites and sampling times.

Differences in the total numbers of both individuals and families caught in pitfall and Malaise traps between wasps-controlled and wasps-maintained sites in pre- and post- 
poisoning periods was analysed, as were the differences in the numbers of both individuals and taxonomic groups between locations (Maitai, Roding and Rotoiti) and any interaction between time and treatment using ANOVA with the number of individuals or families as the dependant variable. Levene's test confirmed that ANOVA data conformed to assumptions of normality and homoscedacity. A post-hoc LSD test was used to determine individual differences between sites.

\subsubsection{Vegetation sampling and honeydew abundance}

To assess the similarity of the plant community between all sampling sites vegetation surveys were conducted. At each site all plants with a stem greater than $5 \mathrm{~cm}$ diameter were recorded along 20 line transects each $5 \mathrm{~m}$ in length, placed haphazardly at each study site within $10 \mathrm{~m}$ of each experimental quadrat. Each plant was recorded to species and abundance was tallied for each transect in each site. Abundances were fourth root transformed to reduce dominance by more abundant species. The Bray-Curtis measure of similarity was used to perform a non-metric multidimensional scaling ordination. PERMANOVA was then used to test for differences in the plant community between sites. At each site during the first sampling period in December 2007 ten Nothofagus trees with honeydew present on trunks were haphazardly selected. All selected trees had a d.b.h. measurement between 20 and $40 \mathrm{~cm}$. All scale insect anal tubes with honeydew droplets were counted within a $30 \mathrm{~cm}$ band $1.5 \mathrm{~m}$ from the ground around each tree. Data were analysed using paired samples T-Test to test for differences between waspscontrolled and wasps-maintained sites. Differences between the numbers of honeydew producing trees ( $N$. fusca and $N$. solandri) within and between locations was calculated using ANOVA with number of trees as the dependant variable and site (wasps-maintained or wasps-controlled) and location (Maitai, Roding or Rotoiti) as fixed factors. 


\subsection{Results}

\subsubsection{Honeydew abundance and vegetation community composition}

There was no significant difference in the number of honeydew droplets per tree between wasps-removed and wasps-maintained sites $\left(\mathrm{T}_{29}=-0.323, \mathrm{p}=0.749\right)$ (Fig. 2.1). We observed an average of $29.8( \pm 1.99)$ anal filaments with honeydew per tree.

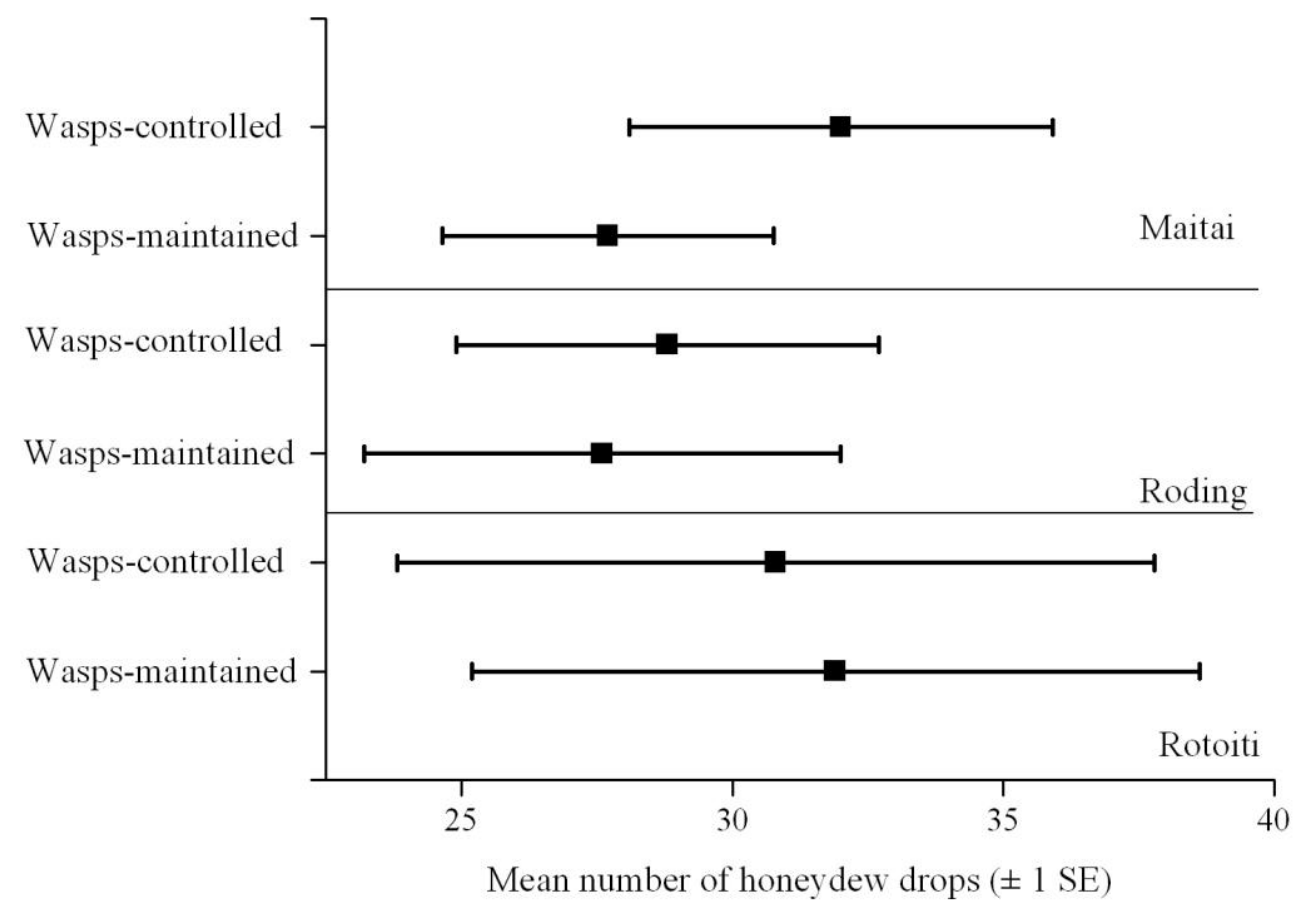

Figure 2.1 Honeydew abundance across all 6 sites

Mean \pm 1 SE. All scale insect anal tubes with honeydew droplets were counted within a $30 \mathrm{~cm}$ band $1.5 \mathrm{~m}$ from the ground around 10 trees haphazardly selected at each site.

There was a significant difference in the number of honeydew producing Nothofagus trees between locations $\left(\mathrm{F}_{2,112}=3.159, \mathrm{p}=0.046\right)($ Fig. 2.2) and a significant interaction between location and site $\left(\mathrm{F} 1_{, 112}=6.575, \mathrm{p}=0.012\right)$. There were fewer honeydew producing Nothofagus trees (N. fusca and N. solandri) in the wasps controlled sites in both Maitai and Roding. 


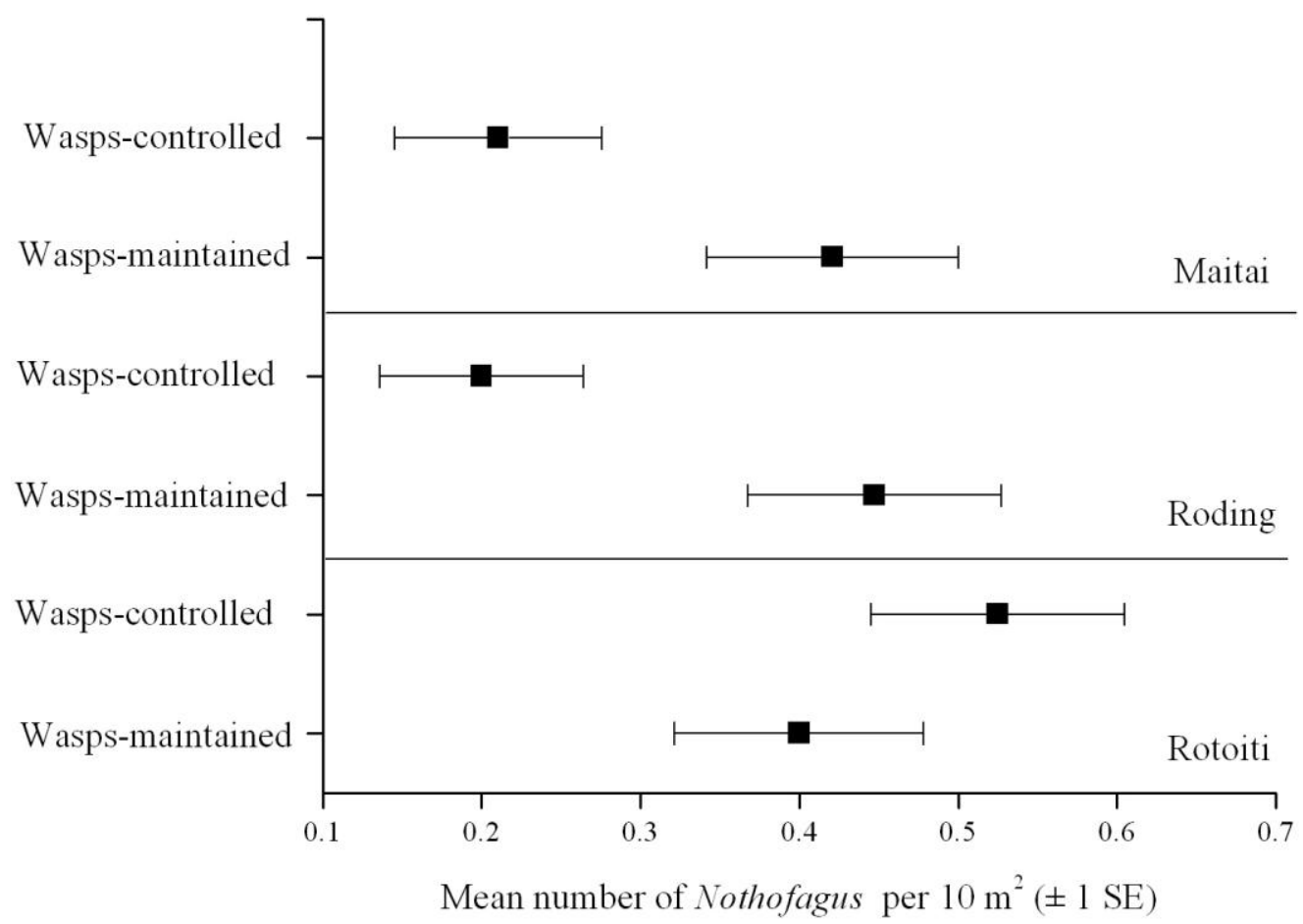

Figure 2.2 Honeydew producing Nothofagus abundance across all 6 sites

Number of honeydew producing Nothofagus per $10 \mathrm{~m}^{2}$ (mean $\pm 1 \mathrm{SE}$ ). At each site the number of Nothofagus fusca and $N$. solandri was recorded along $205 \mathrm{~m}$ line transects placed haphazardly within the study site.

Vegetation community composition did not vary between locations or sites (Fig 2.3, Table 2.1). The canopy was dominated by the mature beech trees Nothofagus solandri and N. menziesii. The understory consisted primarily of Pseudopanax spp., Coprosma spp., Cyathodes juniperina, Leucopogon fasciculatus, Griselinia littoralis and juvenile Nothofagus. 


\section{Table 2.1 PERMANOVA table of results for plant communities}

In this analysis location is Maitai, Rotoiti and Roding and site refers to the six individual sites within the three locations. At each site vegetation was recorded along $205 \mathrm{~m}$ line transects placed haphazardly within the study site. All plants were identified to species.

\begin{tabular}{lccc}
\hline Analysis & Pseudo-F & d.f. & $P$ \\
\hline $\begin{array}{l}\text { Vegetation } \\
\text { Location }\end{array}$ & & & \\
$\quad$ Site & 0.664 & 2,2 & 0.581 \\
& 1.532 & 1,2 & 0.312 \\
\hline
\end{tabular}

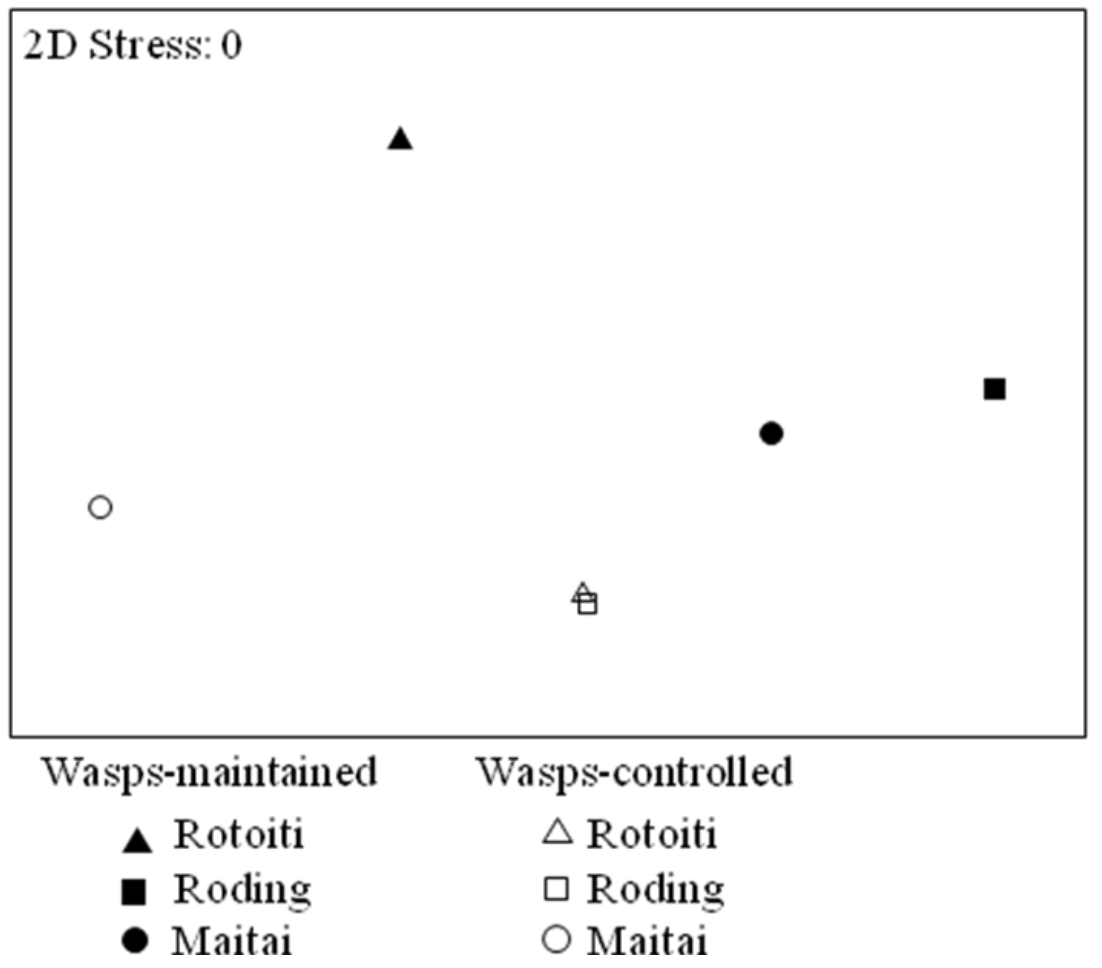

Figure 2.3 MDS plot of vegetation community composition across all six sites.

At each site vegetation was recorded along $205 \mathrm{~m}$ line transects placed haphazardly within the study site. All plants were identified to species. Each point represents pooled data from one sampling site 


\subsubsection{Wasp abundance}

The effect of poisoning was monitored by Malaise trapping in both wasps-controlled and wasps-maintained sites in pre- and post-poisoning periods and was determined to reduce common wasp densities in the wasps-controlled sites by an average of $69.2 \%( \pm$ 16.5) post-poisoning (Table 2.2, Fig. 2.4). This single poisoning event significantly reduced common wasp numbers for the remainder of the season. There was a significant interaction between location and time, due to fewer common wasps overall at Rotoiti postpoisoning, independent of the poisoning treatment. The post-hoc analysis revealed that Rotoiti was significantly different $(p=0.003$ ), this is due to the high numbers of common wasps at Rotoiti in both the wasps-maintained and wasps-controlled sites in the prepoisoning period.

\section{Table 2.2 ANOVA results for wasp abundance}

Location is Maitai, Roding or Rotoiti. Treatment is wasps-maintained or wasps-controlled and time is pre- or post-poisoning

\begin{tabular}{lccc}
\hline \multicolumn{1}{c}{ Analysis } & $\mathrm{F}$ & d.f. & $P$ \\
\hline & & & \\
Location & 2.73 & 2,28 & 0.08 \\
Treatment & 10.19 & 1,28 & $<0.01$ \\
Time & 12.61 & 1,28 & $<0.001$ \\
Treatment x Time & 4.19 & 1,28 & $<0.05$ \\
& & & \\
\hline
\end{tabular}




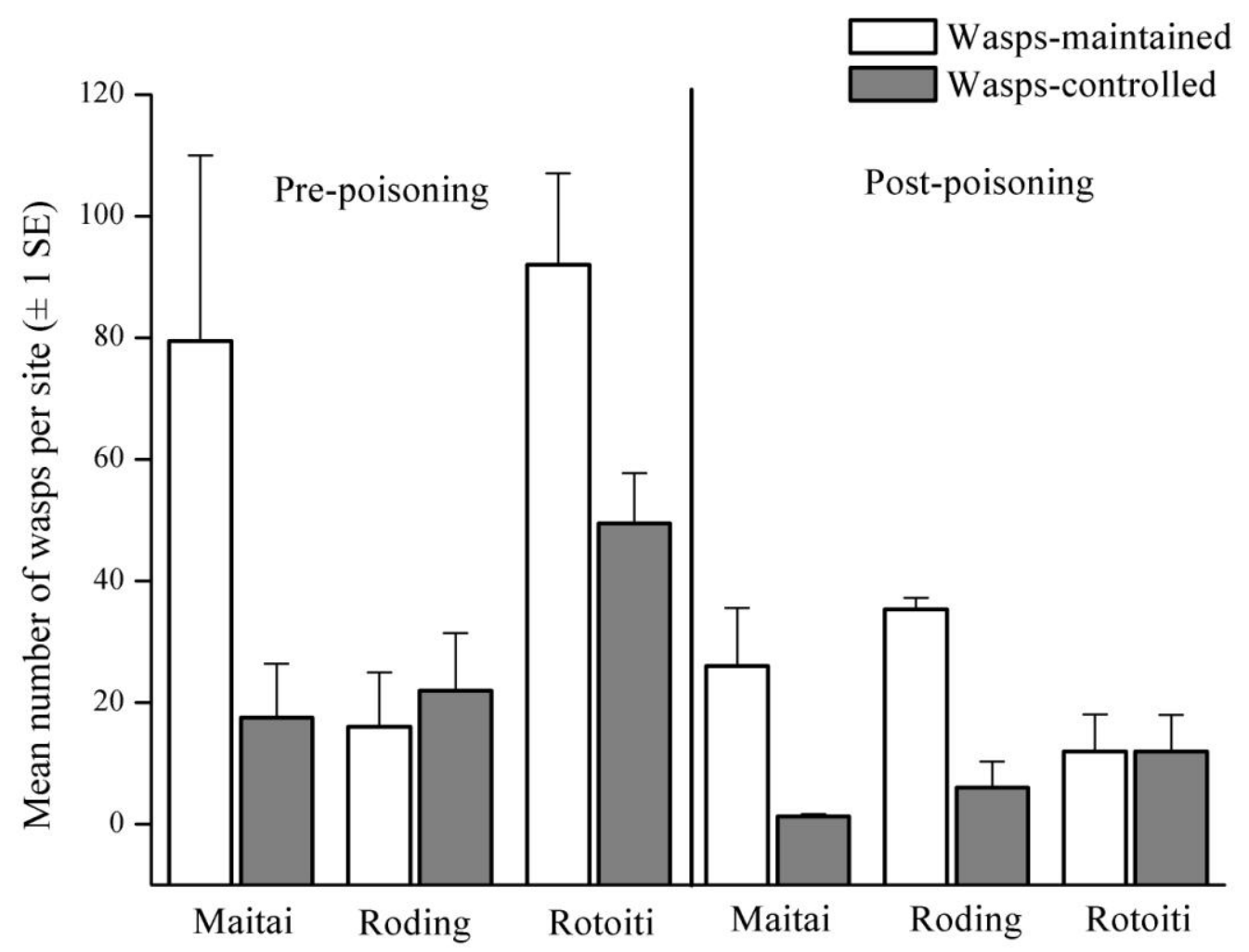

Figure 2.4 Numbers of common wasps caught in Malaise traps

Mean number of common wasps ( $\pm 1 \mathrm{SE})$ in wasps-maintained and wasp-controlled sites both pre- and postpoisoning.

\subsubsection{Invertebrate community composition}

There were a total of 11,319 individuals from 44 taxonomic groups present in Malaise traps over the two trapping seasons (Fig 2.5). PERMANOVA revealed that the community composition of invertebrate communities caught in Malaise traps was significantly different between sampling periods (Table 2.3, Fig. 2.6). There was no difference between treatments or between locations. Additionally there was no interaction between treatment and time indicating that the observed differences are due to seasonal differences in community composition. 

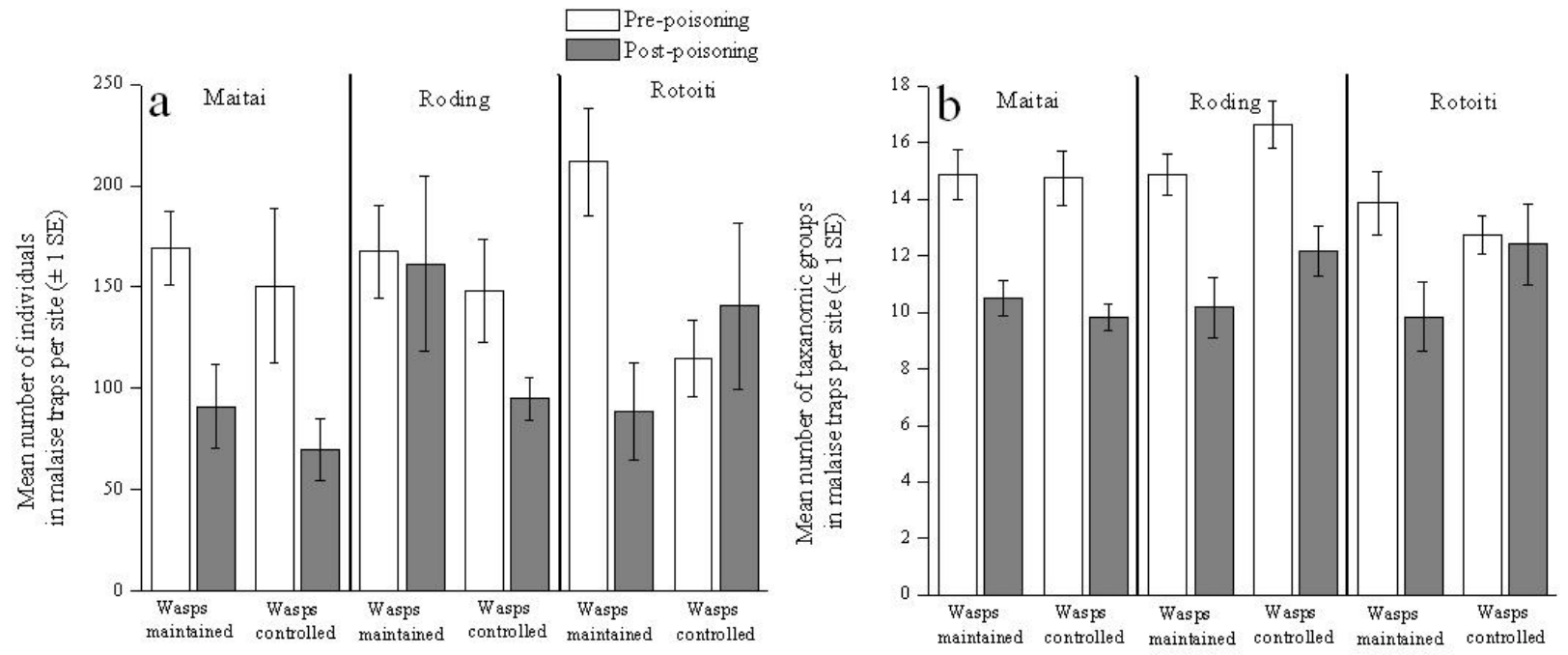

Figure 2.5 Mean number of individuals and taxonomic groups collected in Malaise traps

Numbers of individuals (fig. 2.5a) and taxonomic groups (fig. 2.5b) in both wasps-controlled and waspsmaintained treatments, before and after wasp poisoning in all locations

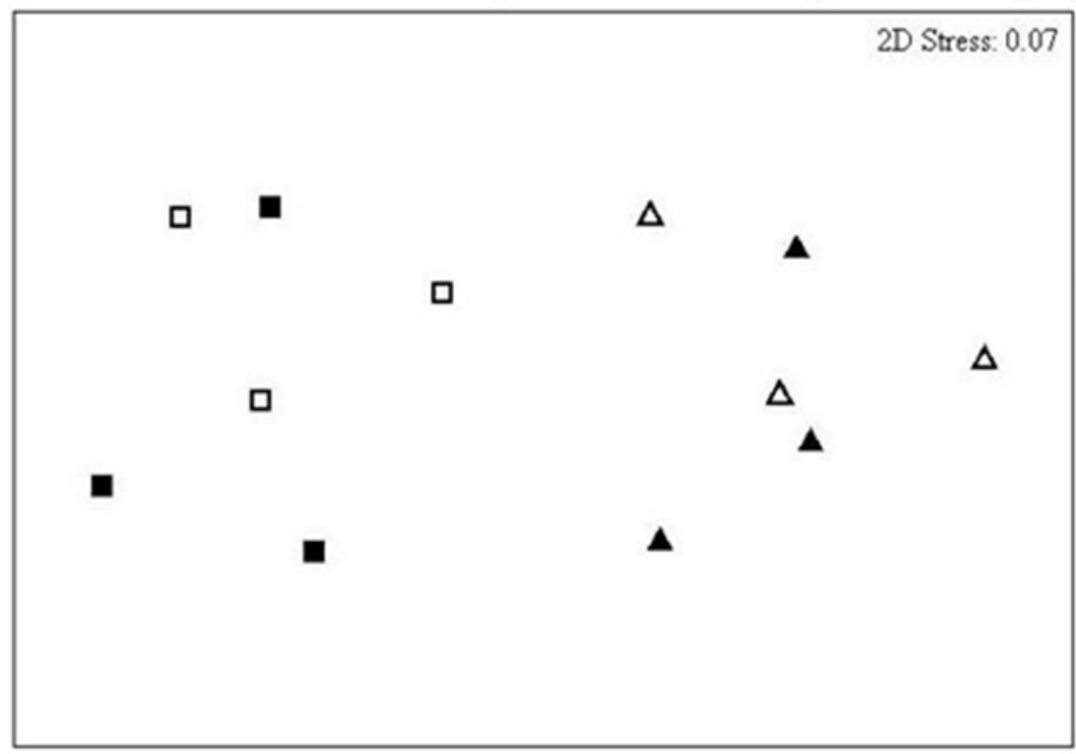

Wasps-maintained Wasps-controlled
$\Delta$ Pre-poisoning
$\triangle$ Pre-poisoning
- Post-poisoning
Post-poisoning

\section{Figure 2.6 MDS plot for Malaise traps}

Samples were taken before and after common wasp poisoning in wasps-controlled and wasps-maintained sites. Wasps-controlled sites had wasp poison placed and wasp density was reduced by an average of $69.2 \%$ $( \pm 16.5)$. Wasps-maintained sites were not poisoned and common wasps remained at natural levels. Data were collected over two years. Each point represents pooled data from one sampling site 
Table 2.3 PERMANOVA table of results for invertebrate community composition

In this analysis time is pre- or post-poisoning, treatment is wasps-maintained or wasps-controlled, location is Maitai, Rotoiti and Roding.

\begin{tabular}{llcc}
\hline \multicolumn{1}{c}{ Analysis } & Pseudo-F & d.f. & $P$ \\
\hline Malaise & & & \\
$\quad$ Time & 9.148 & 1,8 & $<0.01$ \\
Treatment & 0.586 & 1,8 & 0.825 \\
Location & 0.811 & 2,9 & 0.568 \\
Time x Treatment & 0.893 & 1,8 & 0.57 \\
& & & \\
Pitfalls & & & \\
Time & 3.302 & 1,8 & $<0.01$ \\
Treatment & 0.707 & 1,8 & 0.715 \\
Location & 2.106 & 2,9 & $<0.05$ \\
Time x Treatment & 0.323 & 1,8 & 0.956 \\
& & & \\
\hline
\end{tabular}

SIMPER analysis determined that plots were $32 \%$ dissimilar between sampling periods. Of this variation $40 \%$ was explained by seven taxonomic groups; Trichoptera, Pompilidae, Mordellidae, Colydiidae, miscellaneous Diptera, Hemiptera and Empididae. Trichoptera were three times more abundant in the pre-poisoning period and Pompilidae were twice as abundant before poisoning. The ANOSIM results indicate that overall differences were driven by different relative abundances in different sampling periods rather than overall differences in species composition (Table 2.4). 


\section{Table 2.4 ANOSIM table of results for pitfall and Malaise traps}

In this analysis time is pre- or post-poisoning, treatment is wasps-maintained or wasps-controlled, location is Maitai, Rotoiti and Roding.

\begin{tabular}{llr}
\hline Analysis & Global R & \multicolumn{1}{c}{$P$} \\
\hline Malaise & & \\
$\quad$ Time & & \\
Treatment & 0.963 & $<0.01$ \\
Location & -0.13 & 0.75 \\
& -0.049 & 0.56 \\
Pitfalls & & \\
Time & & \\
Treatment & 0.296 & 0.06 \\
Location & -0.241 & 0.87 \\
& 0.278 & $<0.05$ \\
\hline
\end{tabular}

When comparing the total number of individuals caught in Malaise traps (Fig. 2.5a) between sampling periods there was a significant difference $\left(F_{1,30}=7.55 p<0.01\right)$. More individuals were caught in Malaise traps in the pre-poisoning period. There was no difference in the numbers of individuals caught in Malaise traps between waspscontrolled and wasps-maintained treatments $\left(\mathrm{F}_{1,30}=3.13 \mathrm{p}=0.08\right)$. There was no significant difference in the number of individuals caught in Malaise traps between locations $\left(\mathrm{F}_{2,30}=0.453 \mathrm{p}=0.64\right)$ and there was no interaction between treatment and time $\left(\mathrm{F}_{1,30}=0.589 \mathrm{p}=0.45\right)$.

There was a significant difference in the number of taxonomic groups caught in Malaise traps between sampling periods (Fig. 2.5b) $\left(\mathrm{F}_{1,30}=30.58 \mathrm{p}<0.001\right)$. There were significantly more taxonomic groups caught in Malaise traps in the pre-poisoning period. There was no difference in the number of taxonomic groups caught in Malaise traps between wasps-controlled and wasps-maintained treatments $\left(\mathrm{F}_{1,30}=0.03 \mathrm{p}=0.87\right)$. There was also no significant difference in the number of taxonomic groups caught in Malaise 
traps between locations $\left(\mathrm{F}_{2,30}=3.19 \mathrm{p}=0.06\right)$ additionally there was no interaction between treatment and time $\left(\mathrm{F}_{1,30}=0.49 \mathrm{p}=0.48\right)$.

There were a total of 30,688 individuals from 42 taxonomic groups caught in pitfall traps over the two trapping years (Fig. 2.7). The PERMANOVA test indicated a significant difference in community composition caught in pitfall traps between sampling periods and a significant difference between locations (Table 2.3, Fig 2.8). There was no difference between treatments and no interaction between treatment and time indicating that the observed differences are due to seasonal differences in composition. The observed difference between locations is attributable to the large number of ants at one of the Maitai sites.

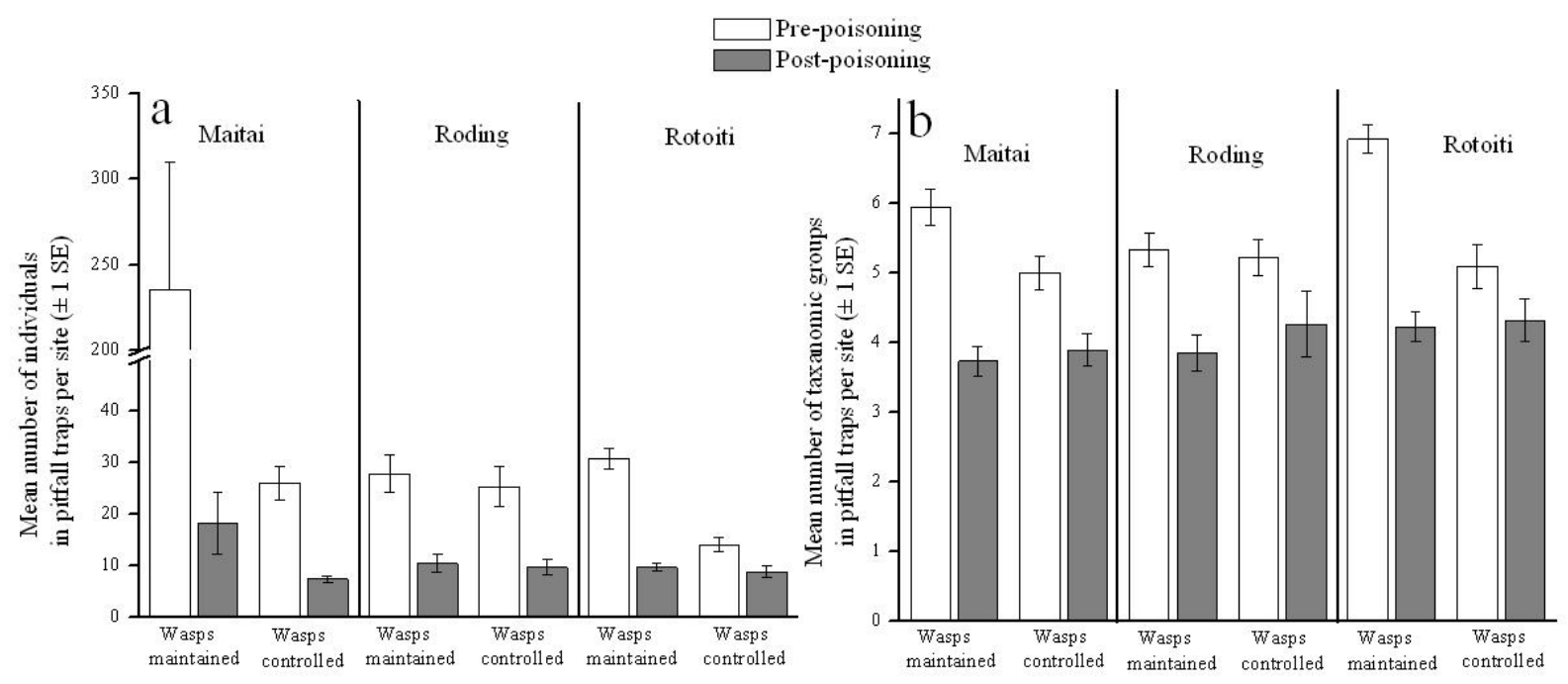

Figure 2.7 Mean number of individuals and taxonomic groups collected in pitfall traps

Numbers of individuals (fig. 2.7a) and taxonomic groups (fig. 2.7b) in both wasps-controlled and waspsmaintained treatments, before and after wasp poisoning in all locations.

SIMPER analysis determined that plots were $29 \%$ dissimilar between sampling periods. Of this variation $30 \%$ was explained by seven taxonomic groups; Histeridae, Staphylinidae, Scarabidae, Collembola, Calliphoridae, Lygaeidae and Psychodidae. Locations were $65 \%$ dissimilar in their invertebrate community composition as determined by SIMPER analysis. $16 \%$ of this variation was due to the large number of 
ants present in one Maitai site, a further $20 \%$ of the variation was as a result of differing abundances of spiders and Staphylinidae. The ANOSIM results indicate that overall differences were driven by different relative abundances in locations rather than overall differences in species composition (Table 2.4). There were some differences in different sampling periods however this was above the $5 \%$ level of significance.

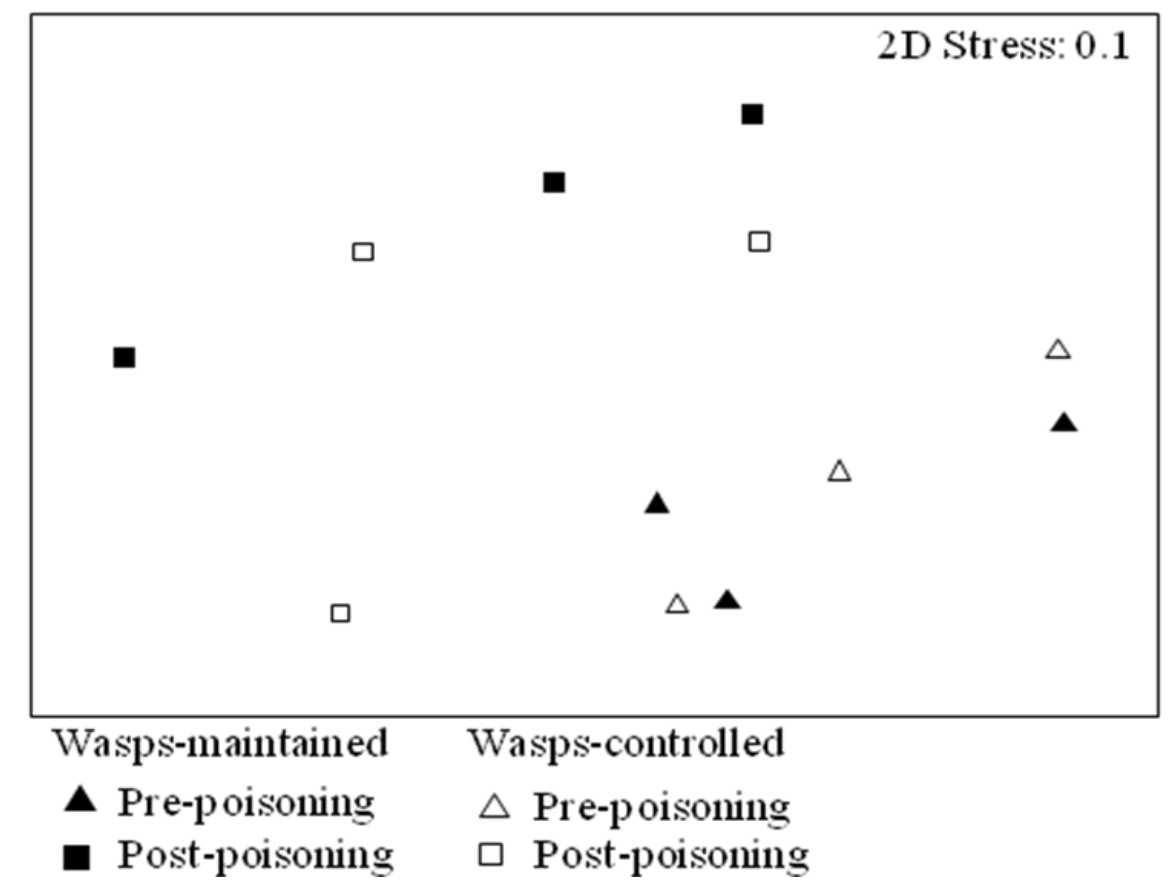

\section{Figure 2.8 MDS plot for pitfall traps}

Samples were taken before and after common wasp poisoning in wasps-controlled and wasps-maintained sites. Wasps-controlled sites had wasp poison applied and wasp density was reduced by an average of $69.2 \%$ $( \pm 16.5)$. Wasps-maintained sites were not poisoned and common wasps remained at natural levels. Data were collected over two years. Each point represents pooled data from one sampling site

ANOVA revealed a significant difference in the total number of individuals caught in pitfall traps between the pre-poisoning and post-poisoning period (Fig. 2.7a) $\left(\mathrm{F}_{1,30}=\right.$ $32.13 \mathrm{p}<0.001)$. There were a greater number of individuals caught in pitfall traps in the pre-poisoning period. There was a significant difference in the numbers of individuals caught in pitfall traps between wasps-controlled and wasps-maintained treatments $\left(\mathrm{F}_{1,30}=\right.$ 
$11.92 \mathrm{p}<0.01)$ there were more individuals in the wasps-maintained treatments; however, this result is skewed by the large number of ants in one maitai site. There was also a significant difference in the number of individuals caught in pitfall traps between locations $\left(F_{2,30}=4.68 \mathrm{p}<0.05\right)$. The post-hoc LSD test revealed that Maitai had significantly more individuals than both Roding and Rotoiti $(\mathrm{p}<0.01$ for each) due to greater numbers of ants at this site. There was, however, no interaction between treatment and time $\left(F_{1,30}=0.873 p\right.$ $<0.36)$.

There was a significant difference in the number of taxonomic groups caught in pitfall traps between sampling periods (Fig. 2.7b) $\left(\mathrm{F}_{1,30}=35.95 \mathrm{p}<0.001\right)$, with more taxonomic groups in the pre-poisoning period. There was a significant difference in the number of taxonomic groups between wasps-controlled and wasps-maintained treatments $\left(\mathrm{F}_{1,30}=5.56 \mathrm{p}<0.05\right)$, wasps-maintained treatments had a greater number than waspscontrolled treatments. There was a significant difference in the number of taxonomic groups caught in pitfall traps between locations $\left(\mathrm{F}_{2,30}=5.09 \mathrm{p}<0.05\right)$. The post-hoc analysis revealed that Rotoiti had more taxonomic groups and was significantly different from Roding $(\mathrm{p}<0.01)$. However, there was no interaction between treatment and time $\left(\mathrm{F}_{1,30}=0.83 \mathrm{p}<0.37\right)$.

There were significant difference in the numbers of $H$. brounii between sampling times (Fig 2.9a) $\left(\mathrm{F}_{1,30}=4.93 \mathrm{p}<0.05\right)$. However, there was no effect of location or treatment on numbers of Huberia brounii, there was also no significant interaction between treatment and time.

Numbers of bush ants decreased significantly over time in wasps-maintained and wasp-controlled sites (Fig. 2.9b) $\left(\mathrm{F}_{1,30}=27.34 \mathrm{p}<0.00\right)$. There was also a significant difference in the numbers of bush ants across locations $\left(\mathrm{F}_{2,30}=5.85 \mathrm{p}<0.01\right)$ the post-hoc analysis revealed that the Maitai location had significantly more bush ants than either 
Roding or Rotoiti ( $\mathrm{p}<0.001$ for both). There was a significant difference in the numbers of bush ants between the wasps-maintained and the wasps-controlled treatments $\left(\mathrm{F}_{1,30}=18.48\right.$ $\mathrm{p}<0.001)$ there were more bush ants in the wasps-maintained treatments. Data were skewed necessitating $\log 10$ transformation due to extraordinarily large numbers of bush ants in one Maitai site in one sampling month. This may be attributable to some pitfall traps inadvertently being placed near bush ant nests. Two traps at this site contained more than 3000 ants whereas for the remainder of traps counts ranged from 0 to 300 .
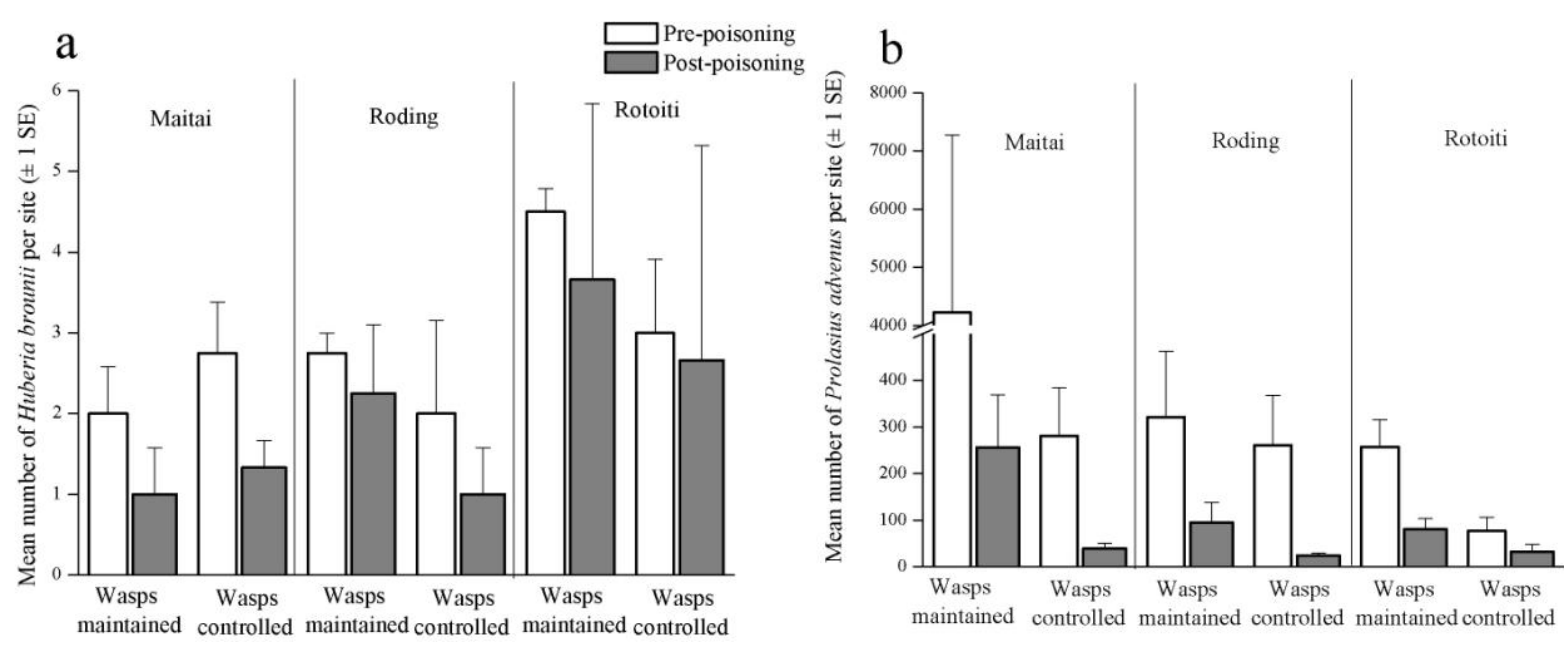

Figure 2.9 Number of ants caught in pitfall traps

Mean numbers of Huberia brounii (2.9a) and bush ants (2.9b) caught in pitfall traps ( \pm 1 SE) in waspsmaintained and wasp-controlled treatments both pre- and post-poisoning over all locations. 


\subsection{Discussion}

\subsubsection{The influence of forest structure and honeydew abundance on community composition}

The presence of an abundant carbohydrate resource in Nothofagus forests has been suggested to have the potential to structure invertebrate communities (Beggs et al. 1998, Beggs 2001). Honeydew abundance did not vary significantly between trees in different sampling sites however there were fewer honeydew producing trees in two of the waspscontrolled sites which may have had an impact on overall honeydew availability in these locations. Overall the vegetation community also did not vary significantly between sites or locations. The differences in the the numbers of individual invertebrates between sites was driven primarily by the high numbers of bush ants in one of the wasps-maintained sites at the Maitai Valley, and appears not to be related to the vegetation community or honeydew abundance.

\subsubsection{Changes in community composition following wasp poisoning}

Previous work has shown that common wasps reduce both the abundance and the diversity of the invertebrate community (Harris 1991, Moller et al. 1991, Beggs et al. 1998, Beggs 2001). It has been suggested that total prey abundance may not be impacted by common wasps as they are generalist predators (Beggs 2001). When one prey species declines, common wasps may switch to another thereby reducing or maintaining diversity and altering community composition, but not reducing overall abundance. In this study our results showed a change in the community composition in the species caught in Malaise traps as a result of sampling period, but no change in composition as a result of the 
poisoning treatment. We found a change in the composition of invertebrates caught in pitfall traps as a result of both sampling period and location. The observed changes in community composition were as a result of differing abundances of taxonomic groups. Some taxonomic groups that were abundant early in the summer declined in number by the end of summer. Trichoptera caught in Malaise traps were three times more abundant at the start of the summer than at the end and Pompilidae were twice as abundant in the first sampling period. In particular the decline in ant numbers contributed most to the observed change in community structure; however, this pattern may be confounded by the fact that there was an unusually high abundance of ants at one Maitai site early in the summer.

There are several hypotheses to explain our findings. 1) There may be no effect of common wasps on the invertebrate community; 2) communities take much longer to recover from invasion than we were able to detect in the short period of our study; 3 ) we may not have reduced common wasp numbers sufficiently to see an effect; 4) we may have conducted the poisoning treatment too late in the season; 5) we may have missed variation by only identifying samples to the family level, and finally; 6) our results may be due to natural seasonal variation in the invertebrate community. We will address each of these potential explanations in turn.

Common wasps may have no effect on the community composition of invertebrates in this system. We did not find any differences in the community composition of invertebrates that we could directly attribute to the reduction in the numbers of common wasp. However, this explanation seems unlikely in the light of numerous other studies that document an impact of common wasps on native invertebrates in New Zealand Nothofagus forests (Harris 1991, Toft and Beggs 1995, Toft and Rees 1998, Beggs and Rees 1999, Beggs 2001). 
Natural communities take a long time to recover from invasions. Common wasps have had a significant impact on the Nothofagus community for the past 20 years. Species that are particularly vulnerable to common wasp predation may have already become scarce in areas with high common wasp abundance such as these Nothofagus forests, and the limited period of our experiment (only two years) may not be of a sufficiently long timeframe to see any recovery in the natural community. Those invertebrates most likely to be impacted by common wasp predation may have disappeared from the community after the initial invasion of common wasps nearly 20 years ago. It may be too late to save the most vulnerable species which have already been subject to invasion by the wasp Vespula germanica in the 1940's, and common wasps in the 1980's, constituting 40 years of predation by Vespula wasps (Toft and Rees 1998). For the community to be able to recover from invasion by Vespula spp. it may take considerably longer than two years to see any change in community structure as a result of wasp poisoning, and additionally recovery relies on vulnerable species being able to disperse back into this environment.

We may not have reduced common wasp numbers sufficiently to see a recovery in the community. It is possible that only those species less impacted by common wasps remain in these communities. To be able to detect any recovery in vulnerable species, common wasp numbers may need to be reduced to a greater extent. Even if the poisoning effort were to continue long term, as is the case at Rotoiti where there is an existing predator control programme where common wasps have been poisoned for the last ten years, the reduction in common wasp numbers by only $70 \%$ may not be enough to have a significant impact on the abundance and diversity of prey species. It has been estimated that to conserve species vulnerable to common wasp predation, common wasp numbers need to be reduced by $80-90 \%$ (Beggs et al. 1998, Toft and Rees 1998, Beggs and Rees 1999). Additionally, there was significant variation in common wasp abundance between 
sites in the pre-poisoning period. Even though there was a reduction in common wasp numbers in the post-poisoning period in all wasps-controlled sites, there was also a reduction in common wasp numbers in two out of three wasps-maintained sites. This variation in abundance may have confounded our results.

We may have conducted the poisoning treatment too late in each season to see an impact of a reduction in common wasp numbers on the invertebrate community. Poisoning took place at the point of highest common wasp abundance, the end of February. This method was employed as studies have shown that poisoning before this time is ineffective as there is often such an abundance of other prey species that common wasps are not attracted to protein bait (Beggs et al. 1998, Beggs 2001). This method does serve to have the greatest impact on common wasp numbers, however; the impact of high common wasp numbers prior to poisoning may have reduced the numbers of prey for the remainder of the summer.

Additionally, our method of identifying invertebrates only to family may have missed variation in the community as a result of common wasp removal. If we had identified our catch to species, or even genus, we may have picked up changes based on preferential predation from common wasps. However, given the time and logistical constraints of species identification it was decided a priori that the family level of classification would be sufficient.

Finally, the observed differences may be as a result of natural seasonal variation in community composition. Our results indicate that the community diversity of both flying insects and ground dwelling insects (as indicated by Malaise and pitfall trap catches respectively) varies through time but were not impacted by a reduction in common wasp numbers. Additionally, it appears that common wasp numbers also decrease seasonally independent of the poisoning treatment. Invertebrate communities may be significantly 
restructured due to predation from common wasps. Species especially vulnerable to common wasp predation may be detectable only during those months when common wasps are at low numbers or absent (Beggs and Rees 1999). Our sampling encompassed the entire southern hemisphere summer months from December to February and therefore the observed variation in community composition may be a reflection of natural seasonal variation in population numbers. The Trichoptera caught in Malaise traps were three times more abundant at the start of the summer than at the end. This variation is a natural phenomenon, as peak summer emergence for Trichoptera is between December and January (Collier and Smith 1998). Similarly Pompilidae are active primarily during the summer months (Roberts 1977), which may account for the observation that Pompilidae were twice as abundant in the first sampling period.

\subsubsection{Changes in ant abundance following common wasp poisoning}

The decline in numbers of bush ants was the major factor contributing to the observed change in invertebrate community composition. The numbers of bush ants declined in pitfall traps between the pre- and post-poisoning period. This decline was not related to an increase in competition from common wasps as numbers of this ant also declined by similar amounts in the wasps-controlled sites. Ants in other systems are known to exhibit seasonal variation in numbers and changes in foraging activity (Levings 1983). This variation may be related to moisture levels, with numbers declining as the environment becomes drier. Numbers of $H$. brounii caught in pitfall traps were very low. There was a mean of $0.013( \pm 0.002)$ ants per trap in the pre-poisoning period and a mean of $0.12( \pm 0.008)$ in the post poisoning period across all sites. This compares with average abundances of bush ants in the pre- and post-poisoning periods of $48.18( \pm 13.11)$ and 5.01 $( \pm 1.15)$ respectively. Observations during this and other field studies (detailed in chapters 
three and four) confirm that numbers of $H$. brounii foragers increase later in the summer. These seasonal changes in ant abundance are clearly not related to our poisoning treatment. The mechanism for this is unknown as very little literature exists on these ants and no papers have yet been published on their ecology and life history. Native ants are abundant in this forest system and seem to be unaffected by common wasp densities. Therefore, it may be important to understand how native ants, with similar foraging habits and life history strategies as invasive common wasps, manage to maintain robust populations when it could be expected that they would be most impacted by the detrimental effects of competition. Future chapters in this thesis will investigate behavioural changes and changes in isotope ratios as a result of competitive interactions between native ants and invasive common wasps.

\subsection{Conclusion}

We predicted that a reduction in common wasp numbers would result in an increase in the number, overall diversity and community composition of native invertebrate species. The observed changes in community composition after a reduction in common wasp numbers were as a result of differing abundances of taxonomic groups rather than a difference in overall community composition. There was an overall decline in the numbers of many taxonomic groups over the summer period. Under pressure from invasive omnivorous species, such as Vespula wasps, the abundance of prey species decline as a result of increased predation. We then see a consequent decline in the number of other predacious species. There are several potential hypotheses to explain our observed results. There may be no effect of common wasps on the invertebrate community; communities 
take much longer than the period of our study to recover from the impacts of invasion; we may have conducted the poisoning treatment too late in the season; we may have missed variation by only identifying samples to the family level; and finally, our results may be due to natural seasonal variation in the invertebrate community. However the most parsimonious explanation may be that we did not reduce common wasp numbers sufficiently to see a corresponding change in the invertebrate community. In order to more robustly determine the community effects of common wasp removal it may be necessary to reduce common wasp numbers by up to $90 \%$ for many years. Even under these conditions species that are particularly vulnerable to common wasp predation or competition may have already been permanently excluded from this system.

\subsection{Acknowledgements}

Laura Warman, Zak Murdoch, John Searle, Oren Werker, Paul Marsden, Ilse Corkery, Julien Grangier, Alan Burne, and Laura Bass provided invaluable field help. Funding was provided by the Royal Society of New Zealand Marsden fund and a Victoria University of Wellington PhD Scholarship. Thanks to the Department of Conservation and the Tasman District Council for access to land. Thanks also to the Department of Conservation and LandCare research for assistance with the poisoning. 


\subsection{References}

Anderson, M. J. 2005. PERMANOVA: a FORTRAN computer program for permutational multivariate analysis of variance. University of Auckland, New Zealand.

Beggs, J. 2001. The ecological consequences of social wasps (Vespula spp.) invading an ecosystem that has an abundant carbohydrate resource. Biological Conservation 99:17-28.

Beggs, J., R. J. Toft, J. P. Malham, J. S. Rees, J. A. V. Tilley, H. Moller, and P. Alspach. 1998. The difficulty of reducing introduced wasp (Vespula vulgaris) populations for conservation gains. New Zealand Journal of Ecology 22:55-63.

Beggs, J. and D. A. Wardle. 2006. Keystone species: Competition for honeydew among exotic and indigenous species. Springer-Verlag, Berlin.

Beggs, J. R. and J. S. Rees. 1999. Restructuring of Lepidoptera communities by introduced Vespula wasps in a New Zealand beech forest. Oecologia 119:565-571.

Bøhn, T., P. Amundsen, and A. Sparrow. 2008. Competitive exclusion after invasion? Biological Invasions 10:359-368.

Buckley, R. C. 1987. Interactions involving plants, homoptera, and ants. Annual Review of Ecology and Systematics 18:111-135.

Carroll, C. R. and D. H. Janzen. 1973. Ecology of foraging by ants. Annual Review of Ecology and Systematics 4:231-257.

Clarke, K. R. and R. N. Gorley. 2006. PRIMER v6: User manual, Plymouth.

Collier, K. J. and B. J. Smith. 1998. Dispersal of adult caddisflies (Trichoptera) into forests alongside three New Zealand streams. Hydrobiologia 361:53-65.

Don, W. 2007. Ants of New Zealand. Otago University Press, Dunedin

Fagan, W. F., M. D. Moran, J. J. Rango, and L. E. Hurd. 2002. Community effects of praying mantids: a meta-analysis of the influences of species identity and experimental design. Ecological Entomology 27:385-395.

Harris, R. J. 1991. Diet of the wasps Vespula vulgaris and V. germanica in honeydew beech forest of the South Island, New Zealand. New Zealand Journal of Zoology 18:159-169.

Holt, R. D. 1977. Predation, apparent competition, and the structure of prey communities. Theoretical Population biology 12:197-229. 
Human, K. G. and D. M. Gordon. 1999. Behavioural interactions of the invasive Argentine ant with native ant species. Insectes Sociaux 46:159 - 163.

Levings, S. C. 1983. Seasonal, annual, and among-site variation in the ground ant community of a deciduous tropical forest: some causes of patchy species distributions. Ecological Monographs 53:435-455.

Mailleux, A., J. Deneubourg, and C. Detrain. 2003. Regulation of ants' foraging to resource productivity. Proceedings of the Royal Society of London 270:1609-1616.

Masciocchi, M., A. Farji-Brener, and P. Sackmann. 2009. Competition for food between the exotic wasp Vespula germanica and the native ant assemblage of NW Patagonia: evidence of biotic resistance? Biological Invasions DOI

\subsection{7/s10530-009-9469-5.}

Moller, H. and J. A. V. Tilley. 1989. Beech honeydew: seasonal variation and use by wasps, honey Bees, and other insects. New Zealand Journal of Zoology 16:289302.

Moller, H., J. A. V. Tilley, B. W. Thomas, and P. D. Gaze. 1991. Effect of introduced social wasps on the standing crop of honeydew in New Zealand beech forests. New Zealand Journal of Zoology 18:171-179.

Morales, C. F., M. G. Hill, and A. K. Walker. 1988. Life history of the sooty beech scale (Ultracoelostoma assimile) (Maskell), (Hemiptera: Margodidae) in New Zealand Nothofagus forests. New Zealand Entomologist 11:24-38.

Roberts, M. 1977. Overwintering strategies in New Zealand insects. Tuatara 23:1-9.

Room, P. M. 1975. Relative distributions of ant species in cocoa plantations in Papua New Guinea. Journal of Applied Ecology 12:47-61.

Rowles, A. D. and D. J. O'Dowd. 2007. Interference competition by Argentine ants displaces native ants: implications for biotic resistance to invasion. Biological Invasions 9:73-85.

Snyder, W. E. and E. W. Evans. 2006. Ecological effects of invasive arthropod generalist predators. Annual Review of Ecology, Evolution, and Systematics 37:95-122.

SPSS. 2008. Release 16.0 Chicago SPSS inc.

Stadler, B. and A. F. G. Dixon. 1999. Ant attendance in aphids: why different degrees of myrmecophily? Ecological Entomology 24:363-369.

Thomas, C. D., H. Moller, G. M. Plunkett, and R. J. Harris. 1990. The prevalence of introduced Vespula vulgaris wasps in a New Zealand beech forest community. New Zealand Journal of Ecology 13:63-72. 
Toft, R. J. and J. R. Beggs. 1995. Seasonality of crane flies (Diptera: Tipulidae) in South Island beech forest in relation to the abundance of Vespula wasps (Hymenoptera: Vespidae). New Zealand Entomologist 18:37-43.

Toft, R. J. and J. S. Rees. 1998. Reducing predation of orb-web spiders by controlling common wasps (Vespula vulgaris) in a New Zealand beech forest. Ecological Entomology 23:90-95.

van Veen, F. J. F., R. J. Morris, and H. C. J. Godfray. 2006. Apparent competition, quantitative food webs and the structure of phytophagous insect communities. Annual Review of Entomology 51:187-208.

Way, M. J. 1963. Mutualism between ants and honeydew producing homoptera. Annual Review of Entomology 8:307-344. 


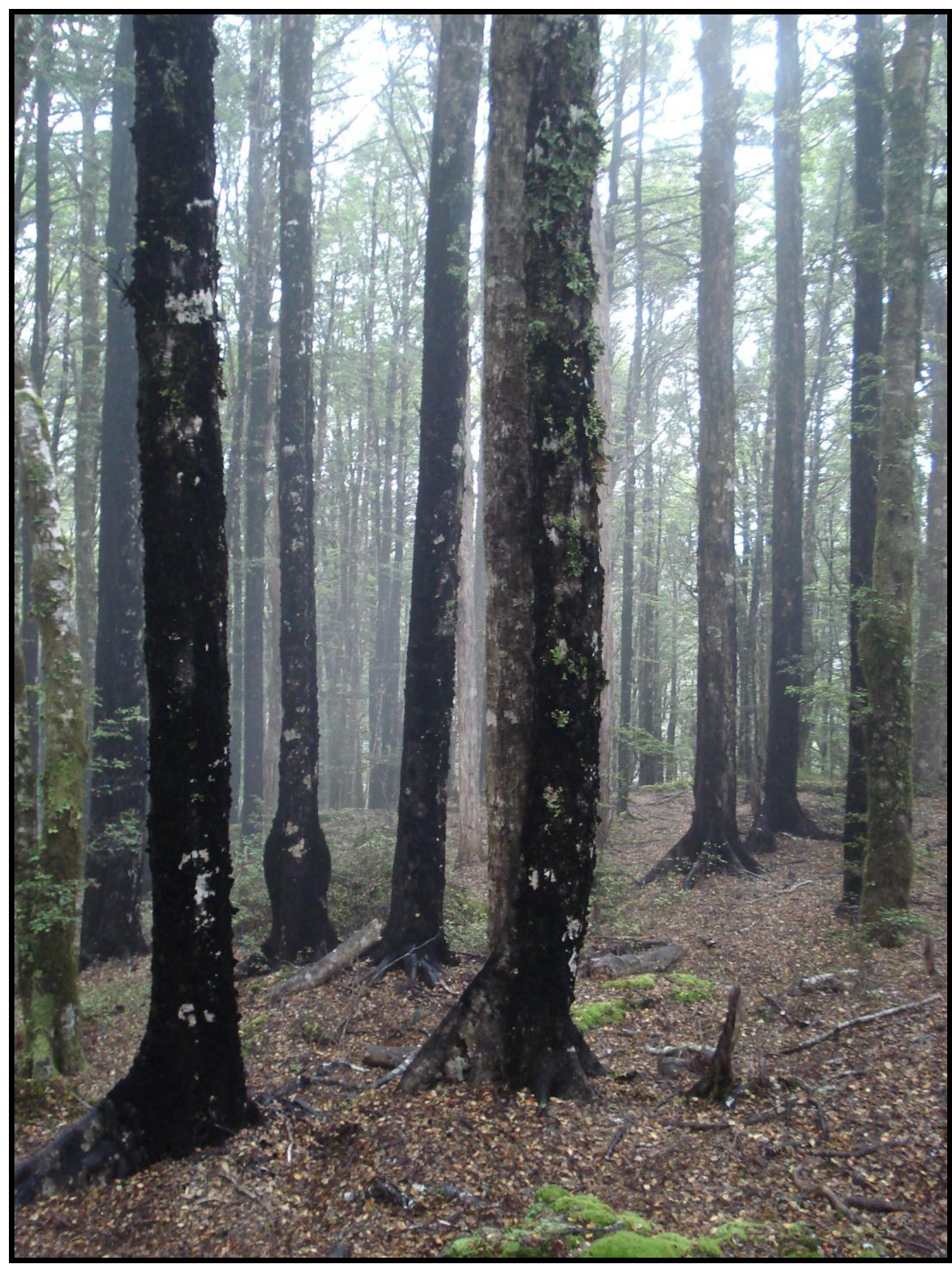

Nothofagus forest in Nelson Lakes National Park 


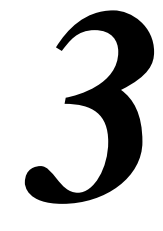

\title{
Chapter Three
}

\author{
Temporal Patterns of Honeydew
}

Foraging by an Endemic Ant and a

Competing Invasive Wasp 


\subsection{Abstract}

Invasive species may have superior abilities to exploit resources in their new environment. Native species affected by competition with invasive species may continue to persist by altering the way in which they use shared resources. Previous research has shown that the invasive common wasp (Vespula vulgaris) now dominates the supply of honeydew in Nothofagus forests of the South Island of New Zealand to the detriment of native birds and insects. In the face of this invasive species the native bush ants (Prolasius advenus) may have adjusted their pattern of resource use to avoid interspecific aggression or exclusion from resources. We studied temporal patterns of honeydew foraging on Nothofagus trees in two different sites, one of which had a long-term programme of common wasp reduction by poisoning. Because bush ants and common wasps compete for the same food resources we predicted that we would see spatial and temporal partitioning of resource use; specifically, fewer bush ants foraging in areas of higher common wasp abundance and more bush ants foraging at night when common wasps do not forage. Our results suggest a reduction in common wasp numbers may provoke an increase in the numbers of bush ants foraging on trees. However, there were more bush ants foraging overall in the wasps-maintained site regardless of sampling period, therefore there may have been inherent differences in our sampling sites. Common wasps were absent from trees during the night whereas bush ants continued to forage in consistent numbers. However, similar numbers of bush ants foraged both during the day and at night in both wasp-controlled and wasp-maintained sites, there was no evidence of a difference in diurnal and nocturnal use of the honeydew resource by bush ants and this observed pattern of foraging was not affected by the reduction of common wasp numbers. Any variation in foraging behaviour may be regulated by abiotic factors and colony resource requirements. 


\subsection{Introduction}

If two species co-occur in a homogenous environment and utilise the same resources one will inevitably become locally extinct. Coexistence is only possible when species use their environment or resources in different manners; this is the principle of niche differentiation (Hutchinson 1957, Hubbell 2005). Understanding resource partitioning is fundamental to understanding strategies of resource use, the effects of competition, and the mechanisms of coexistence (Abrams 1980). Subdivision of resources and different strategies of resource use may control species dynamics and enable two competing species to coexist regionally (Tillman 1994, Schmitt and Holbrook 2003, Kneitel and Chase 2004, Chase 2005).

In the presence of ongoing competition and population interactions species may evolve strategies that promote specialisation and partition niche spaces (Ricklefs 2004). Two organisms may have identical niches but not compete if they obtain resources differently, either spatially or temporally, or if the resource is sufficiently abundant to be used by both organisms at the same time (Welden and Slauson 1986). Resource partitioning can arise through competitive interactions, with most resources partitioned spatially. This occurs at a range of scales and is correlated with the abundance of competitors (Apps et al. 2006). Organisms may also partition resources temporally, occurring when different species differ in terms of when they exploit this resource (Amarasekare 2003, Palmer et al. 2003).

Resources are not commonly partitioned temporally over short periods of time as this may lead to an overall reduction in the resource (Schoener 1974); so the most commonly observed form of temporal resource partitioning is on a seasonal basis, as nutritional requirements may vary with different life stages (Carroll and Janzen 1973). 
However, temporal niche partitioning occurs in ant communities (Vepsäläinen and Savolainen 1990, Cerdá et al. 1997, Lessard et al. 2009) with different daily and seasonal foraging times, driven by different thermal tolerances, enabling coexistence of competing species (Andersen 2008). Retana and Cerdá (2000) have demonstrated that within forest ant communities the influence of temperature fluctuations favour dominant species; therefore, competition is the primary mechanism structuring these communities. Similarly, Raimundo et al. (2009) found that in ant communities weaker competitors temporally segregated foraging to avoid interspecific aggression at food sources.

Invasive species, when compared to local species, may have superior abilities to exploit resources in their new environment enabling them to expand rapidly and outcompete native species (Sakai et al. 2001, Amarasekare 2002, Tillman 2004). For example, within Vespula spp. the ability to regulate colony size and longevity in a new environment, combined with an omnivorous diet, appears to have enabled them to affect multiple trophic levels of an invaded food web through the mechanism of predation and the superior ability to exploit other food resources (Moller 1996, Wilson et al. 2009).

Native species impacted by invasive organisms may continue to persist by altering the way in which they use shared resources. Additionally spatial heterogeneity may provide opportunities for resource partitioning and lead to coexistence (Shurin et al. 2004). Honeydew is an important resource driving common wasp abundance and ecological interactions in the Nothofagus forests of much of New Zealand (Morales et al. 1988). The sooty beech scale insect (Ultracoelostoma spp.) infests the trunks and branches of Nothofagus trees; it feeds on the sap and excretes excess carbohydrate from its waxy anal filament in the form of honeydew. Sooty beech scale is found in many Nothofagus forests throughout New Zealand with the highest densities occurring in the northern half of the South Island (Morales et al. 1988). In other systems with honeydew producing insects, 
invertebrates are known to consume the honeydew, with ants forming the dominant group of consumers (Carroll and Janzen 1973, Buckley 1987, Stadler and Dixon 1999, Mailleux et al. 2003).

The invasive common wasp Vespula vulgaris (L.) (hereafter referred to as 'common wasp'), a native of Europe, established in the 1980s in the Nothofagus forests of the South Island of New Zealand and now dominates these forests (Clapperton et al. 1994) to the detriment of native birds and insects (Harris 1991). The abundant carbohydrate resource in Nothofagus forests is the primary source of energy for common wasps, enabling them to forage for protein in the form of animal prey to feed their developing larvae (Harris 1991). The predominant ant species in these forests is Prolasius advenus (Fr. Smith) commonly known as the New Zealand bush ant (McColl 1975). The bush ant is a generalist forager and has been observed feeding on honeydew consuming small invertebrates and scavenging for larger invertebrates (Don 2007). Thus the diet of these ants closely resembles that of the introduced common wasps.

In the face of a dominant invasive species the native bush ants in Nothofagus forests may have adjusted their pattern of resource use to avoid interspecific aggression or exclusion from resources. Because both bush ants and common wasps compete for similar food resources we predicted that fewer bush ants would be observed foraging in areas of higher common wasp abundance either as a result of a reduction in overall ant numbers due to competitive exclusion or as a result of a niche shift. Additionally, bush ants and common wasps may partition the honeydew resource temporally to avoid direct competition. As bush ants have been observed foraging nocturnally we expected to see more bush ants foraging at night in areas of higher common wasp abundance. In order to better understand patterns of resource use we worked in the only New Zealand site that has experienced a long-term reduction in common wasp densities and in a nearby adjacent site 
with high common wasp abundances. We predicted that this reduction in numbers of a dominant competitor may provoke an increase in the number of bush ants foraging during the day and reduce any difference between the numbers of bush ants foraging both diurnally and nocturnally.

\subsection{Methods}

\subsubsection{Study site and species}

This study was conducted in two sites during January and April 2007 in the Rotoiti Nature Recovery Project area in Nelson Lakes National Park, a 5000 hectare reserve within a national park in the South Island of New Zealand $\left(41^{\circ} 49^{\prime} \mathrm{S}, 172^{\circ} 50^{\prime} \mathrm{E}\right.$ at $615 \mathrm{~m}$ elevation). There is an ongoing predator control program in this reserve in which common wasp numbers have been seasonally reduced by poisoning for the last 10 years. For this reason our study was only conducted in these two sites and not replicated more widely. The vegetation was simple in structure with the canopy dominated by the mature beech trees Nothofagus solandri and N. menziesii. The understory consisted primarily of Pseudopanax spp., Coprosma spp., Cyathodes juniperina, Leucopogon fasciculatus, Griselinia littoralis and juvenile Nothofagus. One site was designated the 'waspsmaintained' site and the second site was designated the 'wasps-controlled' site where at the end of February, mid way through the sampling season, common wasps were poisoned. The common wasp became established in New Zealand in the 1980s and is now a dominant species in Nothofagus forests (Harris 1991, Beggs 2001). The bush ant is a common ant species in these Nothofagus forests; they are generalist foragers and make their nests in the leaf litter under rocks and in logs (Don 2007). 


\subsubsection{Poisoning}

Common wasps were poisoned by the Department of Conservation in the waspscontrolled site at the end of February 2008. Common wasp control had been undertaken at a similar time of year in the previous years. This was achieved by the placement of Xstinguish $^{\mathrm{TM}}$ bait (active ingredient fipronil at $0.1 \mathrm{~g} / \mathrm{kg}$ ) in permanent bait stations. Bait stations were attached to trees in a $50 \times 200 \mathrm{~m}$ grid pattern covering $825 \mathrm{ha}$. This poisoning area is part of a pest control programme at Nelson Lakes National Park that has been ongoing since 1997 (DOC 2006). Any uneaten bait was removed from bait stations after 48 hours. The effect of poisoning was monitored by Malaise trapping and was determined to reduce common wasp densities at this site by an average of $70.9 \%( \pm 28.7)$ (data presented in chapter two). This single poisoning event significantly reduced common wasp numbers in the wasps-controlled site for the remainder of the season.

\subsubsection{Hour observations of foraging}

Ten trees with honeydew and foraging bush ants present were haphazardly selected at each site. All bush ants and common wasps on each tree were counted every hour for a period of 24 hours. Time was separated into day ( 6 am to $8 \mathrm{pm})$ and night ( $9 \mathrm{pm}$ to $5 \mathrm{am}$ ) based on times of sunrise and sunset. The majority of bush ants appeared to forage within 2 m of the ground (C. Duthie Pers. Obs.), therefore only those bush ants and common wasps foraging on trunks up to a height of $2 \mathrm{~m}$ above the ground were counted. Counts lasted 1 minute per tree to reduce the possibility of counting the same animals twice. On all occasions temperatures ranged between $16^{\circ} \mathrm{C}$ during the day and $10{ }^{\circ} \mathrm{C}$ during the night, there was no rain during any of the observational periods. 


\subsubsection{Data analysis}

The number of bush ants and common wasps foraging during the day in waspsmaintained and wasps-controlled sites, pre- and post-poisoning was analysed using ANOVA with total numbers of bush ants and common wasps in each time period as the dependent variable. The fixed factors were treatment (wasps-maintained or waspscontrolled) and month (pre- and post-poisoning); the interaction between treatment and month was also tested. Twenty four hour observations of foraging were analysed using repeated-measures ANOVA. Time (hours) was the fixed factor and month (pre- and postpoisoning), treatment (wasps-maintained or wasps-controlled), and animal (common wasps or bush ants) were the between-subject factors. The relationship between the numbers of bush ants and the numbers of common wasps foraging during the day was analysed using Spearman's correlation. Comparisons of the numbers of bush ants foraging during the day and night in wasps-controlled and wasps-maintained sites in both pre- and post-poisoning periods was analysed using ANOVA with numbers of bush ants as the dependent variable and treatment (wasps-maintained or wasps-controlled), month (pre- and post-poisoning), and time (day, 6am to 9pm, or night, 10pm to 5am) as fixed factors. Data were Log10 transformed and met assumptions of normality. Where the assumption of sphericity was violated in the repeated-measures ANOVA we used the Greenhouse-Geisser correction. All analyses were performed in SPSS 16.0 (2008). 


\subsection{Results}

There were more bush ants foraging on trees in the wasps-maintained site compared to the wasps-controlled site (Fig 3.1). In the wasps-maintained site there was a mean of $93.93 \pm 6.59$ and $98.93 \pm 6.59$ ants in the pre- and post-poisoning periods respectively. In the wasps-controlled site there was a mean of $15.53 \pm 2.39$ and $33.53 \pm$ 2.39 ants in the pre- and post-poisoning periods respectively. Bush ant numbers increased in the wasps-controlled site in the post poisoning period indicated by a significant effect of month on bush ant numbers (Table 3.1), there was no significant interaction between treatment and month as bush ant numbers did not differ in the wasps-maintained area between pre- and post-poisoning periods.

\section{Table 3.1 Results for ANOVA analysis of day-time foraging}

The number of bush ants and common wasps foraging during the day in wasps-maintained and waspscontrolled sites, pre- and post-poisoning. The fixed factors were treatment (wasps-maintained or waspscontrolled) and month (pre- and post-poisoning).

\begin{tabular}{lrrr}
\hline Analysis & F & d.f. & \multicolumn{1}{c}{$P$} \\
\hline Ants & & & \\
$\quad$ Treatment & 210.133 & 1,56 & $<0.001$ \\
$\quad$ Month & 5.376 & 1,56 & 0.024 \\
Treatment x Month & 1.717 & 1,56 & 0.195 \\
& & & \\
& & & \\
Wasps & & & \\
Treatment & 20.302 & 1,56 & $<0.001$ \\
$\quad$ Month & 0.600 & 1,56 & 0.442 \\
Treatment x Month & 15.544 & 1,56 & $<0.001$ \\
& & & \\
\hline
\end{tabular}




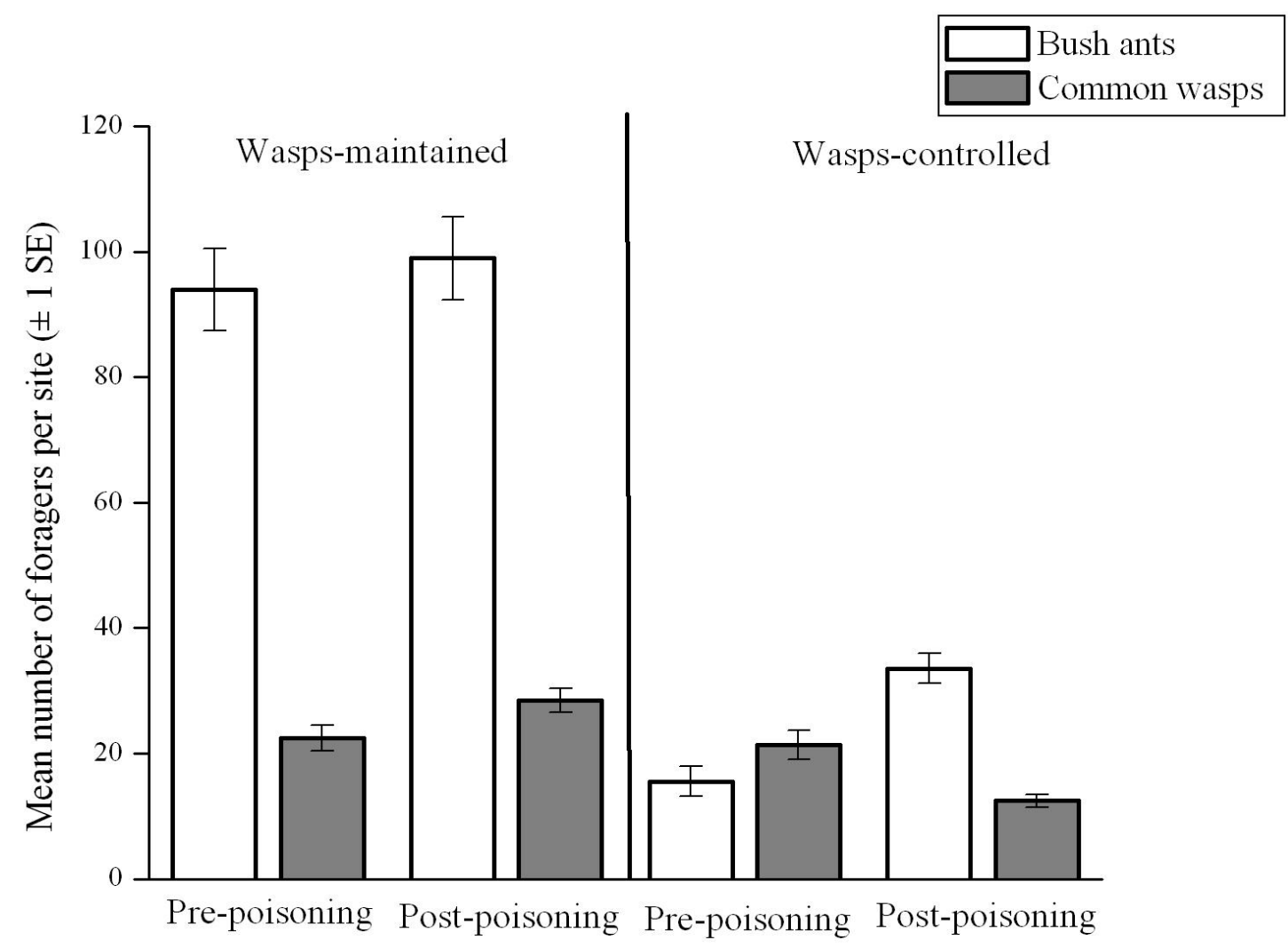

\section{Figure 3.1 Foraging by bush ants and common wasps}

Numbers of bush ants (open bars) and common wasps (closed bars) foraging on trees during the day in both wasps-maintained and wasps-controlled sites, pre- and post-poisoning (data are means $\pm 1 \mathrm{SE}$ )

There were more common wasps foraging in the wasps-maintained site in the postpoisoning period but fewer common wasps foraging in the wasps-controlled site in the post-poisoning period (Fig 3.1). In the wasps-maintained site there was a mean of $22.47 \pm$ 2.06 and $28.47 \pm 1.91$ common wasps in the pre- and post-poisoning periods respectively. In the wasps-controlled site there was a mean of $21.41 \pm 2.33$ and $12.47 \pm 1.02$ common wasps in the pre- and post-poisoning periods respectively. There was a significant interaction between treatment and month. Common wasp numbers decreased in the waspcontrolled site in the post poisoning period yet increased in the wasp-maintained site indicating that the poisoning treatment had the effect of reducing common wasp numbers. 

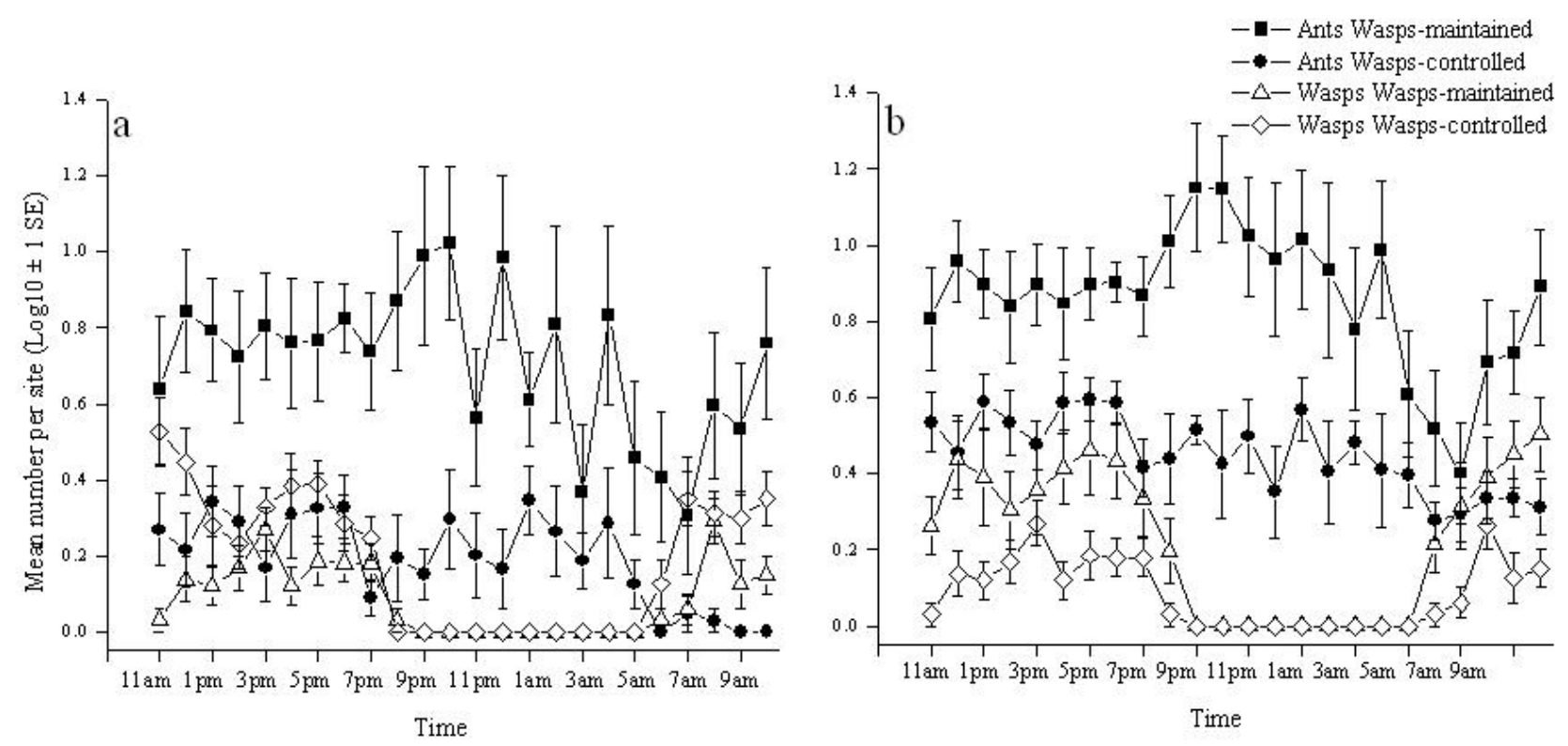

Figure 3.2 twenty-four hour foraging by bush ants and common wasps

Numbers of both bush ants (closed symbols) and common wasps (open symbols) foraging on trees over a 24 hour period in both the wasps-maintained and the wasps-controlled sites before the poison treatment was applied (Fig. 2a) and after the poison treatment was applied (Fig. 2b). All data are means \pm 1 SE. Data have been standardized by $\log 10$ transformation to enable patterns to be more easily interpreted.

Within each $24 \mathrm{~h}$ period, we observed a significant difference in the numbers of bush ants and common wasps across time periods (Fig 3.2, table 3.2). Common wasps remained at low numbers during the day and were absent between the hours of $9 \mathrm{pm}$ and $6 \mathrm{am}$, whereas bush ants continued to forage throughout both day and night. There were significant differences in the numbers of bush ants over time represented by a peak in abundance between 8 and $10 \mathrm{pm}$ as wasps cease to forage for the night and a decline in number at dawn as wasps begin foraging for the day, after 9am ant numbers rise again to relatively stable day time levels. There was also a significant difference in the numbers of ants over time in the different treatment sites due to more bush ants foraging on trees in the wasps-maintained site compared to the wasps-controlled site. There was no significant difference in bush ant numbers between sampling periods (pre- and post-poisoning). There was a significant difference in the numbers of wasps foraging over time, wasps were completely absent between $10 \mathrm{pm}$ and $6 \mathrm{am}$. There was no significant difference in the 
overall numbers of common wasps foraging over time in the different treatment sites or the different sampling periods. There was, however, a significant interaction between treatment and month, as there were more common wasps foraging in the wasps-controlled site in the pre-poisoning period yet more common wasps were foraging in the waspsmaintained site in the post-poisoning period.

\section{Table 3.2 Results for repeated measures ANOVA analysis of 24 hour foraging}

Time (hours) was the fixed factor and month (pre- and post-poisoning), treatment (wasps-maintained or wasps-controlled), and animal (common wasps or bush ants) were the between-subject factors.

\begin{tabular}{llll}
\hline Analysis & F & d.f. & $P$ \\
\hline
\end{tabular}

Common wasps and bush ants

Time

Time x Animal

Time $\mathrm{x}$ Treatment

Time x Month

Time x Animal x Treatment

Time x Animal x Month

Time $\mathrm{x}$ Treatment $\mathrm{x}$ Month

Time $\mathrm{x}$ Animal $\mathrm{x}$ Treatment $\mathrm{x}$ Month
$3.57 \quad 2.50,180.1<0.05$

$7.62 \quad 2.50,180.1<0.001$

$4.02 \quad 2.50,180.1<0.01$

$0.54 \quad 2.50,180.1 \quad 0.62$

$4.31 \quad 2.50,180.1<0.01$

$0.63 \quad 2.50,180.1 \quad 0.57$

$0.48 \quad 2.50,180.1 \quad 0.66$

$\begin{array}{lll}0.80 & 2.50,180.1 \quad 0.48\end{array}$

\section{Bush ants}

Time

Time $\mathrm{x}$ Treatment

Time x Month

Time $\mathrm{x}$ Treatment $\mathrm{x}$ Month

$\begin{array}{ccc}5.15 & 2.46,88.61 & <0.001 \\ 4.20 & 2.46,88.61 & <0.01 \\ 0.57 & 2.46,88.61 & 0.60 \\ 0.57 & 2.46,88.61 & 0.60\end{array}$

Common wasps

Time

Time $\mathrm{x}$ Treatment

$38.29 \quad 3.47,125.01<0.001$

Time x Month

$\begin{array}{lll}1.49 & 3.47,125.01 & 0.21\end{array}$

Time $\mathrm{x}$ Treatment $\mathrm{x}$ Month
$1.49 \quad 3.47,125.01 \quad 0.21$

$5.93 \quad 3.47,125.01<0.001$ 

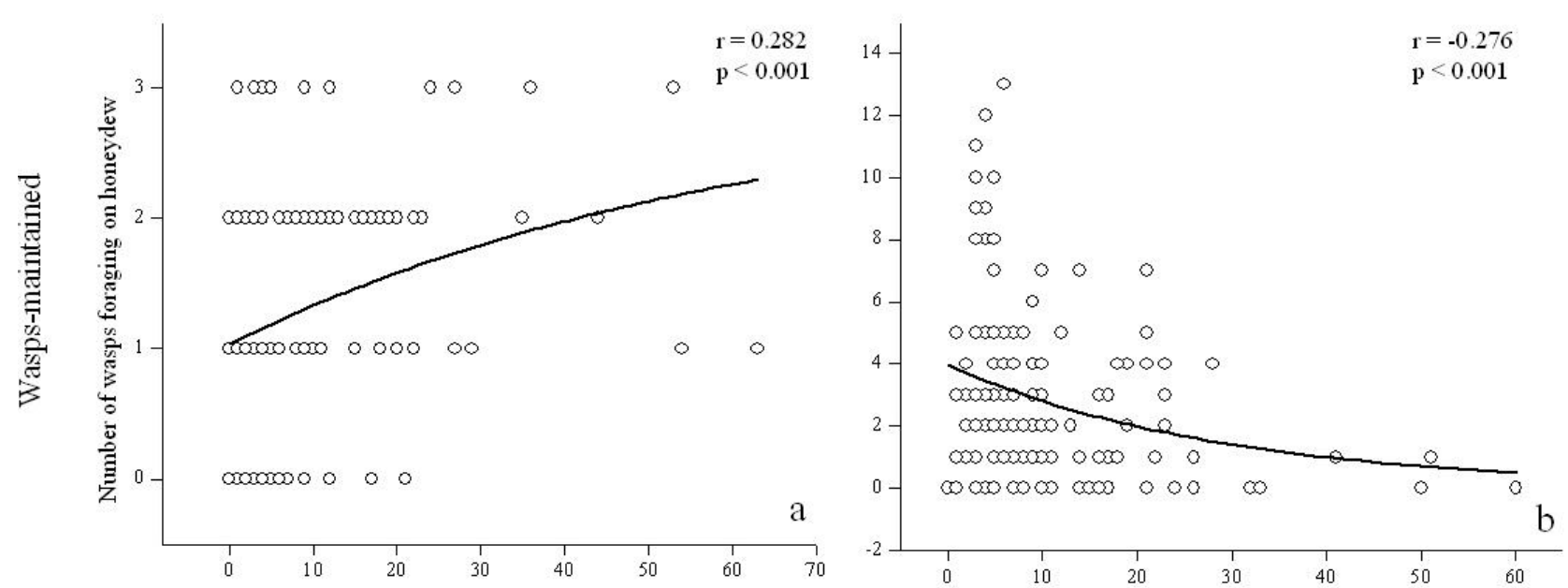

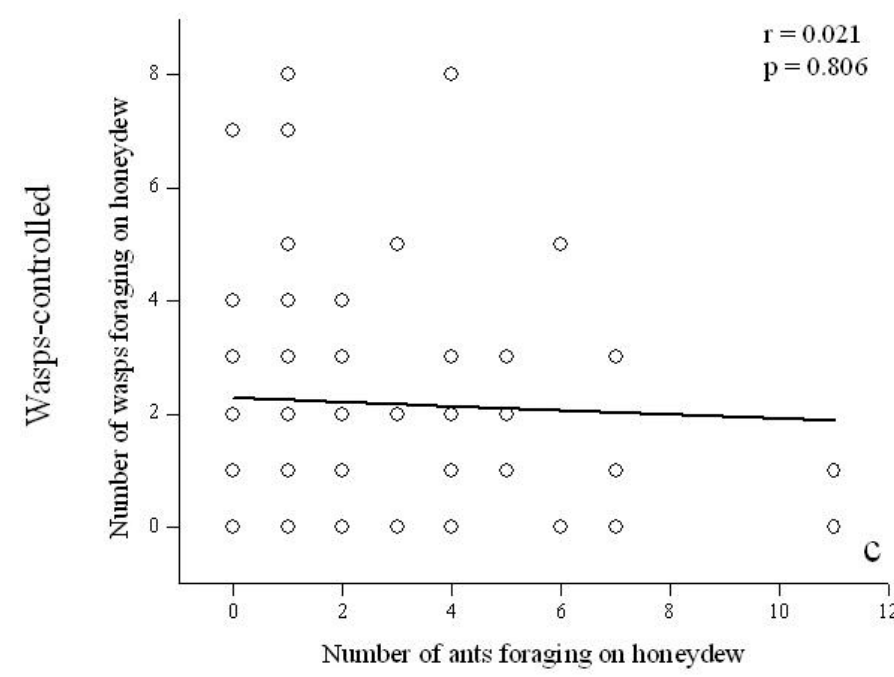

Pre-poisoning

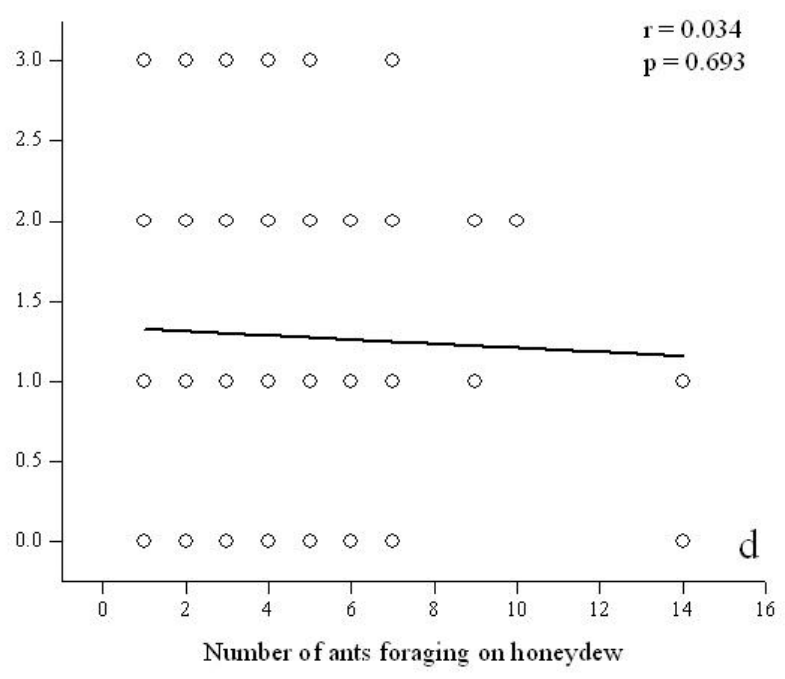

Post-poisoning

Figure 3.3 Relationship between foraging bush ants and common wasps

Relationship between the numbers of bush ants and the numbers of common wasps foraging during the day in the wasps-maintained site pre-poisoning (Fig 3a) and the wasps-maintained site post-poisoning (Fig 3b) and the wasps-controlled site pre-poisoning (Fig 3c) and the wasps-controlled site post-poisoning (Fig 3d). Lines fitted are beta spline curves.

In the wasps-maintained site in the pre-poisoning period, common wasp numbers increased as bush ant numbers increased $(r=0.282 \mathrm{p}<0.001)$ however, in the postpoisoning period common wasp numbers declined with an increase in bush ant numbers ( $\mathrm{r}$ $=-0.276 \mathrm{p}<0.001)($ Fig 3.3). In the wasps-controlled site there was no relationship between bush ant numbers and common wasp numbers in either the pre- or post-poisoning periods. 


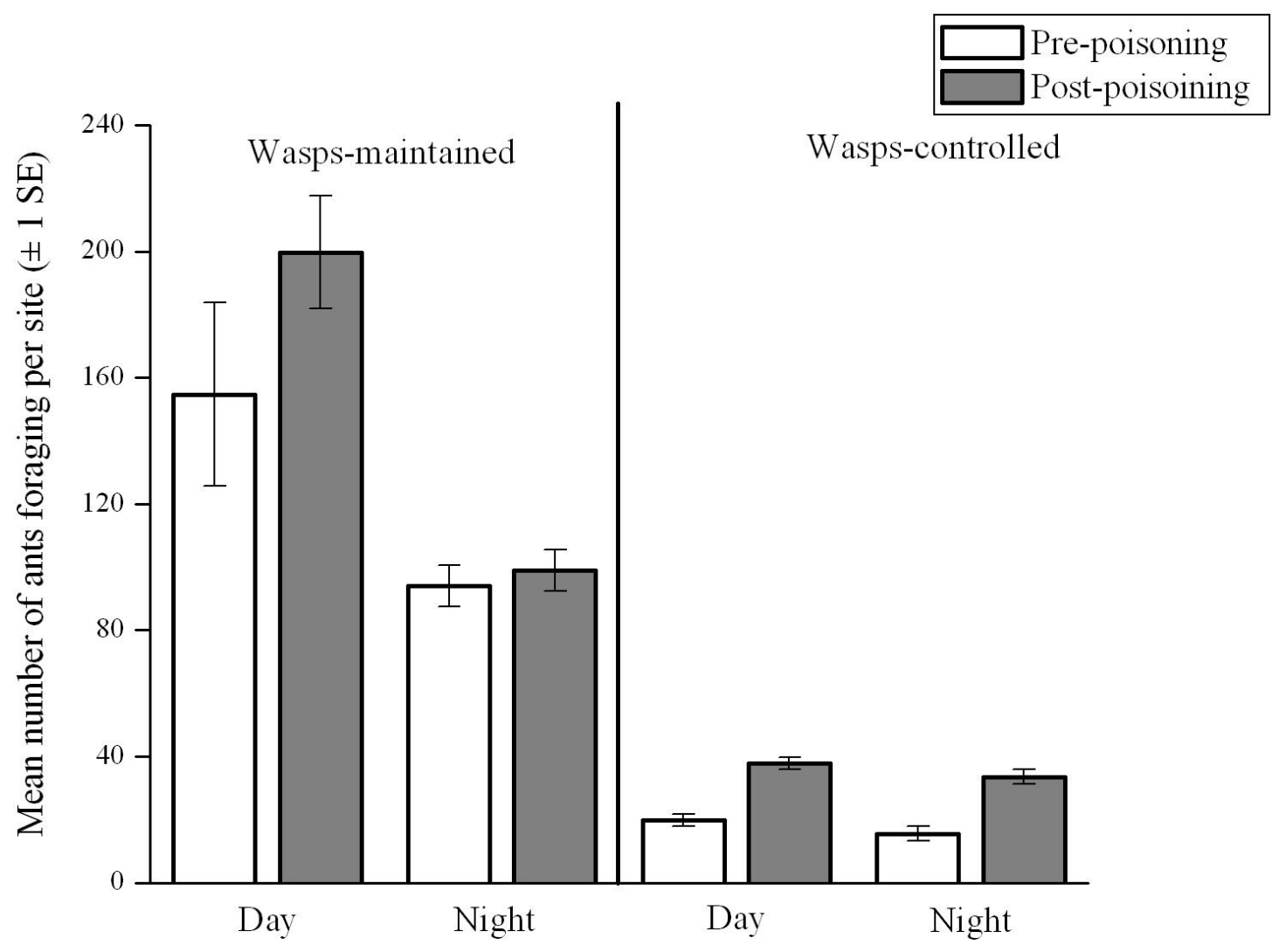

\section{Figure 3.4 Bush ants foraging over 24 hours}

Comparisons of the numbers of bush ants foraging during the day and night in wasps-maintained and waspscontrolled sites before (open bars) and after poisoning (closed bars) (data are means $\pm 1 \mathrm{SE}$ )

There were consistently more bush ants foraging on trees in the wasps-maintained site compared to the wasps-controlled site (Fig 3.4, table 3.3). There were also more bush ants foraging on trees in the post-poisoning period when compared to the pre-poisoning period. There were significantly more bush ants foraging on trees during the night $(103.03 \pm 15.25$ at night, $60.48 \pm 5.34$ during the day). There was a significant interaction between treatment and month; a similar number of ants were foraging during both day and night in the wasps controlled area in the post-poisoning period whereas in the wasps-maintained area considerably more ants foraged during the day in the post poisoning period. 
Table 3.3 Results for ANOVA analysis of ant foraging over 24 hours.

Comparisons of the numbers of bush ants foraging during the day and night in wasps-controlled and waspsmaintained sites in both pre- and post-poisoning periods. Numbers of bush ants were the dependent variable and treatment (wasps-maintained or wasps-controlled), month (pre- and post-poisoning), and time (day, 6am to $9 \mathrm{pm}$, or night, $10 \mathrm{pm}$ to $5 \mathrm{am}$ ) were fixed factors. Data were $\log 10$ transformed to meet assumptions of normality.

\begin{tabular}{lrcc}
\hline Analysis & $\mathrm{F}$ & d.f. & $\mathrm{p}$ \\
\hline & & & \\
Day or Night & 17.798 & 1,88 & $<0.001$ \\
Treatment & 282.564 & 1,88 & $<0.001$ \\
Month & 28.705 & 1,88 & $<0.001$ \\
Time x Treatment & 1.156 & 1,88 & 0.285 \\
Time x Month & 0.003 & 1,88 & 0.959 \\
Treatment x Month & 9.442 & 1,88 & $<0.01$ \\
Time x Treatment x Month & 2.767 & 1,88 & 0.100 \\
& & & \\
\hline
\end{tabular}

\subsection{Discussion}

\subsubsection{Ant foraging in relation to common wasp abundance}

LandCare Research have conducted annual common wasp density surveys at Nelson Lakes National Park since 1988. The mean abundance of nests during this time was $18.5( \pm$ 2.05) (LandCare Research, unpublished data). Common wasp densities in 2007 were recorded at 18.7 nests per hectare; therefore, wasp abundance during this study was at average levels for this location.

Common wasp numbers were successfully reduced in the wasps-controlled site resulting in fewer common wasps foraging on trees in the post-poisoning period.

Additionally, we saw an increase in common wasp numbers in the post-poisoning period in the wasps-maintained site indicating a typical seasonal increase in numbers (Beggs et al. 1998). From our data, at this single location, it appears that a reduction in common wasp numbers may provoke an increase in the numbers of bush ants foraging on trees. The 
numbers of bush ants increased in the wasps-controlled site when common wasp numbers were experimentally reduced and yet bush ant numbers remained stable in the waspsmaintained site in the post-poisoning period. Common wasps and bush ants have been observed foraging for the same type of food, such as dead insects and honeydew, so may directly compete for protein and carbohydrates in these forests. It could be expected that bush ants and common wasps may also directly compete for honeydew and yet bush ants continue to forage on honeydew even when faced with high numbers of common wasps. With a reduction in common wasp numbers bush ants may be better able to utilise the abundant honeydew resource. However, the resulting increase in honeydew use by bush ants may not be entirely a result of a reduction in direct competition but rather an increase in the quantity or quality of the resource. When common wasp numbers are at their peak they are capable of removing up to $99 \%$ of the standing honeydew crop (Moller et al. 1991). Additionally with such high honeydew use the quality of the drops declines (Moller and Tilley 1989), meaning that bush ants would have to forage more on the lesser quality honeydew for the same nutritional pay-off as higher quality honeydew.

Honeydew is a patchy resource and varies with tree age, size, and aspect; consequently the invertebrate community varies across patches within the forest (Ewers 2002). If the honeydew resource were more abundant, or of better quality, in the waspsmaintained site this could enable bush ant populations to become concentrated. Better competitors with greater dispersal ability (in this case common wasps) may result in weaker competitors becoming concentrated in patches with greater resource density (Abrams and Wilson 2004) as common wasps are influenced by their dispersal ability and will not attain densities that would reduce the resources. Alternatively if the honeydew resource were of lesser quality in the wasps-maintained site, due to constant harvesting by common wasps, then bush ants may need to feed more frequently on this resource to gain 
enough nutrition for the colony. Dussutour and Simpson (2008) found that ants are able to regulate their carbohydrate intake and when presented with a less concentrated resource had to feed for longer to meet the 'nutritional intake target' of the colony. Alternatively there may be subtle differences in the microclimate or habitat influencing nest choice by bush ants. Bush ants nest under rock or in logs (Don 2007) and appear to avoid areas where the soil moisture is high.

\subsubsection{Experimental caveats}

This research, which occurred at a single location, is pseudoreplicated and therefore may not be a valid representation of interactions in Nothofagus systems elsewhere. The unique opportunity to investigate interactions within this forest, with such a long-term history of common wasp control, was unable to be replicated elsewhere therefore the results obtained are specific to this location but inferences may be made for other Nothofagus systems. There were more bush ants foraging overall in the wasps-maintained site regardless of the sampling period therefore there may have been inherent differences in our two sampling sites despite their observed similarities in vegetation, aspect, and elevation. Given that common wasps and bush ants share similar life history strategies, and overlap considerably in diet, it may be expected that bush ants would also be impacted by the effect of poisoning. However, poison stations were spaced in a $50 \mathrm{~m}$ by $200 \mathrm{~m}$ grid pattern making it unlikely that significant numbers of bush ants would have access to this poison. Bush ant nest density in this location is $0.06( \pm 0.015)$ nests $\mathrm{m}^{2}$, or 600 nest ha $^{-1}(\mathrm{C}$. Duthie unpublished data). It is possible that a few nests in close proximity to poison stations may have been affected but a significant reduction in bush ant numbers across the entire area due to poison seems unlikely. It is also possible that wasp densities we not 
controlled sufficiently to see conclusive results. These caveats are all related to historic management practices.

\subsubsection{Temporal partitioning of the honeydew resource}

Temporal separation is common amongst ants in hot climates where conditions may be lethal to some species giving sole access to those species able to tolerate extreme temperatures (Andersen 2008, and refs therein). A similar but opposite effect may be seen here where common wasps are unable to tolerate colder temperatures and lower light levels at night and must confine their foraging to the day (Heinrich 1984). Bush ants however, are able to tolerate the colder nighttime temperatures so are able to forage over the whole 24 hour period. Common wasps were completely absent from trees during the night, whereas bush ants continued to forage in consistent numbers throughout the 24 hour period of our observations. However, similar numbers of bush ants foraged both during the day and at night there was no evidence of a difference in diurnal and nocturnal use of the honeydew resource by bush ants and this observed pattern of foraging was not affected by the removal of common wasps. There was however, a distinct pattern to foraging by bush ants in the wasps-maintained area. There was a rise in ant foraging between $8 \mathrm{pm}$ and $10 \mathrm{pm}$ just prior to when wasps ceased foraging for the night and a decrease in forager numbers at 9 am just after wasps began foraging for the day. This could be due to a number of factors such as a change in temperature or light levels or differences in honeydew production by scale insects. Even though bush ants do forage at night it is unknown whether this is an adaptation to competition as there is no literature investigating foraging patterns in this ant species.

Given the absence of any reduction of numbers of bush ants due to common wasp foraging temporal partitioning may not be important in maintaining coexistence between 
bush ants and common wasps as there may already be some form of spatial partitioning. It has been suggested that intraspecific aggregation of species on distinct resource patches may enable coexistence, as with greater aggregation species become more self-limiting and it becomes harder for species to exclude each other (Shorrocks et al. 1984). Common wasps are very abundant in the canopy and on the upper tree trunks, therefore bush ants may be less affected by competition or resource depletion by confining their foraging to the lower trunks. In these Nothofagus forests more honeydew is produced in the subcanopy than on the trunks (Beggs et al. 2005, Wardhaugh et al. 2006). Bush ants have been observed higher on the trunks so are potentially able to climb to the canopy but it seems unlikely they would concentrate their foraging there. Additionally these ants have been observed nesting at the base of Nothofagus trees where they may tend root feeding Hemiptera within their nests. We could therefore hypothesis that there is no competition in this system between bush ants and common wasps as there may be sufficient honeydew resource for all.

\subsection{Conclusion}

There was an increase in the numbers of bush ants foraging on honeydew when we experimentally reduced common wasp numbers. This increase may be due to a change in both the quantity and quality of the available honeydew. For future research honeydew quality could be assessed by HPLC analysis as in Beggs et al. (2005) and Grant and Beggs (1989). There was no evidence of temporal niche partitioning even though bush ants forage at night and common wasps do not. There were no more bush ants foraging nocturnally than there were foraging diurnally. However, bush ants and common wasps may partition the honeydew resource spatially with bush ants concentrating their foraging lower on the 
tree trunks and common wasps foraging mainly in the canopy. The honeydew resource is concentrated in the canopy (Wardhaugh et al. 2006) and common wasps are better able to access this resource than bush ants which energetically may be confined to foraging lower on the tree. Bush ants are capable of climbing to the canopy however the energy required to concentrate their foraging there may make this unlikely. Bush ants are therefore limited to a less abundant resource lower on the trunks. Bush ants may compensate for this by continuing to forage throughout the night when common wasps are absent, however this behaviour may not be as a direct result of competitive pressure. The foraging behaviour of bush ants may indeed be entirely independent of any interactions with common wasps, rather with their behaviour regulated by abiotic factors and colony resource requirements. Additional study sites with long-term wasp control programmes would help elucidate the trends in our data.

\subsection{Acknowledgements}

Laura Warman, Zak Murdoch, and Laura Bass provided invaluable field help. Funding was provided by the Royal Society of New Zealand Marsden fund and a Victoria University of Wellington PhD Scholarship. Thanks to the Department of Conservation for conducting the poisoning programme and access to land. 


\subsection{References}

Abrams, P. 1980. Some comments on measuring niche overlap. Ecology 61:44-49.

Abrams, P. A. and W. G. Wilson. 2004. Coexistence of competitors in metacommunities due to spatial variation in resource growth rates; does $R^{*}$ predict the outcome of competition? Ecology Letters 7:929-940.

Amarasekare, P. 2002. Interference competition and species coexistence. Proceedings of the Royal Society of London B 269:2541-2550.

Amarasekare, P. 2003. Competitive coexistence in spatially structured environments: a synthesis. Ecology Letters 6:1109-1122.

Andersen, A. N. 2008. Not enough niches: non-equilibrial processes promoting species coexistence in diverse ant communities. Austral Ecology 33:211-220.

Apps, C. D., B. N. McLellan, and J. G. Woods. 2006. Landscape partitioning and spatial inferences of competition between black and grizzly bears. Ecography 29:561-572.

Beggs, J. 2001. The ecological consequences of social wasps (Vespula spp.) invading an ecosystem that has an abundant carbohydrate resource. Biological Conservation 99:17-28.

Beggs, J., R. J. Toft, J. P. Malham, J. S. Rees, J. A. V. Tilley, H. Moller, and P. Alspach. 1998. The difficulty of reducing introduced wasp (Vespula vulgaris) populations for conservation gains. New Zealand Journal of Ecology 22:55-63.

Beggs, J. R., B. J. Karl, D. A. Wardle, and K. I. Bonner. 2005. Soluble carbon production by honeydew scale insects in a New Zealand beech forest. New Zealand Journal of Ecology 29:105-115.

Buckley, R. C. 1987. Interactions involving plants, homoptera, and ants. Annual Review of Ecology and Systematics 18:111-135.

Carroll, C. R. and D. H. Janzen. 1973. Ecology of foraging by ants. Annual Review of Ecology and Systematics 4:231-257.

Cerdá, X., J. Retana, and S. Cros. 1997. Thermal disruption of transitive hierarchies in Mediterranean ant communities. Journal of Animal Ecology 66:363-374

Chase, J. M. 2005. Towards a really unified theory for metacommunities. Functional Ecology 19:182-186.

Clapperton, B. K., J. A. V. Tilley, J. R. Beggs, and H. Moller. 1994. Changes in the distribution and proportions of Vespula vulgaris (L.) and Vespula germanica (Fab.) 
(Hymenoptera: Vespidae) between 1987 and 1990 in New Zealand New Zealand Journal of Zoology 21:295-303.

DOC. 2006. Rotoiti Nature Recovery Project. Department of Conservation, Christchurch.

Don, W. 2007. Ants of New Zealand. Otago University Press, Dunedin

Dussutour, A. and S. J. Simpson. 2008. Carbohydrate regulation in relation to colony growth in ants. The Journal of Experimental Biology 211:2224 - 2232.

Ewers, R. 2002. The influence of honeydew on arthropod community composition in a New Zealand beech forest. New Zealand Journal of Ecology 26:23-29.

Grant, W. D. and J. R. Beggs. 1989. Carbohydrate analysis of beech honeydew. New Zealand Journal of Zoology 16:283 - 288.

Harris, R. J. 1991. Diet of the wasps Vespula vulgaris and V. germanica in honeydew beech forest of the South Island, New Zealand. New Zealand Journal of Zoology 18:159-169.

Heinrich, B. 1984. Strategies of thermoregulation and foraging in two vespid wasps, Dolichovespula maculata and Vespula vulgaris. Journal of Comparative Physiology B 154:175-180.

Hubbell, S. P. 2005. Neutral theory in community ecology and the hypothesis of functional equivalence. Functional Ecology 19:166-172.

Hutchinson, G. E. 1957. Concluding remarks. Cold Springs Symposia on Quantitative Biology 22:415-427.

Kneitel, J. M. and J. M. Chase. 2004. Trade-offs in community ecology: linking spatial scales and species coexistence. Ecology Letters 7:69-80.

Lessard, J.-P., R. R. Dunn, and N. J. Sanders. 2009. Temperature-mediated coexistence in temperate forest ant communities. Insectes Sociaux 56:149-156.

Mailleux, A., J. Deneubourg, and C. Detrain. 2003. Regulation of ants' foraging to resource productivity. Proceedings of the Royal Society of London 270:1609-1616.

McColl, H. P. 1975. The invertebrate fauna of the litter surface of a Nothofagus truncata forest floor, and the effect of microclimate on activity. New Zealand Journal of Ecology 2:15-34.

Moller, H. 1996. Lessons for invasion theory from social insects. Biological Conservation 78: $125-142$.

Moller, H., J. A. V. Tilley, B. W. Thomas, and P. D. Gaze. 1991. Effect of introduced social wasps on the standing crop of honeydew in New Zealand beech forests. New Zealand Journal of Zoology 18:171-179. 
Morales, C. F., M. G. Hill, and A. K. Walker. 1988. Life history of the sooty beech scale (Ultracoelostoma assimile) (Maskell), (Hemiptera: Margodidae) in New Zealand Nothofagus forests. New Zealand Entomologist 11:24-38.

Palmer, T. M., M. L. Stanton, and T. P. Young. 2003. Competition and coexistence: exploring mechanisms that restrict and maintain diversity within mutualist guilds. The American Naturalist 162:S63-S79.

Raimundo, R. L. G., A. V. L. Freitas, and P. S. Oliveira. 2009. Seasonal patterns in activity rhythm and foraging ecology in the neotropical forest-dwelling ant Odontomachus chelifer (Formicidae: Ponerinae). Annals of the Entomological Society of America 106:1151-1157.

Retana, J. and X. Cerdá. 2000. Patterns of diversity and composition of Mediterranean ground ant communities tracking spatial and temporal variability in the thermal environment. Oecologia 123:436-444.

Ricklefs, R. E. 2004. A comprehensive framework for global patterns in biodiversity. Ecology Letters 7:1-15.

Sakai, A. K., F. W. Allendorf, J. S. Holt, D. M. Lodge, J. Molofsky, K. A. With, S. Baughman, R. J. Cabin, J. E. Cohen, N. C. Ellstrand, D. E. McCauley, P. O'Neil, I. M. Parker, J. N. Thompson, and S. G. Weller. 2001. Population biology of invasive species. Annual Review of Ecology, Evolution, and Systematics 32:305-332.

Schmitt, R. J. and S. J. Holbrook. 2003. Mutualism can mediate competition and promote coexistence. Ecology Letters 6:898-902.

Schoener, T. W. 1974. The compression hypothesis and temporal resource partitioning. Proceedings of the National Academy of Sciences 71:4169-4172.

Shorrocks, B., J. Rosewell, K. Edwards, and W. Atkinson. 1984. Interspecific competition is not a major organising force in many insect communities. Nature 310:310-312.

Shurin, J. B., P. Amarasekare, J. M. Chase, R. D. Holt, M. F. Hoopes, and M. A. Leibold. 2004. Alternative stable states and regional community structure. Journal of Theoretical Biology 227:359-368.

SPSS. 2008. Release 16.0 Chicago SPSS inc.

Stadler, B. and A. F. G. Dixon. 1999. Ant attendance in aphids: why different degrees of myrmecophily? Ecological Entomology 24:363-369.

Tillman, D. 1994. Competition and biodiversity in spatially structured habitats. Ecology 75:2-16. 
Tillman, D. 2004. Niche tradeoffs, neutrality, and community structure: A stochastic theory of resource competition, invasion, and community assembly. Proceedings of the National Academy of Sciences 101:10854-10861.

Vepsäläinen, K. and R. Savolainen. 1990. The effect of interference by formicine ants on the foraging of Myrmica. Journal of Animal Ecology 59:643-654.

Wardhaugh, C. W., T. J. Blakely, H. Greig, P. D. Morris, A. Barnden, S. Rickard, B. Atkinson, L. L. Fagan, R. M. Ewers, and R. K. Didham. 2006. Vertical stratification in the spatial distribution of the beech scale insect (Ultracoelostoma assimile) in Nothofagus tree canopies in New Zealand. Ecological Entomology 31:185-195.

Welden, C. W. and W. L. Slauson. 1986. The intensity of competition versus its importance: an overlooked distinction and some implications. The Quarterly Review of Biology 61:23-44.

Wilson, E. E., L. M. Mullen, and D. A. Holway. 2009. Life history plasticity magnifies the ecological effects of a social wasp invasion. Proceedings of the National Academy of Sciences 106:12809-12813. 


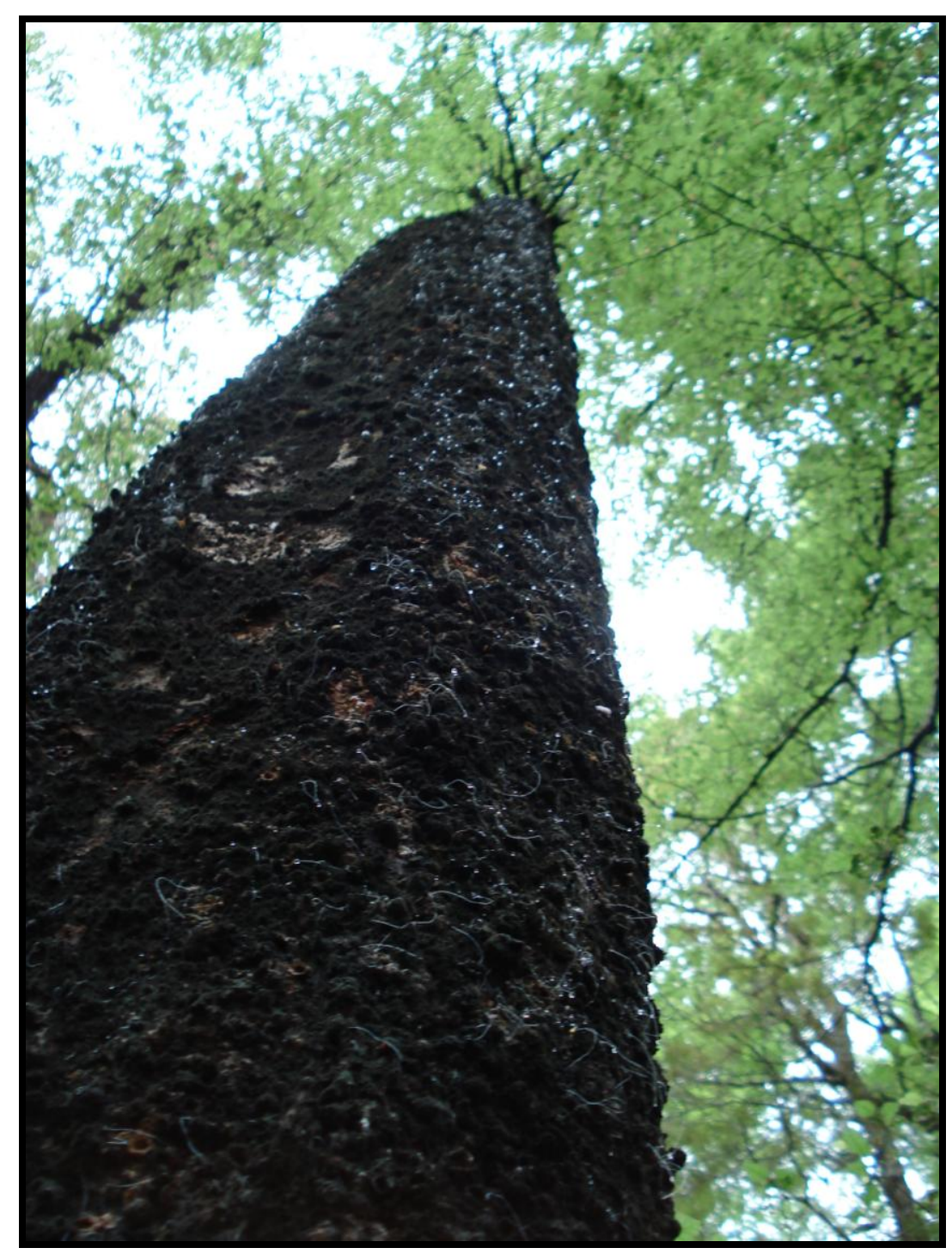

Nothofagus fusca with honeydew 


\section{Chapter Four}

\section{The Trophic Level of Native Ants}

Changes in Response to the

Removal of an Invasive Competitor 


\subsection{Abstract}

Where there is persistence of native species in the face of competition from invasive species trophic interactions may be altered. Stable isotopes can provide a sensitive indicator of environmental change to help quantify the impacts of species invasions on natural food webs. In this study we aimed to examine the effect of an invasive species on native competitors. The introduced common wasp (Vespula vulgaris (Linnaeus)) has successfully established in Nothofagus forests and, by collecting the carbohydrate rich honeydew resource, has reached extremely high densities (Beggs 2001). Prolasius advenus (Fr. Smith), commonly referred to as the New Zealand bush ant, is the predominant ant species in New Zealand Nothofagus forests. Competition between common wasps and bush ants, both for honeydew and prey, may change the trophic ecology of these species. To examine the relative trophic level status of native bush ants and invasive common wasps and any possible change in that status due to reduction of a competitor (common wasps) we examined nitrogen and carbon isotope ratios. Neither native bush ants nor invasive common wasps showed a change in $\delta^{13} \mathrm{C}$ or $\delta^{15} \mathrm{~N}$ enrichment related to a treatment effect. There was, however, a difference in the trophic position of bush ants and common wasps relative to each other. Additionally, bush ants showed an increase in trophic level in sites where common wasps were maintained. Common wasps may be depleting more of the honeydew resource in these sites, restricting bush ants to foraging for prey. Observed changes in these trophic levels may be as a result of natural seasonal variation in consumption related to nutritional requirements of the colony. A comparison of the diets would help determine the impact of increasing common wasp numbers on native bush ants. Further research is needed to determine if native bush ants in our study sites have altered their diet in the face of this common wasp invasion. 


\subsection{Introduction}

Competition between species for a food resource is a driving force structuring ecosystems (Brown and Davidson 1977). In a system where a new species has recently invaded competitive exclusion may occur if there has not been sufficient time for niche differentiation (Mooney and Cleland 2001, Gurnell et al. 2004). This competitive exclusion may result from higher resource-use efficiency or a superior foraging technique by an invader, enabling competitive superiority (Shea and Chesson 2002). For example, Argentine ant (Linepithema humile) invasions in California reduced the number of native species by the mechanisms of superior resource exploitation and interference with native competitors (Human and Gordon 1997). A reduction in the number of native species after Argentine ant invasions alters interactions among the remaining species and leads to a reorganisation of the remaining community (Sanders et al. 2003). Niche adjustments by species with overlapping resource requirements may enable coexistence (Mooney and Cleland 2001, Gilbert et al. 2008). For example, native crabs on Tokelau were excluded from areas of the island following the introduction of the invasive yellow crazy ant. This exclusion not only forced crabs to feed at a lower trophic level but appeared to alter their relative distribution across islands (McNatty et al. 2009).

In the Nothofagus forests of New Zealand's South Island, honeydew produced by the sooty beech scale insect (Ultracoelostoma spp.) is an abundant resource with 3800 to $4600 \mathrm{~kg}$ dry weight of honeydew produced hectare ${ }^{-1}$ year $^{-1}$ (Ewers 2002, Beggs et al. 2005). Sooty beech scale insects can add a large amount of soluble carbon into the Nothofagus forest ecosystem in the form of honeydew. High in sugars, with a carbon content of $42 \%$ (Beggs et al. 2005), this honeydew is an important food source for birds, lizards, and invertebrates (Morales et al. 1988, Markwell et al. 1993, Ewers 2002). The 
introduced common wasp (Vespula vulgaris (Linnaeus)) has successfully established in Nothofagus forests and, by collecting the carbohydrate rich honeydew resource, has reached extremely high densities (Beggs 2001). Vespula vulgaris are generalist foragers and also prey on many native insects (Beggs et al. 1998, Beggs 2001). In other systems with honeydew producing insects ants form the dominant group of consumers (Carroll and Janzen 1973, Stadler and Dixon 1999, Mailleux et al. 2003). Prolasius advenus (Fr. Smith), commonly referred to as the New Zealand bush ant, is the predominant ant species in New Zealand Nothofagus forests (McColl 1975, Don 2007). Bush ants are generalist foragers and have been frequently observed feeding on honeydew produced by the sooty beech scale insect (see chapter three).

Social Hymenoptera, such as common wasps and bush ants in this forest system, can simultaneously fill multiple trophic roles as primary predators (via feeding upon herbivores), secondary predators (via feeding on predatory arthropods), and as primary consumers (via feeding on exudates from herbivores which produce honeydew) (Mooney and Tillberg 2005). The degree of resource partitioning among these animals may have important consequences for the dynamics of this forest system. Competition between common wasps and bush ants both for honeydew and prey may change the trophic ecology of these species. Resource requirements in social insects such as bush ants and common wasps change seasonally so the effects of interspecific competition may also vary seasonally. In the Southern Hemisphere summer common wasp numbers peak between January and May and studies have shown that numbers of other invertebrates decline as a result of both predation and strong competitive interactions (Moller and Tilley 1989, Beggs et al. 1998, Beggs 2001). As common wasp foraging on honeydew increases there is a corresponding decline in the size and the sugar content of honeydew drops (Moller et al. 1991). Honeydew can be a complete food source, not just a collection of sugars but a 
complex mixture of nutrients containing amino acids, proteins, minerals, and B-vitamins (Way 1963).When drops are left undisturbed water is evaporated from them and they undergo a process of concentration resulting in a higher quality resource (Moller and Tilley 1989).

Stable isotopes can provide a sensitive indicator of environmental change to quantify the impacts of species invasions on natural food webs (Vander Zanden et al. 1999). The $\delta^{15} \mathrm{~N}$ values in an animal's tissue can provide information about that animal's diet and relative trophic level; wherein on average the $\delta^{15} \mathrm{~N}$ value of predators is $3-4 \%$ higher than the values of their prey. Values of $\delta^{13} \mathrm{C}$ provide information about the resource base and values change little as carbon moves through the food web (de Niro and Epstein 1981, Peterson and Fry 1987, Post 2002, Sanders and Platner 2007, Schmidt et al. 2007). Therefore, the analysis of stable isotopes can be useful in investigating the impact of an invasive species on the resource use of native competitors.

In this study we aimed to examine the effect of an invasive species on native competitors, using the native bush ant Prolasius advenus and the invasive common wasp Vespula vulgaris as a study system. We asked if the isotope ratios and trophic level of native competitors change in response to the removal of this invasive species. Additionally, as predation and competition pressure from an invasive species may impact populations of other predators, such as spiders and Carabidae, we asked if the trophic positions and isotope ratios of these other predators change in response to the removal of an invasive species. 


\subsection{Methods}

\subsubsection{Study sites}

Three pairs of experimental sites were set up in different locations in the Nelson region. Locations were a minimum of $20 \mathrm{~km}$ apart. At each location the vegetation was similar, with the canopy dominated by the mature beech trees, Nothofagus solandri and $N$. menziesii. The understory consisted primarily of Pseudopanax spp., Coprosma spp., Cyathodes juniperina, Leucopogon fasciculatus, Griselinia littoralis and juvenile Nothofagus. The locations were in the nature recovery area of Nelson Lakes National Park $\left(41^{\circ} 48^{\prime} \mathrm{S}, 172^{\circ} 50^{\prime} \mathrm{E}\right.$ at $630 \mathrm{~m}$ and $41^{\circ} 49^{\prime} \mathrm{S}, 172^{\circ} 50^{\prime} \mathrm{E}$ at $\left.630 \mathrm{~m}\right)$, Maitai Valley, east of Nelson City $\left(41^{\circ} 17^{\prime} \mathrm{S}, 173^{\circ} 21^{\prime} \mathrm{E}\right.$ at $160 \mathrm{~m}$ and $41^{\circ} 18^{\prime} \mathrm{S}, 173^{\circ} 22^{\prime} \mathrm{E}$ at $\left.265 \mathrm{~m}\right)$ and the Roding Valley, south-east of Nelson City $\left(42^{\circ} 21^{\prime} \mathrm{S}, 173^{\circ} 16^{\prime} \mathrm{E}\right.$ at $220 \mathrm{~m}$ and $41^{\circ} 21^{\prime} \mathrm{S}$, $173^{\circ} 17^{\prime} \mathrm{E}$ at $270 \mathrm{~m}$ ). Each pair of sites comprised a control site (wasps-maintained), and a treatment site (wasps-controlled) where at the end of February, mid-way through the experimental season, common wasps were poisoned. Poisoning was achieved by the placement of bait stations containing Xstinguish ${ }^{\mathrm{TM}}$ bait (active ingredient fipronil at $0.1 \mathrm{~g} / \mathrm{kg}$ ). Bait stations were attached to trees in a $50 \times 200 \mathrm{~m}$ grid pattern in a $1 \mathrm{~km}^{2}$ area surrounding each study site. Except for Nelson Lakes National Park where due to an existing pest control programme an $8.25 \mathrm{~km}^{2}$ area was poisoned. Any uneaten bait was removed from bait stations after 48 hours. Each site in the pair was separated by no less than $1.5 \mathrm{~km}$. The effect of poisoning was monitored by Malaise trapping and was later determined to reduce common wasp densities by an average of $69.2 \%( \pm 16.5)$ This single poisoning event significantly reduced common wasp numbers for the remainder of the season. Differences in common wasp abundances between pre- and post-poisoning periods 
was analysed using ANOVA with number of common wasps as the dependant variable and location (Maitai, Roding and Rotoiti), treatment (wasps-maintained or wasps-controlled) and time (pre- and post-poisoning) as the fixed factors. A Post-hoc LSD test was performed to determine any difference in common wasp reduction between locations. All ANOVA analyses were performed in SPSS 16.0 (2008).

\subsubsection{Isotope analysis}

To ascertain the relative trophic level status of native bush ants and invasive common wasps and any possible change in that status due to removal of a competitor (common wasps) we tested nitrogen and carbon isotope ratios. We opportunistically collected samples of bush ants and common wasps from each location in December 2008 and April 2009 both before and after common wasp poisoning ${ }^{1}$. As samples are based on weight and not number, we collected two individual common wasps, and two samples of approximately 50 bush ants at each of the six sites. Bush ants and common wasps were collected alive and starved for $24 \mathrm{~h}$ prior to processing to purge gut contents and avoid skewing the results toward recent feeding (Tillberg et al. 2006). The animals were then killed by freezing and stored frozen until processing.

To assess the change in trophic position and relative isotope ratios of other secondary consumers we sampled spiders and Carabid beetles using pitfall traps. From each of the six study sites we collected no fewer than two samples of spiders (secondary consumers), Carabidae (secondary consumers), and Collembola (primary consumers). Collembola were collected to establish a baseline for trophic level analysis (e.g. Wise et al. 2006). One $10 \mathrm{~m}$ x $10 \mathrm{~m}$ quadrat was established at each study site. Ten pitfall traps were placed haphazardly within the quadrat no closer than $2 \mathrm{~m}$ to any other pitfall trap. Pitfall

\footnotetext{
${ }^{1}$ Further samples will be collected before and after poisoning in the summer of 2009/2010.
} 
traps were plastic cups with a diameter of $70 \mathrm{~mm}$, one third filled with water. At the end of each collection period traps were sieved to remove water and the samples were frozen for transportation back to the laboratory. At the laboratory all samples were separated and dried at $60{ }^{\circ} \mathrm{C}$, then ground to a fine powder using a mortar and pestle prior to analysis. Carbon and nitrogen stable isotope analysis was performed using a Dumas elemental analyzer (Europa ScientiWc ANCA-SL) interfaced to an isotope mass spectrometer (Europa ScientiWc 20/20 Stable Isotope Analyzer).

\subsubsection{Data analysis}

The trophic level of each invertebrate sampled was estimated using $\delta^{15} \mathrm{~N}$ data with a baseline correction method to interpret $\delta^{15} \mathrm{~N}$ relative to that of a primary consumer's $\delta^{15} \mathrm{~N}$ after Vander Zanden et al. (1999). In this study the baseline representative of primary consumers was the $\delta^{15} \mathrm{~N}$ of Collembola (e.g. Wise et al. 2006). Each invertebrate's trophic position was calculated using the formula:

Trophic position invertebrate $=\left(\left(\delta^{15} \mathrm{~N}_{\text {invertebrate }}-\delta^{15} \mathrm{~N}_{\text {baseline }}\right) / 3.4\right)+2$

where 3.4 is the assumed increase in $\delta^{15} \mathrm{~N}$ per trophic level. Trophic level scores of 3 or greater are indicative of a secondary consumer. Trophic level changes were analysed using ANOVA. Trophic level was the dependent variable with 'Animal' (wasps or ants, spiders or Carabidae), 'Time' (pre-poisoning or post-poisoning) and 'Site' (wasps-controlled or wasps-maintained) as the fixed factors. Interactions between animal, site and time were also investigated.

The relative change in isotope ratios between wasps-controlled and waspsmaintained sites for both $\delta^{13} \mathrm{C}$ and $\delta^{15} \mathrm{~N}$ was calculated by first log transforming the data 
then dividing the wasps-controlled isotope value by the wasps-maintained value. Results were then back-transformed to account for the multiplicative nature of ratios. Changes in $\delta^{15} \mathrm{~N}$ and $\delta^{13} \mathrm{C}$ isotope values were analysed by comparing the $95 \%$ confidence intervals with the wasps-maintained value of one. If the wasps-controlled confidence interval included one the value was determined to be not significantly different from the waspsmaintained value.

\subsection{Results}

Poisoning reduced common wasp numbers in the wasps-controlled sites by an average of $69.2 \%( \pm 16.5)$ (Fig. 4.1, Table 4.1). There was a significant interaction between treatment and time, due to fewer common wasps overall in the Rotoiti location post-poisoning, independent of the poisoning treatment. The post-hoc analysis revealed that Rotoiti was significantly different $(\mathrm{p}=0.003)$, this is due to the high numbers of common wasps at Rotoiti in both the wasps-maintained and wasps-controlled sites in the pre-poisoning period.

\section{Table 4.1 ANOVA results for wasp abundance}

Location is Maitai, Roding or Rotoiti. Site is wasps-maintained or wasps-controlled and time is pre- or postpoisoning

\begin{tabular}{lccc}
\hline \multicolumn{1}{c}{ Analysis } & F & d.f. & $P$ \\
\hline Location & & & \\
Treatment & 2.73 & 2,28 & 0.08 \\
Time & 10.19 & 1,28 & $<0.01$ \\
Treatment x Time & 12.61 & 1,28 & $<0.001$ \\
& 4.19 & 1,28 & $<0.05$ \\
\hline
\end{tabular}




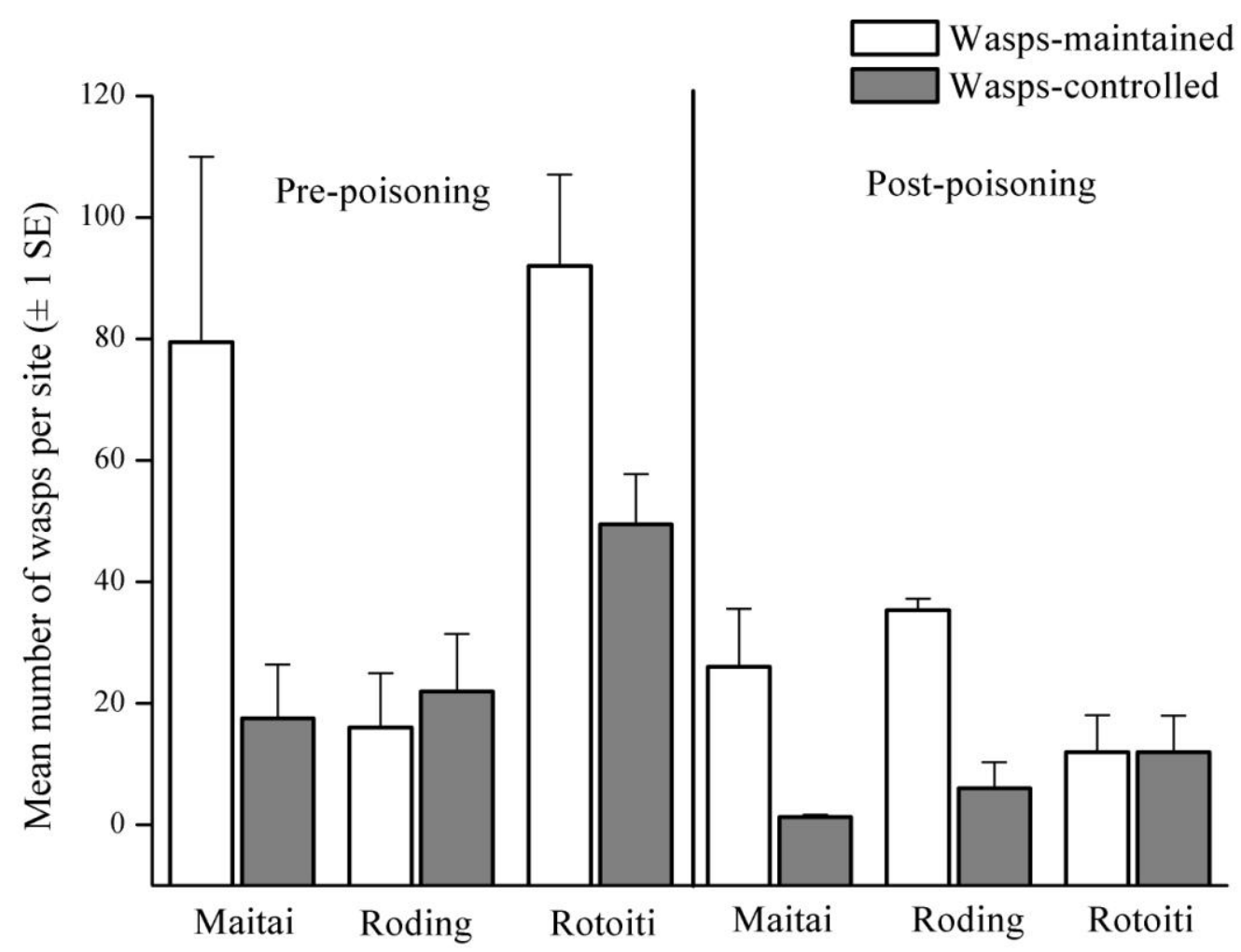

Figure 4.1 Reduction in common wasp numbers after poisoning at the different treatment sites Numbers of common wasps in wasps-controlled and wasps-maintained sites in both pre- and post-poisoning periods. Data are means $\pm 1 \mathrm{SE}$

\subsubsection{Do the isotope ratios of native species change after the removal of an invasive competitor?}

Bush ants showed a significant change in $\delta^{13} \mathrm{C}$ enrichment over time in both preand post-poisoning periods in the wasps-controlled sites relative to the wasps-maintained sites (Fig. 4.2a). There was a significant change in the $\delta^{15} \mathrm{~N}$ enrichment of bush ants in the pre-poisoning period between the wasps-controlled and wasps-maintained sites (Fig. 4.2b); however, ratios did not differ in the post-poisoning period.

Common wasps showed a significant increase in $\delta^{15} \mathrm{~N}$ enrichment pre-poisoning in the wasps-controlled site relative to the wasps-maintained site (Fig. 4.2b). There was no 
significant change in enrichment in the post-poisoning period. No significant change in isotope ratios of common wasps was observed for either $\delta^{13} \mathrm{C}$ associated with common wasp reduction (Fig. 4.2a); $\delta^{13} \mathrm{C}$ values appeared to remain constant over time regardless of treatment.

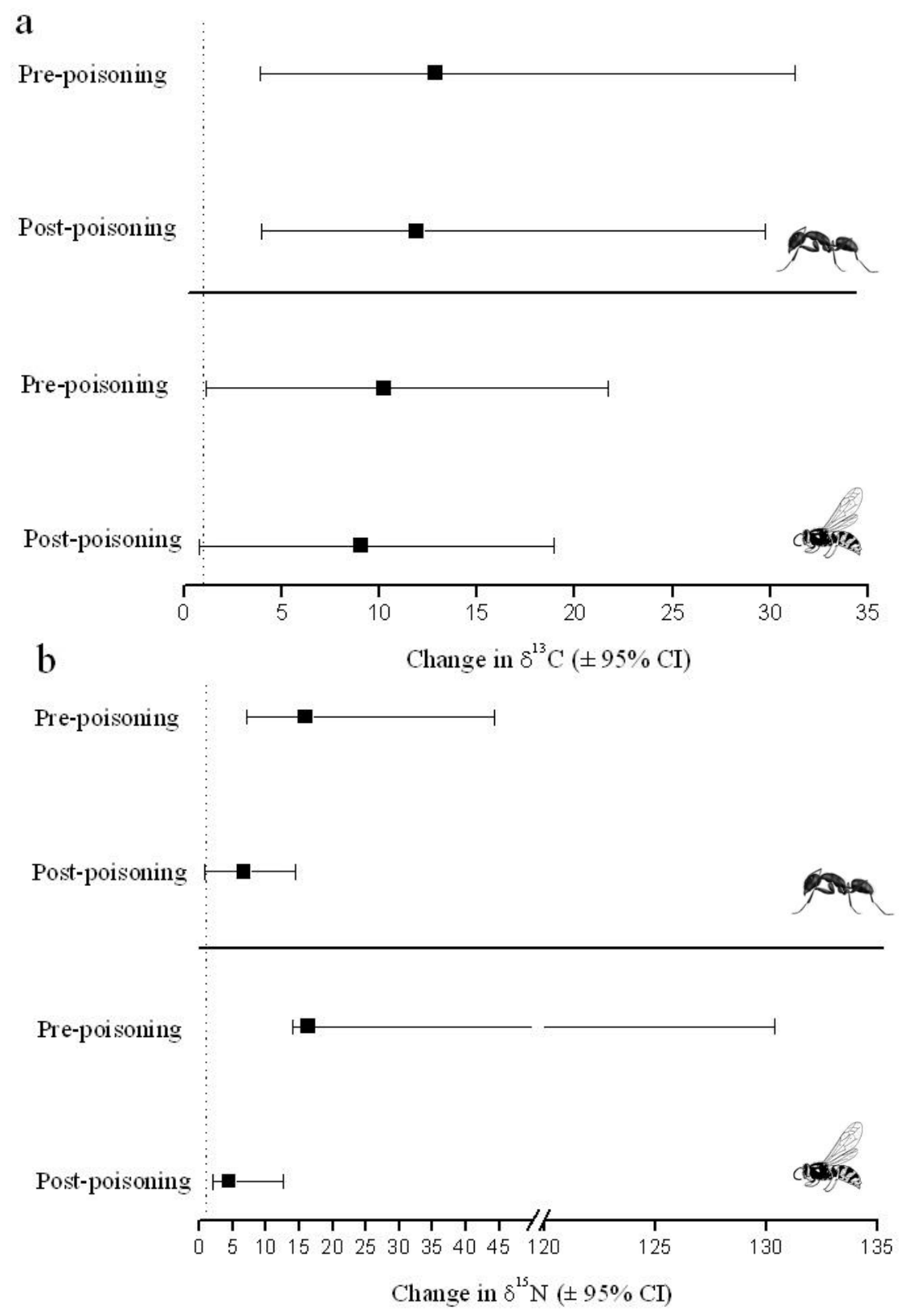

Figure 4.2 Isotope changes in bush ants and common wasps pre- and post-poisoning

Change in the enrichment of $\delta^{13} \mathrm{C}(4.2 \mathrm{a})$ and $\delta^{15} \mathrm{~N}(4.2 \mathrm{~b})$ in bush ants and common wasps between pre- and post-poisoning periods. Confidence intervals that encompass the value of 1 (dashed line) indicate no change in enrichment in the wasps-controlled site relative to the wasps-maintained site. Data are means $\pm 95 \% \mathrm{CI}$ 
a

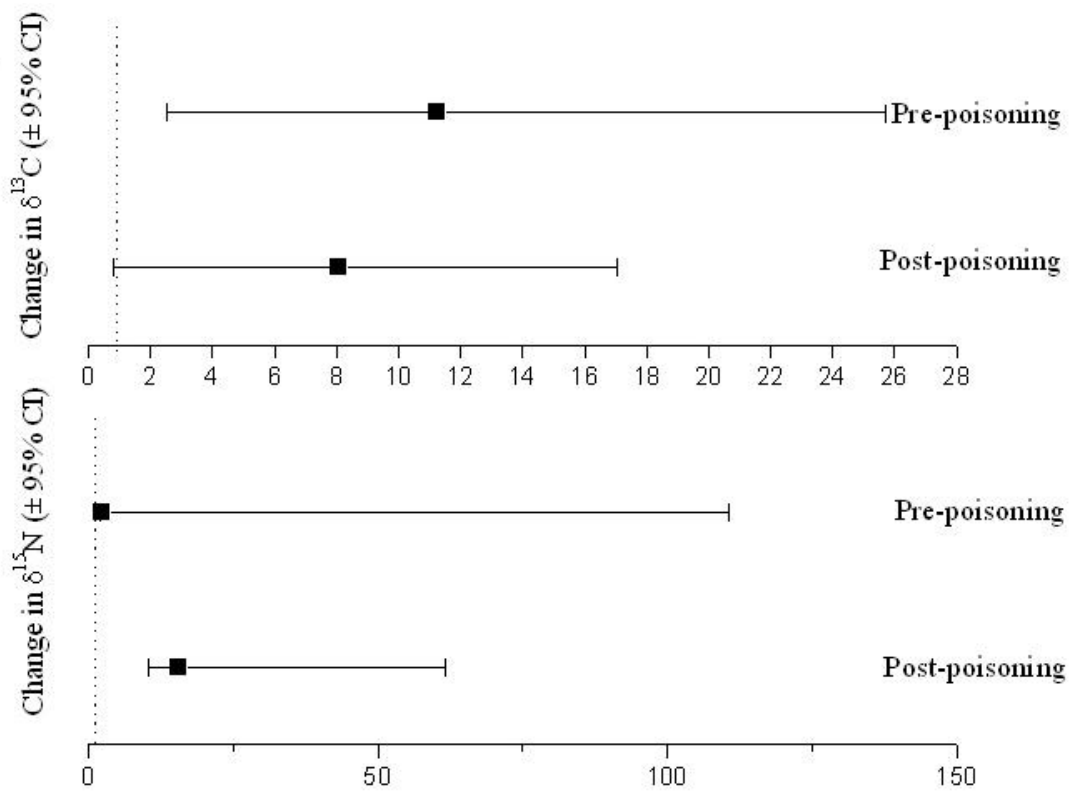

b

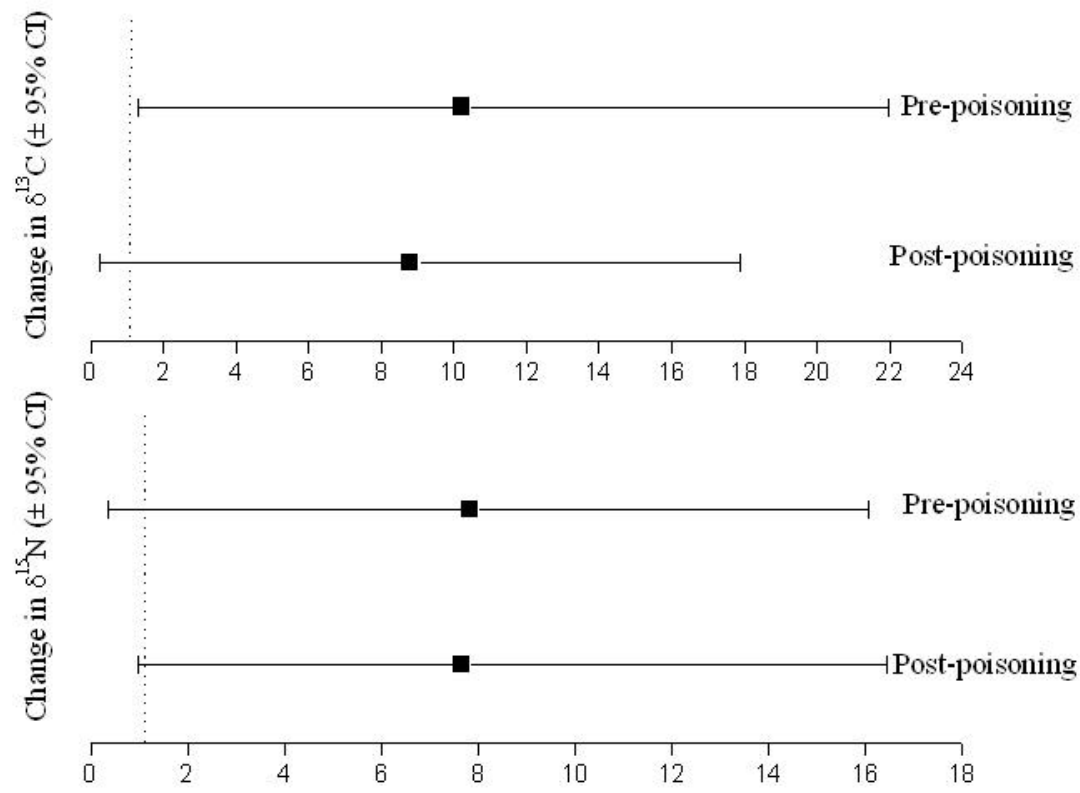

Figure 4.3 Isotope changes in spiders and Carabidae pre- and post-poisoning

Change in the enrichment of $\delta^{13} \mathrm{C}$ in and $\delta^{15} \mathrm{~N}$ in spiders (4.3a) and Carabidae (4.3b) between pre- and postpoisoning periods. Confidence intervals encompassing the value of 1 (dashed line) indicate no change in enrichment in the wasps-controlled site relative to the wasps-maintained site. Data are means $\pm 95 \% \mathrm{CI}$

There was a significant change in enrichment of $\delta^{13} \mathrm{C}$ of Carabidae and spiders the pre-poisoning period in the wasps-controlled site relative to the wasps-maintained site (Fig. 4.3a \& b); however, there was no change in the post-poisoning period. There was also a significant change in enrichment of $\delta^{15} \mathrm{~N}$ of spiders, but not Carabidae, in the post- 
poisoning period in the wasps-controlled site relative to the wasps-maintained site (Fig.

$4.3 \mathrm{a} \& \mathrm{~b})$ and no change in the pre-poisoning period for either Carabidae or spiders.

\subsubsection{Do trophic positions change after the removal of an invasive competitor?}

The trophic level of bush ants, common wasps, spiders and Carabidae were assessed using $\delta^{15} \mathrm{~N}$ data with a baseline correction method (Vander Zanden et al. 1999). There was a significant difference between the trophic level scores of bush ants and common wasps (Table 4.2, Fig. 4.4), with bush ants showing consistently higher scores than common wasps in wasps-controlled and wasps-maintained sites in both pre- and postpoisoning assessment periods. However, the trophic positions of bush ants and common wasps in all treatments were well within the range indicative of a secondary consumer (Vander Zanden et al. 1999).

Table 4.2 ANOVA results for changes in trophic position

Animal is wasps or ants, Time is pre- or post poisoning and Site is wasps-controlled or wasps-maintained

\begin{tabular}{lccc}
\hline Analysis & F & d.f. & $P$ \\
\hline & & & \\
Animal & 95.32 & 1,71 & $<0.001$ \\
Time & 35.62 & 1,71 & $<0.001$ \\
Site & 2.17 & 1,71 & 0.15 \\
Animal x Site & 0.04 & 1,71 & 0.84 \\
Time x Site & 4.03 & 1,71 & $<0.05$ \\
Animal x Time & 6.11 & 1,71 & $<0.05$ \\
Animal x Time x Site & 1.72 & 1,71 & 0.19 \\
& & & \\
\hline
\end{tabular}

There was a significant effect of time, the trophic levels of bush ants and common wasps increased between sampling periods in both wasps-controlled and wasps-maintained sites. There was a significant interaction between time and site, there was a greater increase in trophic level of both ants and wasps in the wasps-maintained areas post-poisoning than there was in the wasps-controlled areas. There was also a significant interaction between 
animal and time; bush ants showed a greater increase in trophic level in the wasps-

maintained area than in the wasps-controlled area in the post-poisoning period whereas wasps increased in trophic level to an equal degree in both areas.
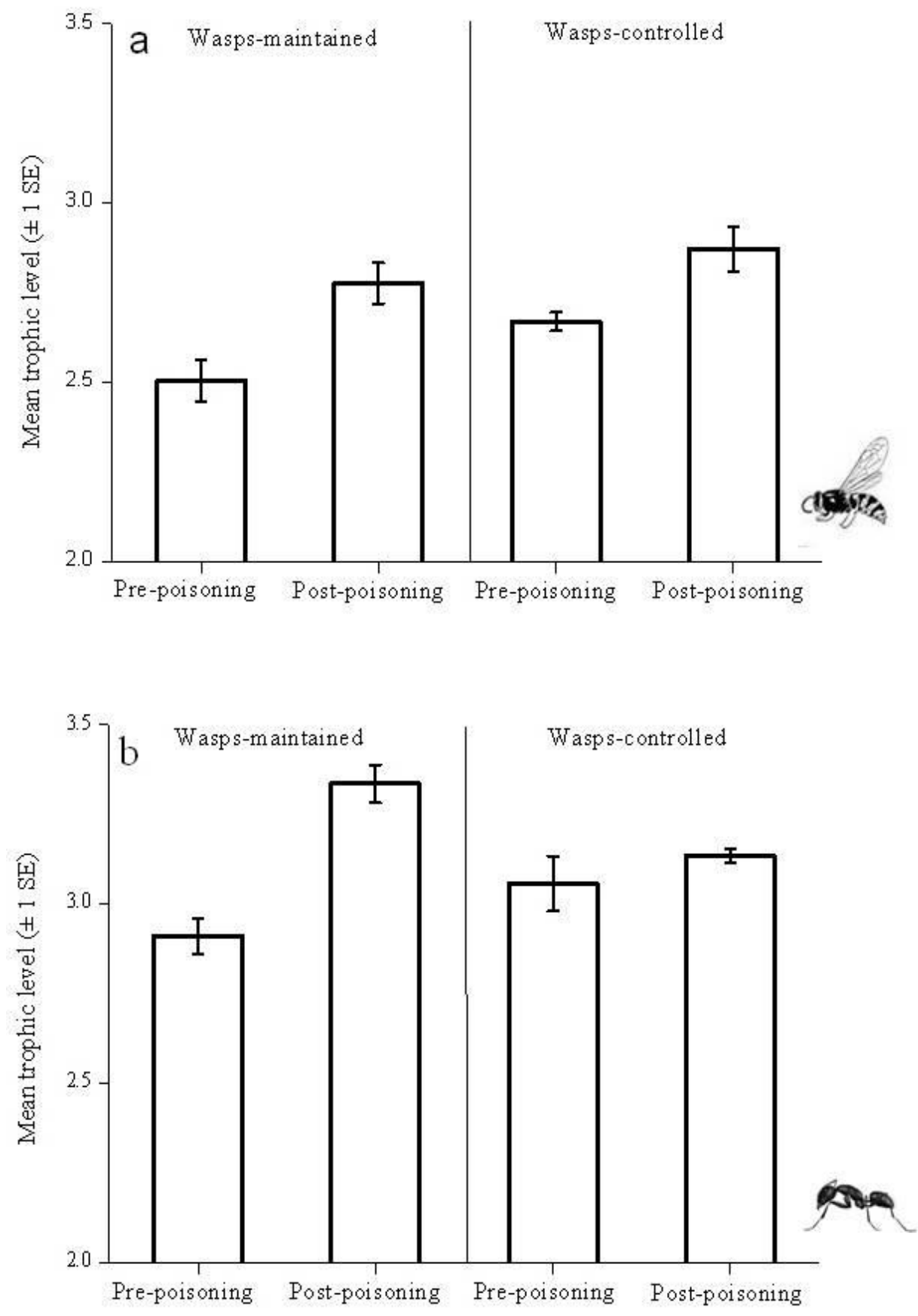

Figure 4.4 Mean trophic levels of common wasps and bush ants

Trophic levels of common wasps (4.4a) and bush ants (4.4b) in wasps-controlled and wasps-maintained sites both pre- and post-poisoning. Trophic level values of 3 and above are indicative of the level of secondary consumer. Data are mean values $\pm 1 \mathrm{SE}$. 
Trophic scores of both spiders and Carabidae were indicative of secondary consumer status in all treatments (Fig. 4.5). There was no significant difference in the trophic level of spiders before or after poisoning (Fig. 4.5a, table 4.3). There was also no significant difference in the trophic level of spiders in wither the wasps-controlled or wasps-maintained sites and no interaction between site and time; trophic levels increased in the post-poisoning period regardless of treatment. There was a significant difference in the trophic level of Carabidae over time (Fig. 4.5b, table 4.3), the trophic level increased overall in the post-poisoning period. However, there was no significant difference in the trophic level of spiders in either the wasps-controlled or wasps-maintained sites, and no interaction between site and time.

Table 4.3 ANOVA results for changes in trophic position of spiders and Carabidae

Time is pre- or post-poisoning and site is wasps-controlled or wasps-maintained

\begin{tabular}{lccc}
\hline Analysis & F & d.f. & $P$ \\
\hline Spiders & & & \\
$\quad$ Time & 3.53 & 1,8 & 0.09 \\
$\quad$ Site & 0.22 & 1,8 & 0.65 \\
$\quad$ Time x Site & 0.15 & 1,8 & 0.71 \\
& & & \\
Carabidae & & & \\
$\quad$ Time & 78.88 & 1,8 & $<0.01$ \\
Site & 4.09 & 1,8 & 0.07 \\
Time x Site & 4.09 & 1,8 & 0.07 \\
& & & \\
\hline
\end{tabular}



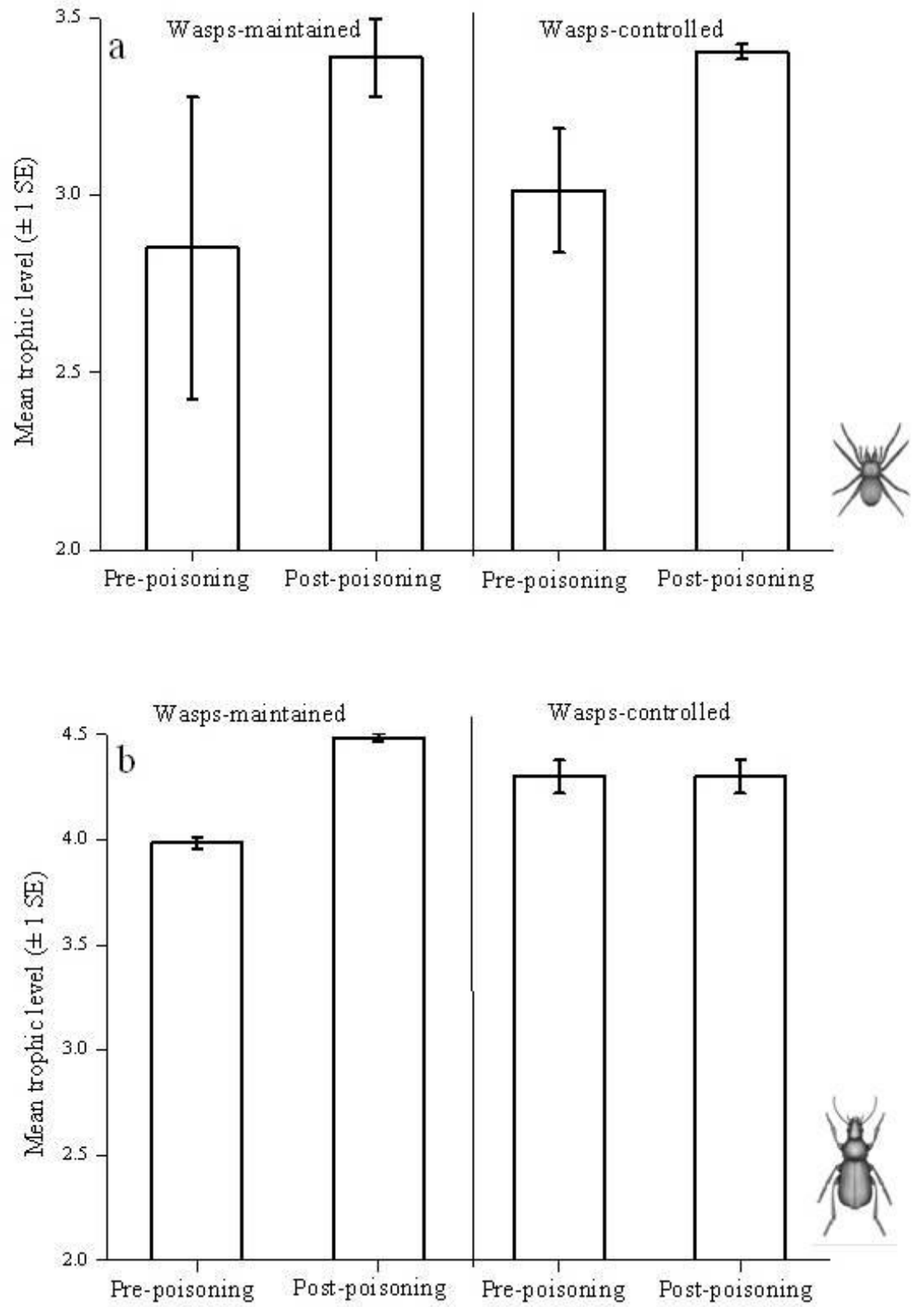

\section{Figure 4.5 Mean trophic level of spiders and Carabidae}

Trophic levels of spiders ( 4.5 a) and Carabidae (4.5b) in wasps-controlled and wasps-maintained sites both pre- and post-poisoning. Trophic level values of 3 and above are indicative of the level of secondary consumer. Data are mean values $\pm 1 \mathrm{SE}$. 


\subsection{Discussion}

This study aimed to test the effect of an invasive species on the isotope ratios of a native competitor, using the native bush ants, Prolasius advenus, and the invasive common wasps, Vespula vulgaris. We asked if the isotope ratios and trophic level of native competitors change in response to the removal of this invasive species. Additionally, as predation and competition pressure from an invasive species may impact populations of other predators, such as spiders and Carabidae, we asked if the trophic positions and isotope ratios of these other predators change in response to the removal of an invasive species. Arthropod communities can be significantly disrupted when invaded by another predatory arthropod (Porter and Savignano 1990, Human and Gordon 1997, Hoffman et al. 1999, Krushelnycky and Gillespie 2008). In addition to changes in community structure, invasions may alter trophic positions and isotope ratios of the invaded populations. Following invasion by crazy ants, native crabs on the islands of Tokelau showed a decrease in $\delta^{15} \mathrm{~N}$ suggesting exclusion from previously used resources (McNatty et al. 2009). Further, pressure by an invasive predator can serve to increase the abundance of primary producers and thus causing isotopic shifts across the community (Britton et al. 2009). In this study both bush ants and common wasps showed an increase in the ratio of $\delta^{15} \mathrm{~N}$ in the pre-poisoning period but not in the post-poisoning period. The $\delta^{13} \mathrm{C}$ ratios of common wasps did not change in the wasps-controlled area relative to the waspsmaintained area in either sampling period; however bush ants showed an increase in the wasps-controlled areas relative to the wasps-maintained areas in both periods. There was also an increase over time in the trophic levels of both bush ants and common wasps.

Other predators in this system may be impacted by the introduction of an invasive predator. In our study there was a change in the enrichment of $\delta^{13} \mathrm{C}$ in both spiders and 
Carabidae in the pre-poisoning period but not in the post-poisoning period. The ratio of $\delta^{15} \mathrm{~N}$ for spiders in creased in post-poisoning period but not in the pre-poisoning period; however, the $\delta^{15} \mathrm{~N}$ ratio of Carabidae did not change in either period. The trophic level of these two predators also increased over time independent of the poisoning treatment.

\subsubsection{Do the isotope ratios of native species change after the reduction in number of an invasive competitor?}

Ratios of $\delta^{13} \mathrm{C}$ and $\delta^{15} \mathrm{~N}$ were examined in both native and invasive species to determine if the exclusion of an invasive competitor would alter the isotope enrichment of native competitors. In the pre-poisoning sampling period both native bush ants and invasive common wasps showed an increase in $\delta^{15} \mathrm{~N}$ enrichment in the wasps-controlled sites relative to the wasps-maintained sites. This relative increase may be related to the greater number of wasps in the wasps-maintained sites in this pre-poisoning period meaning that relatively more prey items were available in the wasps-controlled sites.

Bush ants showed an increase in $\delta^{13} \mathrm{C}$ enrichment in both the pre- and postpoisoning sampling periods when comparing the wasps-controlled sites to the waspsmaintained sites; however common wasps showed no change in either period. This increase in $\delta^{13} \mathrm{C}$ in bush ants may be as a result of less competition from wasps as there were fewer wasps overall in the wasps-controlled sites independent of sampling time.

Other studies have found changes in isotope ratios after the removal of an invasive predator. For example Lepak et al. (2006) found that two years after the removal of an invasive smallmouth bass the isotope values and consequently the trophic level of the competing native lake trout increased as a result of increased access to prey fish. In our study there was an increase in enrichment of $\delta^{13} \mathrm{C}$ of both spiders and Carabidae in the pre- 
poisoning period in the wasps-controlled sites relative to the wasps-maintained sites but no change in the post-poisoning period.

Spiders showed a small increase in $\delta^{15} \mathrm{~N}$ ratios in the wasps-controlled sites, where common wasp numbers were reduced, in the post-poisoning period compared to waspsmaintained sites where common wasps remained at natural levels, while Carabidae showed no difference indicating no change in protein consumption. It may be that spiders are more impacted by common wasp predation potentially compete for more similar food resources than do Carabidae and common wasps. In this study Carabidae were only identified to family, and it may be the case that individual species of Carabidae were differently affected by common wasp abundances. A more detailed study needs to be conducted to more accurately quantify the impact on these species.

\subsubsection{Do trophic positions change after the reduction in number of an invasive competitor?}

Trophic levels were assessed using the stable isotope $\delta^{15} \mathrm{~N}$ with a baseline correction method as in Vander Zanden et al. (1999). Results showed that the overall trophic level of native bush ants is higher than that of the invasive common wasps; however, both are well within the range of a secondary consumer. Both of these species are omnivorous and rely on carbohydrates in the form of honeydew and protein from insect prey (Richter 2000, Dussutour and Simpson 2009). In a study by Tillberg et al. (2007) invasive Argentine ants showed a decrease in trophic level as a result of resource depletion and their increasing reliance on honeydew. Bush ants have been observed foraging for honeydew in these forests, and have associations with root Homoptera present in some bush ant nests at the base of Nothofagus trees (Don 2007, J. Grangier Pers. Comm.). 
Honeydew is present on both the trunks and branches of Nothofagus trees with more honeydew produced in the sub-canopy than on the trunks (Beggs et al. 2005), therefore bush ants may have less access to the honeydew resource than common wasps and rely more on prey items for colony survival. This would have the effect of elevating their trophic position above that of common wasps. The increased access to the honeydew resource by common wasps may have implications for their foraging behaviour (Beggs and Wardle 2006). Predators with high nitrogen requirements are more likely to be active hunters rather than sit-and-wait predators; this behaviour serves to increase expenditure of excess carbon (Denno and Fagan 2003). Therefore, common wasps may use more of the honeydew resource to fuel predatory behaviour.

There was a significant effect of time, with the trophic level of both bush ants and common wasps increasing between sampling periods. This increase in trophic level may be a reflection of a change in dietary requirements, provoking an increase in protein consumption. Protein and carbohydrates are the two key dietary components that ensure colony growth and survival, and a shift in the ratio of these components depends on the presence of larvae. The ratio is protein-biased when larvae are present but carbohydratebiased when larvae are absent (Behmer 2009, Dussutour and Simpson 2009). The increase in trophic position after the removal of common wasps may not be a reflection of a reduction in competition but rather a reflection of a seasonal dietary change to promote brood production or a seasonal increase in prey availability.

The observed interaction between time and site was reflected in an increase in the trophic level of bush ants and common wasp in the wasps-maintained sites in the post poisoning period when compared to the wasps-controlled sites. The observed increase in trophic level may be as a result of fewer primary consumers as prey. There may be more predation in the wasps-maintained sites due to a greater number of wasps, thereby reducing 
the availability of primary consumers as prey. Comparison of the isotope ratios of predators is subject to the isotopic variation amongst prey (Quevedo et al. 2009). If predators are feeding on other secondary consumers, this consumption will be reflected in an increase in trophic level. The chance of primary consumers such as caterpillars making it through the summer season is greatly reduced due to common wasp predation in the early summer (Beggs and Rees 1999).

The interaction between site and time was reflected differently in bush ants and common wasps. Bush ants showed a greater increase in trophic level in the waspsmaintained than in the wasps-controlled sites while wasps increased to the same degree in both treatments. Increased predation due to an increased number of common wasps in the wasps-maintained sites may have restricted the diet of bush ants to secondary consumers and thereby elevating their trophic levels to a greater degree than sites where there was a greater diversity of prey.

Overall variations in isotope ratios of generalists, reflecting trophic positions, have been attributed to ambient variation at the base of the food web, with variation in $\delta^{15} \mathrm{~N}$ linked to variation in phosphorus in the leaf litter (McGlynn et al. 2009). Therefore, the increase in the observed trophic level may be as a result of an increase in $\delta^{15} \mathrm{~N}$ in the Collembola used in this study as a baseline. There remains, however, a difference in the trophic position of bush ants and common wasps relative to each other.

Both the Carabidae and spiders sampled have trophic levels indicative of a secondary consumer indicating that the majority of their diet is obtained from protein sources. This is in accordance with their known diet (Wise et al. 2006). There was no increase in the trophic position of spiders in the wasps-controlled or wasps-maintained sites after the reduction in number of common wasps. The trophic level of Carabidae increased between sampling periods in the sites where common wasp numbers were 
reduced. As with the trophic increases seen in both bush ants and common wasps, this increase may reflect seasonal changes in dietary requirements and appears not to be related to the reduction of common wasps. Spiders and Carabidae have also remained abundant in areas subject to invasion by Argentine ants (Tillberg et al. 2007). Spiders and Carabidae are secondary consumers and may not be competitively affected by common wasps therefore common wasps may not limit access to resources.

There was significant variation in common wasp abundance both between sites and between treatments in the pre-poisoning period. Even though there was a reduction in common wasp numbers in the post-poisoning period in all wasps-controlled sites, there was also a reduction in common wasp numbers in the wasps-maintained sites. This variation in abundance may have confounded our results.

\subsection{Conclusion}

Bush ants and common wasps coexist on the same trophic levels; they both simultaneously fill multiple trophic roles as primary predators, secondary predators, and primary consumers, however, bush ants have a greater trophic level than common wasps. Additionally, bush ants showed an increase in trophic level in sites where common wasps were maintained. Common wasps may be depleting more of the honeydew resource in these sites restricting bush ants to foraging for prey. However, changes in the trophic levels of both bush ants and common wasps may also be as a result of natural seasonal variation in consumption related to the nutritional requirements of the colony. This change may be due to an increase in predation due to the nutritional requirements of new brood. Common wasps are known to consume an extraordinary amount of invertebrate prey during the 
summer months to the detriment of all other predators in these forests (Beggs et al. 1998, Beggs 2001).

From these results it appears that common wasps are not altering the trophic level of the other secondary predators tested as there was no change in enrichment of $\delta^{15} \mathrm{~N}$ and $\delta^{13} \mathrm{C}$ of Carabidae between wasps-controlled and wasps-maintained sites in either the preor post-poisoning period and there was only a relatively small increase in the enrichment of $\delta 15 \mathrm{~N}$ observed in spiders in the post-poisoning period. The observed changes in trophic levels of these animals may be as a result of natural seasonal variation in diet. A comparison of the diets of common wasps, spiders and Carabidae would help determine the impact of increasing common wasp numbers on these other predators. The impacts of species invasions are complex, particularly among those species that fill multiple trophic roles. Native species that persist in the face of invasions may alter their resource use to enable coexistence. Further research is needed to determine if native competitors in our study sites have altered their diet in the face of this common wasp invasion.

\subsection{Acknowledgements}

Zak Murdoch, Julien Grangier, Alan Burne, and Laura Bass provided invaluable field help. Funding was provided by the Royal Society of New Zealand Marsden fund and a Victoria University of Wellington PhD Scholarship. Thanks go to 'bug club' for editing earlier drafts of this manuscript. Thanks also to the Department of Conservation and the Tasman District Council for access to land, and Department of Conservation and Richard Toft and Jo Rees for assistance with the poisoning. 


\subsection{References}

Beggs, J. 2001. The ecological consequences of social wasps (Vespula spp.) invading an ecosystem that has an abundant carbohydrate resource. Biological Conservation 99:17-28.

Beggs, J., R. J. Toft, J. P. Malham, J. S. Rees, J. A. V. Tilley, H. Moller, and P. Alspach. 1998. The difficulty of reducing introduced wasp (Vespula vulgaris) populations for conservation gains. New Zealand Journal of Ecology 22:55-63.

Beggs, J. and D. A. Wardle. 2006. Keystone species: Competition for honeydew among exotic and indigenous species. Springer-Verlag, Berlin.

Beggs, J. R., B. J. Karl, D. A. Wardle, and K. I. Bonner. 2005. Soluble carbon production by honeydew scale insects in a New Zealand beech forest. New Zealand Journal of Ecology 29:105-115.

Beggs, J. R. and J. S. Rees. 1999. Restructuring of Lepidoptera communities by introduced Vespula wasps in a New Zealand beech forest. Oecologia 119:565-571.

Behmer, S. T. 2009. Animal behaviour: Feeding the superorganism. Current Biology 19:R366 - R368.

Britton, R. J., G. D. Davies, and C. Harrod. 2009. Trophic interactions and consequent impacts of the invasive fish Pseudorasbora parva in a native aquatic food web: a field investigation in the UK. Pages 1573-1464 Biological Invasions. Springer, Netherlands.

Brown, J. H. and D. W. Davidson. 1977. Competition between seed-eating rodents and ants in desert ecosystems. Science 196:880-882.

Carroll, C. R. and D. H. Janzen. 1973. Ecology of foraging by ants. Annual Review of Ecology and Systematics 4:231-257.

de Niro, M. J. and S. Epstein. 1981. Influence of diet on the distribution of nitrogen isotopes in animals. Geochim Cosmochim Acta 45:341-351.

Denno, R. F. and W. F. Fagan. 2003. Might nitrogen limitation promote omnivory among carnivorous arthropods? Ecology 84:2522 - 2531.

Don, W. 2007. Ants of New Zealand. Otago University Press, Dunedin

Dussutour, A. and S. J. Simpson. 2009. Communal nutrition in ants. Current Biology 19:740 - 744. 
Ewers, R. 2002. The influence of honeydew on arthropod community composition in a New Zealand beech forest. New Zealand Journal of Ecology 26:23-29.

Gilbert, B., D. S. Srivastava, and K. R. Kirby. 2008. Niche partitioning at multiple scales facilitates coexistence among mosquito larvae. Oikos 117:944-950.

Gurnell, J., L. A. Wauters, P. W. Lurz, and G. Tosi. 2004. Alien species and interspecific competition: effects of introduced eastern grey squirrels on red squirrel population dynamics. Journal of Animal Ecology 73:26-35.

Hoffman, B. D., A. N. Andersen, and G. J. E. Hill. 1999. Impact of an introduced ant on native rain forest invertebrates: Phedole megacephala in monsoonal Australia. Oecologia 120:595-604.

Human, K. G. and D. M. Gordon. 1997. Effects of Argentine ants on invertebrate biodiversity in Northern California. Conservation Biology 11:1242-1248.

Krushelnycky, P. D. and R. G. Gillespie. 2008. Compositional and functional stability of arthropod communities in the face of ant invasions. Ecological Applications 18: $1547-1562$.

Lepak, J. M., C. E. Kraft, and B. C. Weidel. 2006. Rapid food web recovery in response to removal of an introduced apex predator. Canadian Journal of Fisheries and Aquatic Sciences 63:569-575.

Mailleux, A., J. Deneubourg, and C. Detrain. 2003. Regulation of ants' foraging to resource productivity. Proceedings of the Royal Society of London 270:1609-1616.

Markwell, T. J., D. Kelly, and K. W. Duncan. 1993. Competition between honey bees (Apis mellifera) and wasps (Vespula spp.) in honeydew beech (Nothofagus solandri var. solandri) forest. New Zealand Journal of Ecology 17:85-93.

McColl, H. P. 1975. The invertebrate fauna of the litter surface of a Nothofagus truncata forest floor, and the effect of microclimate on activity. New Zealand Journal of Ecology 2:15-34.

McGlynn, T. P., H. K. Choi, S. T. Mattingly, A. Upshaw, E. K. Poirson, and J. Betzelberger. 2009. Spurious and functional correlates of the isotopic composition of a generalist across a tropical rainforest. BMC Ecology 9.

McNatty, A., K. L. Abbott, and P. J. Lester. 2009. Invasive ants compete with and modify the trophic ecology of hermit crabs on tropical islands. Oecologia 160:187 - 194.

Moller, H. and J. A. V. Tilley. 1989. Beech honeydew: seasonal variation and use by wasps, honey Bees, and other insects. New Zealand Journal of Zoology 16:289302. 
Moller, H., Tilley, J.A.V., Thomas, B.W., \& Gaze, P.D. (1991) Effect of introduced social wasps on the standing crop of honeydew in New Zealand beech forests. New Zealand Journal of Zoology, 18, 171-179.

Mooney, H. A. and E. E. Cleland. 2001. The evolutionary impact of invasive species. Proceedings of the National Academy of Sciences 98:5446-5451.

Mooney, K. A. and C. V. Tillberg. 2005. Temporal and spatial variation to ant omnivory in pine forests. Ecology 86:1225-1235.

Morales, C. F., M. G. Hill, and A. K. Walker. 1988. Life history of the sooty beech scale (Ultracoelostoma assimile) (Maskell), (Hemiptera: Margodidae) in New Zealand Nothofagus forests. New Zealand Entomologist 11:24-38.

Peterson, B. J. and B. Fry. 1987. Stable isotopes in ecosystem studies. Annual Review of Ecology, Evolution, and Systematics 18:293-320.

Porter, S. D. and D. A. Savignano. 1990. Invasion of polygyne fire ants decimates native ants and disrupts arthropod community. Ecology 71:2095-2106.

Post, D. 2002. Using stable isotopes to estimate trophic position: models, methods, and assumptions. Ecology 83:703-718.

Quevedo, M., R. Svanbäck, and P. Eklöv. 2009. Intrapopulation niche partitioning in a generalist predator limits food web connectivity. Ecology 90:2263-2274.

Richter, M. R. 2000. Social wasp (Hymenoptera: Vespidae) foraging behaviour. Annual Review of Entomology 45:121-150.

Sanders, D. and C. Platner. 2007. Intraguild interactions between spiders and ants and topdown control in a grassland food web. Oecologia 150:611-624.

Sanders, N. J., N. J. Gotelli, N. E. Heller, and D. M. Gordon. 2003. Community disassembly by an invasive species. Proceedings of the National Academy of Sciences 100:2474-2477.

Schmidt, S. N., J. D. Olden, C. T. Solomon, and M. J. Vander Zanden. 2007. Quantitative approaches to the analysis of stable isotope food web data. Ecology 88:2793-2802.

Shea, K. and P. Chesson. 2002. Community ecology theory as a framework for biological invasions. Trends in Ecology and Evolution 17:170-176.

SPSS. 2008. Release 16.0 Chicago SPSS inc.

Stadler, B. and A. F. G. Dixon. 1999. Ant attendance in aphids: why different degrees of myrmecophily? Ecological Entomology 24:363-369. 
Tillberg, C. V., D. A. Holway, E. G. LeBrun, and A. V. Suarez. 2007. Trophic ecology of invasive Argentine ants in their native and introduced ranges. Proceedings of the National Academy of Sciences 104:20856-20861.

Tillberg, C. V., D. P. McCarthy, A. G. Dolezal, and A. V. Suarez. 2006. Measuring the trophic ecology of ants using stable isotopes. Insectes Sociaux 53:65-69.

Vander Zanden, M. J., J. M. Casselman, and J. B. Rasmussen. 1999. Stable isotope evidence for the food web consequences of species invasions in lakes. Nature 401:464-467.

Way, M. J. 1963. Mutualism between ants and honeydew-producing homoptera. Annual Review of Entomology 8:307-344.

Wise, D. H., D. M. Moldenhauer, and J. Halaj. 2006. Using stable isotopes to reveal shifts in prey consumption by generalist predators. Ecological Applications 16:865-876. 


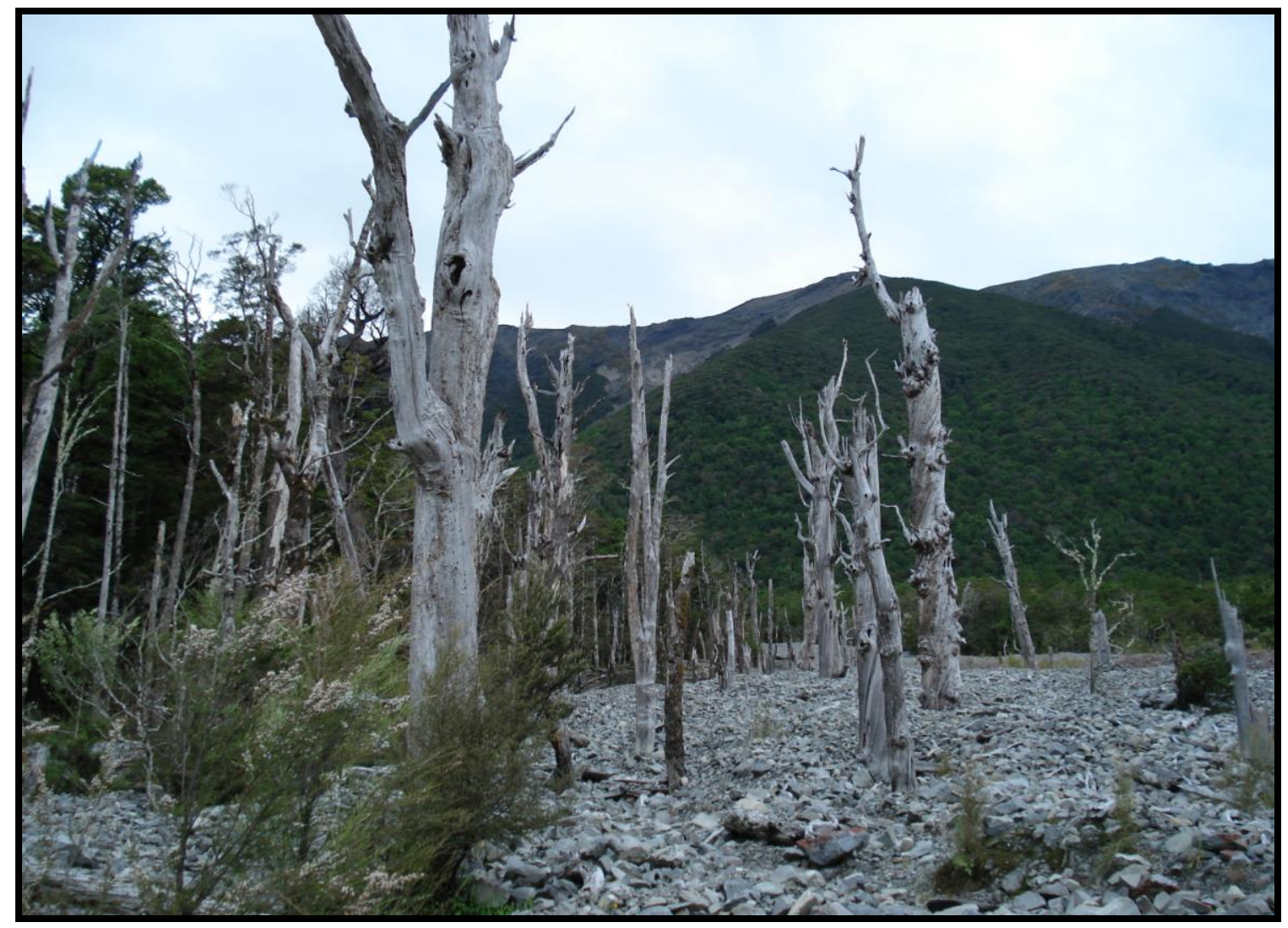

Outwash fan at Rotoiti 
5 Chapter Five

Density-Dependent Behavioural

Plasticity in Competitive

Interactions between Native Ants

and Invasive Wasps. 


\subsection{Abstract}

Invasive species may competitively exclude native species from resources unless the native species can adapt behaviourally thereby enabling co-occurrence. Given that the influence of a competitor on resources is generally density-dependent, the behavioural responses of native species to foraging invasive species should depend on the densities of both species. Common wasps (Vespula vulgaris) appear to be using cues from native ants to enhance their foraging. Here we demonstrate how foraging by the native ants Prolasius advenus (the New Zealand bush ant) and Huberia brounii results in increased foraging by invasive common wasps, and show how this interaction is density-dependent on ant abundance. Common wasps were on average 2.3 times more numerous at food stations where ants were present. Common wasps removed significantly more food when foraging with ants than when common wasps foraged on their own. Recruitment patterns of common wasps provoke an aggressive response by bush ants. When present in greater numbers bush ants were significantly more likely to attack common wasps. Behavioural adaptations by native ants have impacts on foraging success and competitive interactions, and may enable cooccurrence between these two potential competitors. 


\subsection{Introduction}

Competition between species for a food resource can be a driving force structuring ecosystems and contributing to observed patterns of species distribution and abundance (Brown and Davidson 1977, Human and Gordon 1999, Chase et al. 2002, Sanders and Gordon 2003, Lester et al. 2009). Interspecific competition between species on the same trophic level often leads to a competitively dominant species displacing a subordinate species at food resources, and can result in competitive exclusion (Brown 1971, Holway 1999). However, competitive exclusion is not the only outcome; some competitors manage to coexist despite differences in dominance. It is possible that behavioural adaptations by native species to dominant invaders may enable species co-occurrence in the face of competition for resources (Mooney and Cleland 2001). For example, in a study of the effects of yellow crazy ants on native hermit crabs, crabs adjusted their foraging behaviour to minimise contact with ants (McNatty et al. 2009).

In most circumstances the influence of a competitor is density-dependent. Small numbers of foragers may provoke little response whereas large numbers of foragers will elicit more of a response from a foraging competitor. In a study of the fire ant Solenopsis invicta in Florida competition among colonies was density dependant with brood raids increasing as colony density increased (Adams and Tschinkel 1995). Additionally, in laboratory experiments with invasive Argentine ants, aggressive behaviour towards native ants was more likely to occur at higher densities of Argentine ants (Sagata and Lester 2009). Some plasticity in the density-dependant response of heterospecific competitors could be an important adaptive trait enabling co-occurrence.

The invasive common wasp, Vespula vulgaris (L.) (hereafter referred to as 'common wasp'), a native of Europe, established in the 1980s in the Nothofagus forests of 
the South Island of New Zealand and now dominates these forests to the detriment of native birds and insects (Clapperton et al. 1994). By collecting the carbohydrate-rich honeydew resource produced by the sooty beech scale insect (Ultracoelostoma spp.) common wasps have reached extremely high densities (Beggs et al. 1998, Beggs 2001). At an average abundance of 10,000 workers per hectare, common wasps attain higher densities in these forests than seen anywhere else in the world (Thomas et al. 1990). Common wasps have been estimated to consume a similar insect prey biomass over the summer to autumn period as the entire bird fauna over the whole year, outcompeting all other predators in this system (Moller and Tilley 1989, Harris 1991, Beggs 2001). The predominant ant species in New Zealand Nothofagus forests is Prolasius advenus (Fr. Smith) or the New Zealand bush ant (McColl 1975). Bush ants are generalist foragers and have been observed feeding on honeydew, consuming small invertebrates, and scavenging for larger invertebrates (Don 2007). Huberia brounii Forel is a second endemic ant species that inhabits native forests and is common in leaf litter. Like bush ants, the biology of this species is not well known (Don 2007). Huberia is a genus endemic to New Zealand while bush ants belong to a genus with all other representatives in Australia (Shuttack 2000). The common wasp genus Vespula is exotic to and invasive in Australia and New Zealand (Donovan 1984, Matthews et al. 2000). Therefore neither genus of ants has had recent historical or evolutionary interactions with this wasp.

This research examined interactions between native ants and invasive common wasps during foraging. Our specific goals were to determine whether the presence of exotic wasps influences the foraging success of native ants, or conversely whether the presence of native ants influences the foraging success of invasive common wasps. We aimed to determine if the amount of food taken by both ants and common wasps differs when each species forages individually or together. We tested if aggressive behaviour of 
common wasps or native ants is density-dependent. Additionally we assessed whether numerical dominance corresponds to behavioural dominance at food resources.

\subsection{Methods}

\subsubsection{Study site}

This study was conducted from February to April 2009 in the nature reserve in Nelson Lakes National Park, a 5000 hectare reserve within the 100,000 hectare national park in the South Island of New Zealand $\left(41^{\circ} 49^{\prime} \mathrm{S}, 172^{\circ} 50^{\prime} \mathrm{E}\right.$ at $615 \mathrm{~m}$ elevation). The vegetation is simple in structure with the canopy dominated by the mature beech trees, Nothofagus solandri and N. menziesii. The understory consists of Pseudopanax spp., Coprosma spp., Cyathodes juniperina, Leucopogon fasciculatus, Griselinia littoralis and juvenile Nothofagus.

\subsubsection{Wasp or ant exclusion experiments}

To determine whether the presence of common wasps influenced the foraging success of native ants we compared the foraging success of native ant species in the presence and absence of common wasps. Exclusion experiments were conducted in three quadrats measuring $10 \mathrm{~m} \times 10 \mathrm{~m}$. Within each quadrat 10 experimental units were placed haphazardly. Each experimental unit consisted of three food stations: one which excluded common wasps, one which excluded ants, and one which allowed access to both. In this forest bush ant nests occur at a density of approximately $0.06 \mathrm{~m}^{2}, H$. brounii at a density of $0.05 \mathrm{~m}^{2}$ and common wasps at a density of $0.03 \mathrm{~m}^{2}$ (C. Duthie unpublished data). Therefore we could be confident that experimental units were likely to be visited by ants 
and common wasps from different nests both from within the quadrat and from surrounding areas. The experiment was conducted four times on four separate days during the middle of each day. Observations were recorded every $10 \mathrm{~min}$ for a period of $3 \mathrm{~h}$. At every observational period the number of ants and common wasps at each food station was recorded. The ants were able to be identified to species in the field but samples were taken back to the laboratory for confirmation.

All food stations contained approximately $5 \mathrm{~g}$ of tuna in oil placed on a white plastic disc $10 \mathrm{~cm}$ in diameter. The common wasp exclusion food stations were placed within a wire mesh cage with a mesh diameter of $2 \mathrm{~mm}$ allowing access to ants but not common wasps. The ant exclusion food stations were placed on another plastic disc $20 \mathrm{~cm}$ in diameter with the edges coated in tanglefoot ${ }^{\circledR}$ (Tanglefoot Co., Grand Rapids, Michigan, USA). The three food stations were placed in a triangular arrangement no closer than 50 $\mathrm{cm}$ to each other, and the whole experimental unit was no closer that $2 \mathrm{~m}$ to any other unit.

Exclusion experiments were analysed using repeated-measures ANOVA to test for the differences in numbers of bush ants and H. brounii present at food over time in the presence and absence of common wasps. Also analysed were the numbers of common wasps recruiting to foods over time in the presence of both bush ants and $H$. brounii. Time (minutes) was the explanatory variable and numbers of ants and common wasps were between subject factors. Relevant assumptions of normality, homoescedacity and sphericity were examined here and in all parametric statistics presented below. Where the assumption of sphericity was violated (for specific analyses) the Greenhouse-Geisser correction was used. 


\subsubsection{Resource dominance on a natural food}

To assess resource dominance on a more typical food resource we used adult yellow mealworm beetles (Tenebrio molitor) as a substitute for naturally occurring invertebrate prey. These experiments were conducted in two quadrats measuring $10 \mathrm{~m}$ x 10 m. The experiment was conducted four times on two separate days. Ten experimental units were placed haphazardly within each quadrat no closer than $2 \mathrm{~m}$ to any other unit. A single freshly decapitated beetle was placed on a white plastic disc $10 \mathrm{~cm}$ in diameter.

Observations were made every $20 \mathrm{~min}$ for $3 \mathrm{~h}$. At each observational period the number of ants and common wasps at each food station was recorded. Ants and common wasps were able to be identified to species in the field but samples were taken back to the lab for confirmation.

To test for the differences in numbers of ants and common wasps recruiting to beetles over time these experiments were analysed using repeated-measures ANOVA. Time (minutes) was the fixed factor and numbers of ants and common wasps were between subject factors.

\subsubsection{Food collection experiments}

Collection experiments were conducted to determine the amount of food taken by both ants and common wasps when each species was foraging individually or together. Experimental units were set up as in the exclusion trials. However, we added an additional treatment of a food item that was made unavailable to both ants and common wasps to account for the weight of food lost to evaporation. Food used in this experiment was tuna in oil as in the exclusion experiments. This experiment was conducted three times on three separate days. To mitigate any effects of the weighing process on foraging on the first day observations were taken every half hour, on the second day observations were taken every 
hour, and on the third day observations were taken every $2 \mathrm{~h}$. Foods were weighed in grams to 2 decimal places at the beginning of each experiment and at each observation period using a portable balance (Diamond brand, model A04).

Collection experiments were analysed using ANOVA to test for a difference in food consumed between treatments. Weight was the dependent variable and treatment and day were explanatory variables. A post-hoc LSD test was used to determine individual differences between treatments and days.

\subsubsection{Behavioural interactions between common wasps and ants}

Behavioural interaction experiments were conducted to examine if aggressive behaviour of common wasps or ants was density-dependent. These experiments were conducted in quadrats measuring $5 \mathrm{~m} \times 5 \mathrm{~m}$. Each experiment was conducted in a different quadrat no closer than $20 \mathrm{~m}$ from the site of a previous experiment. A total of five experiments were conducted on four separate days with each experiment lasting three hours. Tuna was utilised in these experiments rather than mealworms to reduce the chance of the baits being removed before the end of the experimental period. Ten tuna food stations were placed haphazardly within each experimental quadrat with approximately $5 \mathrm{~g}$ of tuna in oil placed on a white plastic disc $10 \mathrm{~cm}$ diameter. Each food station was no closer that $1 \mathrm{~m}$ to any other. Interactions between ants and common wasps at food stations were recorded for a period of three hours. Ant behaviour was categorised into four classes: (1) 'retreat', ants retreated from a common wasp; (2) 'ignore', ants ignored the presence of a common wasp; (3) 'rush', ants run directly at a common wasp; and, (4) 'bite', ants bite the common wasp either on the legs or antennae. Common wasp behaviour was categorised into four classes: (1) 'ignore', common wasps ignored the ants; (2) 'leave', common wasps left the food station; (3) 'distressed', common wasps appeared visibly 
distressed shaking their heads and grooming; and, (4) 'wasp removed ant', the common wasp picked up an ant from the food station and dropped it unharmed nearby. Interactions were recorded as they occurred during the experimental period. The time of each observation was recorded along with the number of ants and common wasps present on the food station, and the species of ant. Only the initial behaviour and response was recorded at any food station for any one observation time.

Behavioural data were analysed using multinomial logistic regression. Individual data from all replicates was pooled for each treatment. Aggression scores (1 - 4) were dependent on species (ant or common wasp) and numbers of ants present (in classes 1-5, 610, 11-15 and 16+). The reference category for the regression analysis was behavioural category 1 .

\subsubsection{Forager abundance}

To assess forager abundance of both common wasps and ants pitfall and Malaise traps were set for four days during the April experiments. Two $20 \times 20$ m quadrats were established $20 \mathrm{~m}$ away from the experimental quadrats. One Malaise trap was placed in the centre of each quadrat and 20 pitfall traps were placed haphazardly within the quadrat no closer than $2 \mathrm{~m}$ to any other pitfall trap. Pitfall traps were plastic cups with a diameter of $70 \mathrm{~mm}$; they were $1 / 3$ filled with water with the addition of a drop of detergent to break the surface tension. Forager abundance on food stations in the exclusion experiments was assessed by counting the numbers of each species of ant and common wasp both with and without heterospecific foragers. Differences in the numbers of foragers present in pitfall traps was analysed using ANOVA with number of individuals as the dependant variable and species of ant as the explanatory variable. 


\subsection{Results}

\subsubsection{Wasp or ant exclusion experiments}

Exclusion experiments determined whether the presence of common wasps influences the foraging success of native ants or vice versa. Both common wasps and ants usually discovered the food within 10 minutes of the start of the experiment. There were up to 35 ants present at some stations however, there was seldom more than one common wasp per food station in any one observation period. Neither species of ant co-occurred at food stations. Common wasps were on average 2.3 times more numerous at food stations where ants were present.

There was no significant difference between the numbers of bush ants present on foods in the presence of common wasps than in exclusion treatments. In both treatments the numbers of bush ants increased over time (Fig. 5.1a, table 5.1). Huberia brounii was more abundant at foods that had common wasps present. Significantly more H. brounii were present on foods in the presence of common wasps than in exclusion treatments; on average there were 3.6 times more ants at food station that had common wasps present. This may reflect a reluctance of $H$. brounii to forage in the common wasp exclusion food stations due to an avoidance of novel items in their environment; they are more cautious than bush ants and very easily startled (C. Duthie Pers. Obs.). The two treatments were influenced by time, when common wasps were present $H$. brounii declined in abundance after 100 minutes however, their numbers steadily increased in the wasp exclusion treatments (Fig. 5.1b, table 5.1). More common wasps visited food stations with ants present than those without. Additionally, there was a significant difference between the number of common wasps present on foods in the presence of $H$. brounii and the number 
of common wasps present on foods in the presence of bush ants, overall more common wasps visited food stations with $H$. brounii present than those with bush ants present. The numbers of common wasps present with bush ants decreased after 80 minutes; however, numbers present with $H$. brounii increased throughout the experiment (Fig. 5.1c, table 5.1). 
(a)

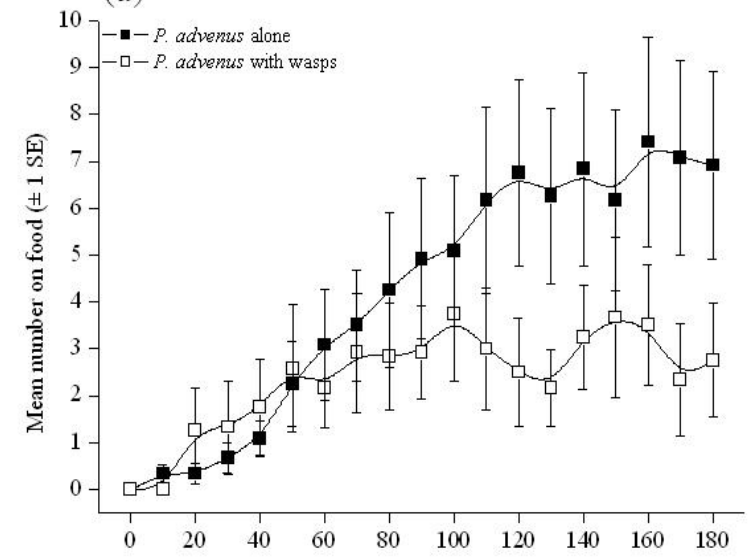

(b)

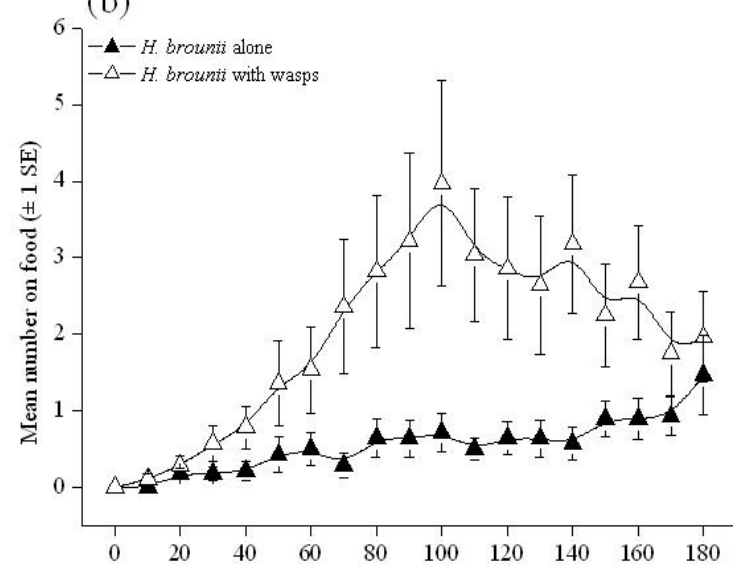

(c)

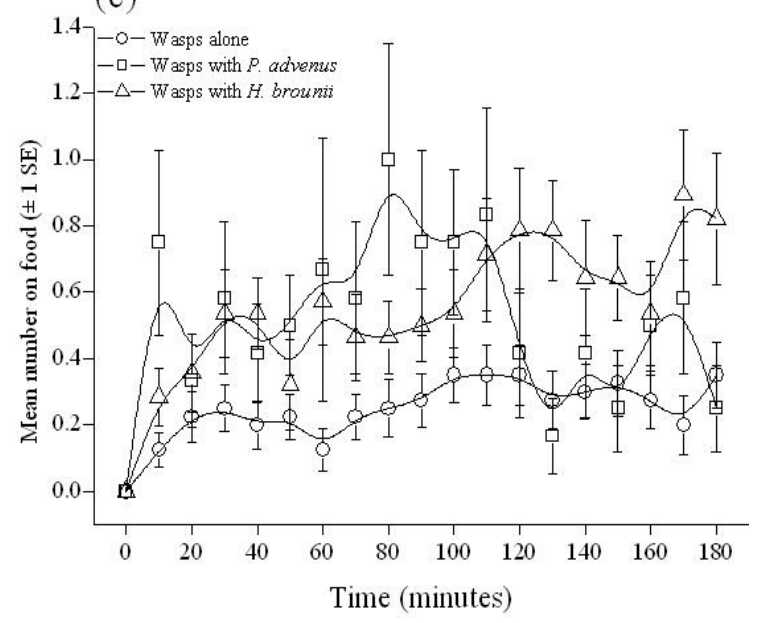

Figure 5.1 Recruitment of Huberia brounii, Prolasius advenus and Vespula vulgaris to food stations numbers of $P$. advenus on food stations which excluded common wasps (closed squares) and numbers of $P$. advenus on food stations with allowed common wasps (open squares), (b) numbers of $H$. brounii on food stations which excluded common wasps (closed triangles) and numbers of $H$. brounii on food stations with allowed common wasps (open triangles), and (c) Numbers of common wasps on food stations which excluded ants (circles), numbers of common wasps on food stations on which P. advenus were present (squares) and numbers of common wasps on food stations on which H. brounii were present (triangles), all data are means \pm 1 SE. $\beta$-spline curves are fitted. 


\section{Table 5.1 Results for repeated-measures ANOVA analysis of exclusion experiments}

Each experimental unit consisted of three treatments: one which excluded common wasps, one which excluded ants, and one which allowed access to both. Time (minutes) was the fixed factor and numbers of ants and common wasps were between subject factors.

\begin{tabular}{lccr}
\hline Analysis & F & d.f. & \\
\hline & & & \\
Prolasius advenus & & & \\
$\quad$ With wasps vs. no wasps & 1.563 & 1,11 & 0.237 \\
Time & 7.608 & 18,198 & $<0.001$ \\
Treatment x Time & 2.333 & 18,198 & 0.002 \\
& & & \\
Huberia brounii & & & \\
$\quad$ With wasps vs. no wasps & 7.891 & 1,27 & 0.009 \\
Time & 6.524 & 18,486 & $<0.001$ \\
Treatment x Time & 3.466 & 18,486 & $<0.001$ \\
& & & \\
Common wasps and P. advenus & & & \\
With ants vs. no ants & 3.027 & 1,8 & 0.120 \\
Time & 1.11 & 18,144 & 0.348 \\
Treatment x Time & 1.417 & 18,144 & 0.131 \\
& & & \\
Common wasps and H. brounii & & & \\
With ants vs. no ants & 10.933 & 1,20 & $<0.001$ \\
Time & 4.141 & 18,360 & 0.003 \\
Treatment x Time & 1.43 & 18,360 & 0.114 \\
& & & \\
\hline
\end{tabular}

\subsubsection{Resource dominance on a natural food}

These experiments assessed resource dominance on a typical food resource on which both ants and common wasps are likely to forage. Bush ants cooperatively removed mealworms from the food stations; this is reflected in a sharp decline in the number of ants at food stations after 60 minutes. This behaviour potentially enables bush ants to access more of the food as Huberia brounii did not display this cooperative behaviour. While there was no significant difference in overall numbers of bush ants and Huberia brounii at food stations (Fig. 5.2a \& 5.2b) $\left(\mathrm{F}_{1,18}=0.012, \mathrm{p}=0.9147\right)$ there was a significant 
interaction between species and time $\left(\mathrm{F}_{8,32}=6.397, \mathrm{p}<0.001\right)$ reflected in the decline of $P$. advenus at food stations. Neither $H$. brounii nor common wasps were able to remove beetles from the food stations and therefore remained feeding on haemolymph at the food stations rather than carrying food away. There was no difference in the numbers of common wasps with bush ants and the numbers of common wasps with $H$. brounii at food stations (Fig. 5.2a \& 5.2b) $\left(\mathrm{F}_{1,17}=0.068, \mathrm{p}=0.797\right)$.

(a)

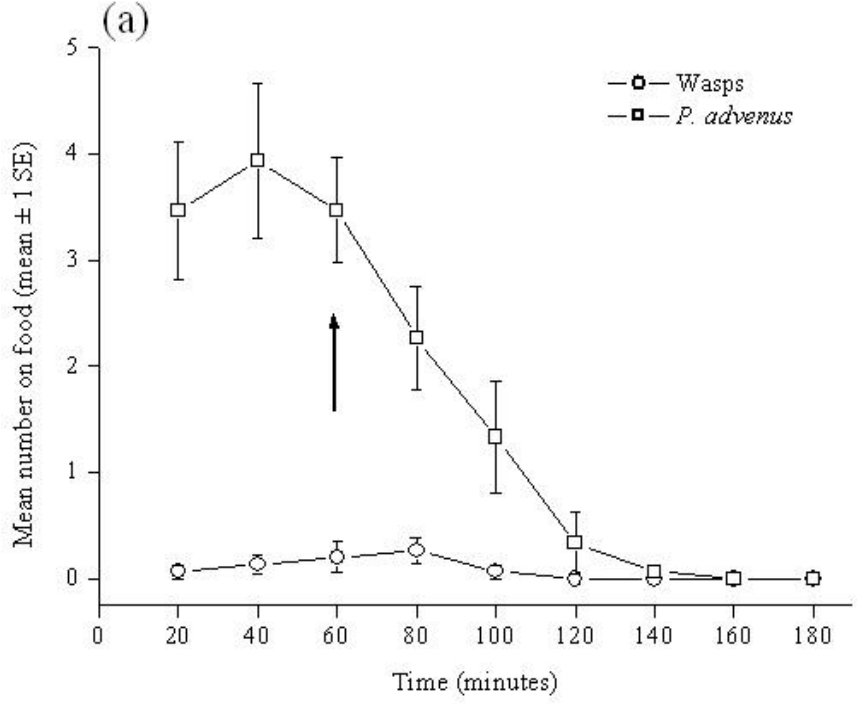

(b)

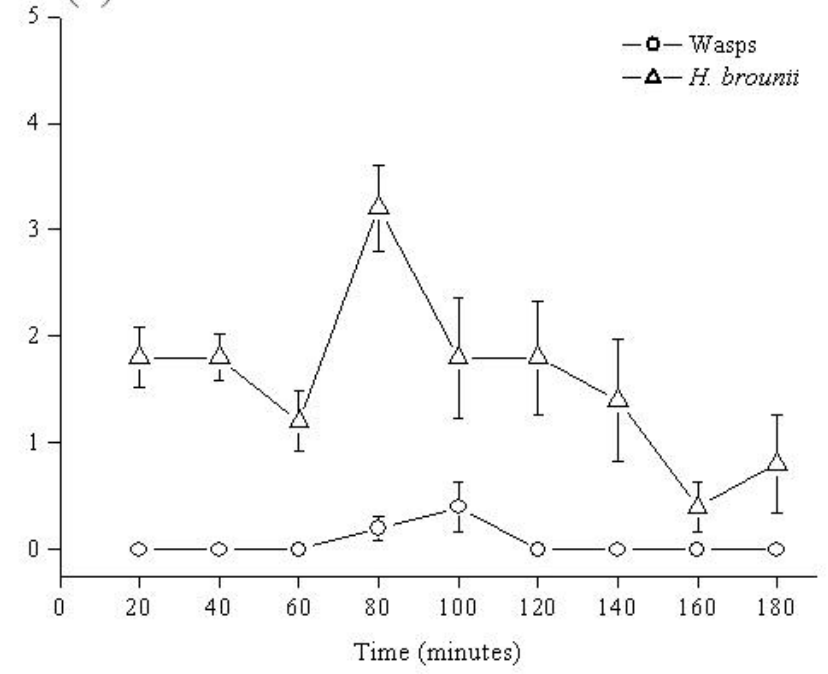

Figure 5.2 Recruitment of Huberia brounii, Prolasius advenus and Vespula vulgaris to beetle food stations

(a) Those food stations with $P$. advenus present (b) Those food stations with $H$. brounii present. All data are means $\pm 1 \mathrm{SE}$. The arrow in (a) marks the average time when $P$. advenus began to carry the beetle away.

\subsubsection{Food collection experiments}

Collection experiments determined the amount of food taken by ants and common wasps both together and separately (Fig. 5.3). There was a significant interaction between treatment and day in the amount of food collected $\left(\mathrm{F}_{6,27}=5.055, \mathrm{p}=0.001\right)$. A post hoc LSD test shows that 'ants only' collected significantly less food than both 'wasps only' and 'wasps and ants' ( $\mathrm{p}<0.01$ and $\mathrm{p}<0.001$, respectively). 'Wasps and ants' collected 
significantly more food than 'wasps only' $(p=0.015)$. Surprisingly, the amount of food collected by 'ants only' was not significantly different from evaporation rates $(\mathrm{p}=0.809)$. This result corresponds with field observations, in which the ants appeared to primarily consume the oil associated with the tuna and remove very small pieces of tuna. Day three of observations was significantly different from days one and two $(\mathrm{p}<0.001)$ with more food removed by common wasps on day three, presumably due to the fact that on that day the food was left for longer periods resulting in less disturbance of foraging common wasps.

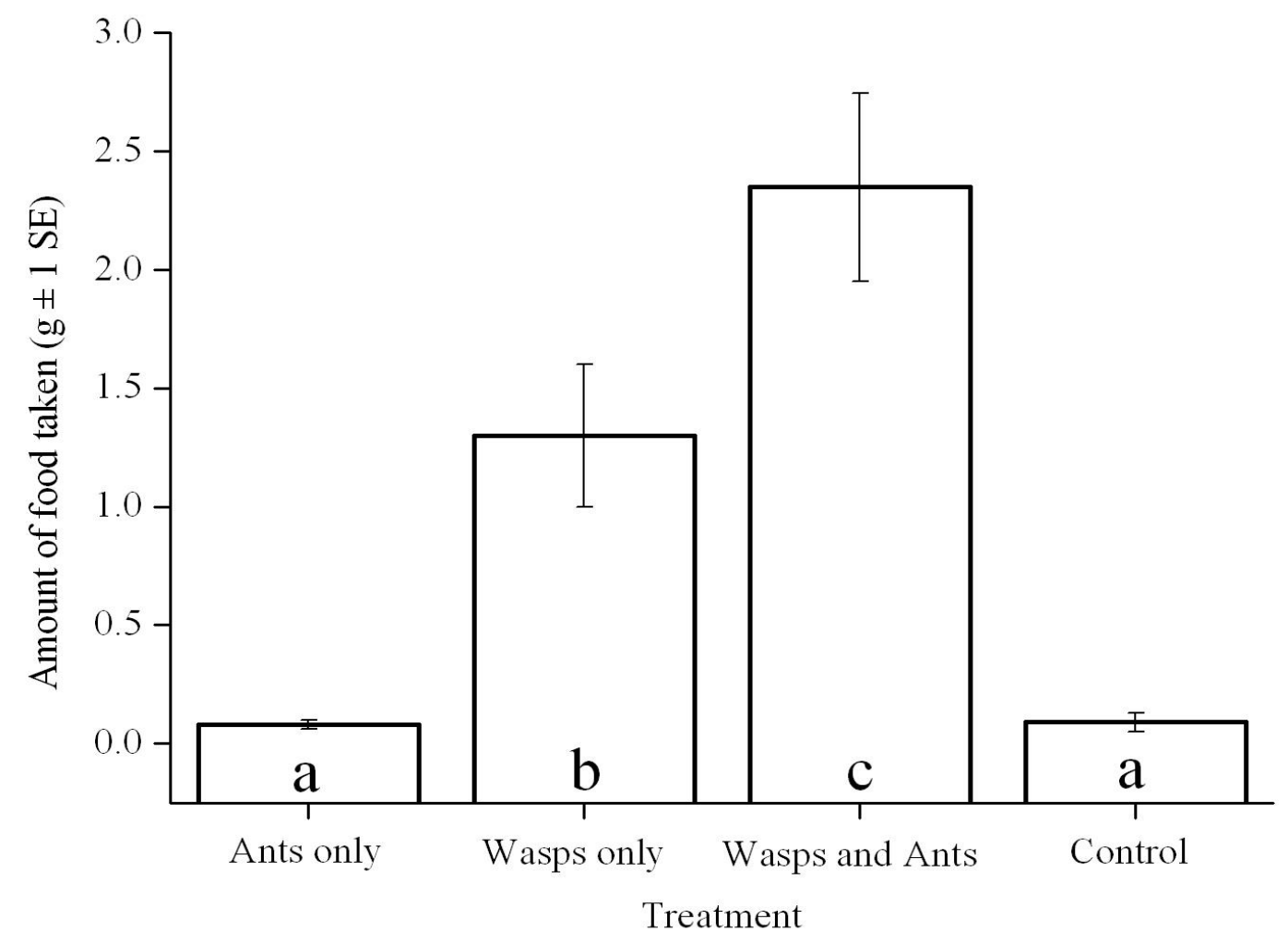

\section{Figure 5.3 Food collected by ants and common wasps after 3 hours}

Treatments were; Ants only (common wasps were excluded), wasps only (ants were excluded), wasps and ants (both ants and common wasps are allowed access), and Control (both ants and common wasps are excluded). Letters $\mathrm{a}, \mathrm{b}$ and $\mathrm{c}$ refer to the LSD comparisons. All data are mean $\pm 1 \mathrm{SE}$. 


\subsubsection{Behavioural interactions between common wasps and ants}

Behavioural interaction experiments were conducted to examine if the aggressive behaviour of common wasps or ants is density-dependent. Substantially different responses to common wasps were displayed by the two ant species. Bush ants were significantly more likely to attack common wasps when these ants were present in greater numbers (Fig. 5.4a) (odds ratio $=98.589, \mathrm{p}<0.001)$. Bush ants seldom retreated and this behavioural response decreased as the numbers of ant workers increased. There was no significant difference in the behavioural response of Huberia brounii to common wasps (Fig. 5.4b), regardless of the number of ants present, (odds ratio $=35.098, p=0.996)$. The predominant recorded response of $H$. brounii was to retreat or ignore the presence of common wasps. However, during the course of the experiment $H$. brounii was observed to fall over and "play dead" when retreat appeared not an option.

Common wasps appeared to be excluded from the foods when there were greater numbers of bush ants. When common wasps foraged in the presence of bush ants, (Fig. 5.4c) they were more likely to ignore the ants when ants were present in low numbers (odds ratio $=68.905, \mathrm{p}=0.048$ ) and more likely to leave when there were more ants present. More bush ants were removed by common wasps when ants were at low abundances. Common wasps seldom showed any response to the presence of $H$. brounii (Fig. 5.4d), there was no significant difference in the behavioural response of common wasps to $H$. brounii regardless of the numbers of ants present (odds ratio $=25.915, \mathrm{p}=$ 0.998). 

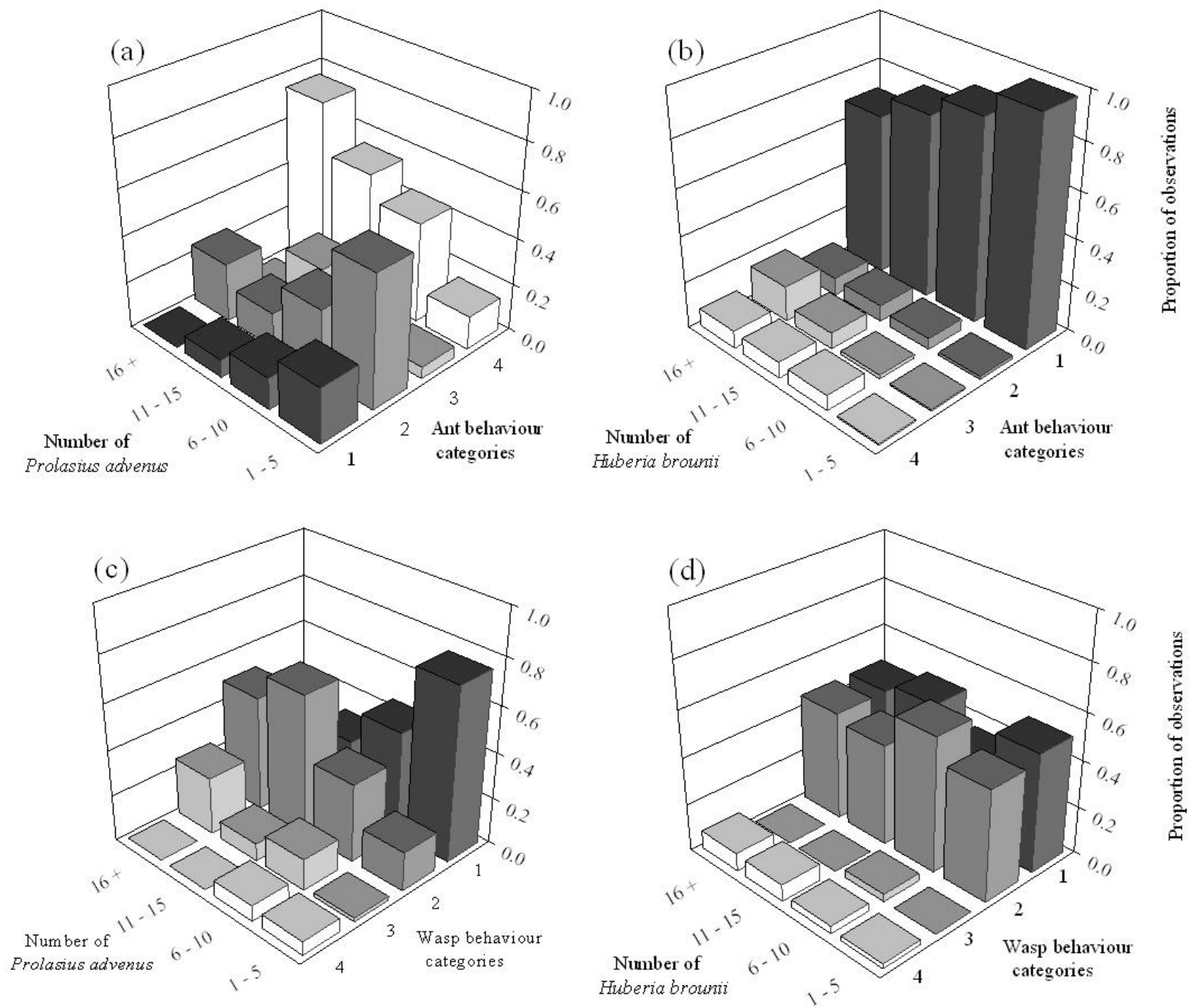

Figure 5.4 Behavioural interactions between two species of native ants (Prolasius advenus and Huberia brounii) and the invasive common wasp Vespula vulgaris

(a) Behavioural responses of $P$. advenus to common wasps. (b) Behavioural responses of $H$. brounii to common wasps. (c) Behavioural responses of common wasps to P. advenus. (d) Behavioural responses of common wasps to H. brounii. Behavioural categories for ants (4a \& 4b) are 1- Retreat, 2- Ignore, 3- Rush, 4Bite. Behavioural categories for common wasps (4c \& 4d) are 1- Ignore, 2- Leave, 3- Distressed, 4- Wasp removed ant. Note that behavioural categories in figure $4 \mathrm{a}$ have been reversed to enable all bars to be seen. Numbers of behavioural observations range from 182 to 238 for this experiment. 


\subsubsection{Forager abundance}

Pitfall and Malaise traps were used to assess forager abundance of both common wasps and ants. Huberia brounii were the most abundant ant present in pitfall traps $\left(\mathrm{F}_{1,38}=\right.$ $6.923, \mathrm{p}=0.012)$, with a mean of $1.75( \pm 0.56)$ ants per trap. In contrast there were $0.75( \pm$ $0.09)$ bush ants per trap. Interestingly we also caught $0.5( \pm 0.22)$ Huberia striata in pitfall traps even though these ants were never present in any of our experimental treatments. For this reason they were excluded from the analysis. There were $128( \pm 26)$ common wasps in each Malaise trap during the sampling period. In contrast with the trapping results, bush ants were the most common ant at food stations, both alone and when common wasps were present (4.16 \pm 0.38 and $2.35 \pm 0.25$ ants per food station respectively) (differences in abundance at food stations are analysed in the wasp or ant exclusion experiments section). Huberia brounii were less numerous at food stations both alone and when common wasps were present $(0.54 \pm 0.05$ and $1.98 \pm 0.17$ ants per food station respectively). There were $0.24 \pm 0.02$ common wasps per food station when they occurred alone and $0.53 \pm 0.04$ and $0.46 \pm 0.06$ per food station when they occurred with $H$. brounii and bush ants respectively.

\subsection{Discussion}

We observed a significant increase in the number of common wasps on foods on which ants were foraging. This increased common wasp foraging resulted in a higher food consumption when both species are present than when they forage alone. There are a number of possible reasons for this result. Firstly, common wasps may be picking up on visual foraging signals from ants. Secondly, common wasp conspecific attraction is 
density-dependent in some Vespula species and they will recruit more when there are already common wasps present at a food source. Some species even preferentially land on feeders occupied by heterospecifics (Richter and Tisch 1999, D'Adamo and Lozada 2005). In our study, an increase in ant numbers on foods was correlated with an increase in the numbers of common wasps. This heterospecific attraction was reflected in greater numbers of common wasps present at baits where ants were also present. Ants appear, therefore, to unwittingly help common wasps access food resources. Additionally, density-dependent foraging behaviour increases the number of aggressive encounters on food resources.

Mechanisms for communication are especially important in social animals. A diverse range of animals use visual and olfactory signals from both conspecifics and heterospecifics to find a food source (Giraldeau 1984). It could be expected that organisms that are related, such as social hymenoptera, or that have a similar evolutionary history, may be able to also use heterospecific signals for foraging. In Vespula wasps, visual signals by resident wasps can influence the foraging behaviour of both conspecific and heterospecific foragers with two out of seven species studied preferentially landing on feeders occupied by heterospecifics (Richter and Tisch 1999). Vespula wasps can also be influenced by visual and pheromone signals from both conspecifics and heterospecifics when foraging (Hendrichs and Hendrichs 1998, D'Adamo and Lozada 2005). Regardless of whether Vespula vulgaris use visual or olfactory signals from foraging ants, they may be using the presence of ants to find a food source. Another hypothesis is that common wasps may forage in greater numbers when there are more competitors present in an attempt to dominate the resource. Alternatively the increase in the average numbers of common wasps when ants are present could, in part, be due to the fact that with ants present a common wasp will frequently retreat and then quickly return to try again. Without ants present the common wasp will spend more time at the food station to gather the maximum 
amount of food possible before returning to the nest, therefore the time spent between visits will be considerably longer when food has been removed. However, these potential hypotheses require further research to investigate their validity as explanations for our observed results.

Common wasps periodically removed ants of both species from food stations. They were more likely to remove bush ants when these ants were at low numbers simply because when there were greater numbers of ants the common wasps could not gain access to the food. In these cases they were observed to land briefly on the side of the food station and then leave. The less aggressive nature of Huberia brounii enabled common wasps to remove these ants when the ants were at high densities without being subject to aggression. The behavioural response of common wasps removing ants was initially thought to be that of predation, however video footage clearly showed common wasps picking up ants and dropping them unharmed no more than $10 \mathrm{~cm}$ from the food. This behaviour seemed to serve the purpose of clearing space at the food station to allow common wasps to feed and may be seen as a novel and extreme form of interference competition that requires further study.

The two native ant species in this study behaved very differently to each other in the presence of common wasps. Bush ants were more aggressive than H. brounii; they seldom retreated from common wasps and were more likely to attack common wasps even when present in relatively low numbers. The aggressive response of bush ants to common wasps generally came from ants that were not actively foraging on the bait but rather around the periphery of the food. This behaviour enabled them to dominate food resources and exclude common wasps, or at least disturb them. Given their disparity in size and the highly aggressive nature of common wasps it is a surprising finding of this study that common wasps are subordinate to bush ants. Masciocchi et al. (2009) concluded that 
aggressive behaviours of native ants in Patagonia combined with worker aggregation may confer a competitive advantage when faced with competition from the invasive wasps $V$. germanica. From our observations it seems that ants leave a food source by choice rather than being excluded by common wasps. Huberia brounii are less aggressive than bush ants. They will more commonly retreat or ignore common wasps and when threatened or surprised will 'play dead' and $H$. brounii did not significantly alter their behavioural responses to common wasps regardless of the number of ants present. Observations during these experiments suggest that $H$. brounii may attack common wasps when they are surprised or cornered and were more likely to attack when present in large numbers but this may be due to the fact that any possible escape route was blocked by other workers, which is in sharp contrast to another exhibited behaviour of 'playing dead' when surprised.

Tanner and Adler (2009) have suggested that aggression may be reduced between existing competitors through the mechanism of an established hierarchy. There is no established hierarchy between these ant species and common wasps as V. vulgaris has only been established in New Zealand for a relatively short period of time. Huberia is an endemic genus and has no historical knowledge of Vespula wasps. Additionally, there are no native Vespula wasps in Australia where the rest of the Prolasius genus is located. Our experiments using a more natural food source (beetles) showed that bush ants were able to co-operatively remove beetles from the food stations potentially enabling these ants more access to the food via scramble competition. Huberia brounii did not exhibit this cooperative behaviour and were present on the beetles in low numbers. In these experiments common wasps were unable to carry the beetle away and were restricted to feeding on it in situ. However when presented with a food resource that was able to be portioned up and carried away (e.g. tuna) common wasps were able to carry off substantially more than ants. Natural resources may be partitioned in a way that common 
wasps are limited by what they can carry away alone whereas ants are able to cooperatively carry off larger insects.

Invasive species often have detrimental effects on communities as their success as invaders may depend on superior competitive abilities facilitated by such behavioural characteristics as interspecific aggression and coloniality (Moller 1996, Holway and Suarez 1999). Invasive predators such as common wasps may alter the existing dynamics of native communities by depleting food sources (Kenis et al. 2009). Native species that display some behavioural plasticity may negate the detrimental effects of competition thereby enabling co-occurrence (Miner et al. 2005). The results of pitfall and Malaise trapping indicate that common wasps were more numerically abundant than ants in this forest system; however, ants were more abundant on food stations. There may be an increase in ant numbers on food to achieve competitive exclusion in the face of an aggressive competitor. In previous studies, increased population size has been shown to negate the potential for the detrimental effects of competition (Adler et al. 2007). Bush ants may be able to assess the benefit of defending a food resource from common wasps and when it is necessary to defend food, more workers are recruited. Huberia brounii were more numerically abundant than bush ants in pitfall traps however there were more bush ants than $H$. brounii present on food stations. This may be a reflection of the different behaviour exhibited by these two ant species, in that bush ants are altogether more aggressive than $H$. brounii. Tanner (2006) determined that ants that are part of a large group are likely to be more aggressive than ants from smaller groups. This increased aggression improved competitive abilities and resource defence. Bush ants reside in colonies that are large and have multiple queens (Don 2007) in contrast to H. brounii whose nests are small. Additionally, it seems that $H$. brounii avoid novel things in their environment which may account for the reduced numbers present on food stations. There 
were also fewer common wasps than ants at food stations. There may have been an effect of our experimental design in this result, in that common wasps may have been somehow repelled from the ant exclusion treatment. Future work could address the issue of the experimental design in a more controlled environment.

In conclusion, common wasps clearly compete with the native ants Prolasius advenus and Huberia brounii, as they compete for the same invertebrate prey and use the same carbohydrate resources (honeydew from the sooty beech scale insect). This study has suggested that common wasps may find and access resources more readily when ants are present. These ants may facilitate foraging by common wasps, demonstrated by the increase in common wasp numbers when foraging in the presence of ants. The outcome of competition is not easy to predict and may vary in different communities and with different densities of competitors. The impact of competition occurring between common wasps and these two native ant species is likely to be density dependant. Additionally competitive responses vary depending on the species of ant and the type of food resource.

\subsection{Acknowledgements}

Zak Murdoch and Julien Grangier provided invaluable field help. Funding was provided by the Royal Society of New Zealand Marsden fund and a Victoria University of Wellington PhD Scholarship. Thanks also to the Department of Conservation for access to land. An earlier draft of the manuscript was greatly improved by comments from two anonymous reviewers. 


\subsection{References}

Adams, E. S. and W. R. Tschinkel. 1995. Density-dependent competition in fire ants: effects on colony survivorship and size variation. Journal of Animal Ecology 64:315-324.

Adler, F. R., E. G. LeBrun, and D. H. Feener. 2007. Maintaining diversity in an ant community: Modelling, extending and testing the dominance-discovery trade-off. The American Naturalist 169:323-333.

Beggs, J. 2001. The ecological consequences of social wasps (Vespula spp.) invading an ecosystem that has an abundant carbohydrate resource. Biological Conservation 99:17-28.

Beggs, J., R. J. Toft, J. P. Malham, J. S. Rees, J. A. V. Tilley, H. Moller, and P. Alspach. 1998. The difficulty of reducing introduced wasp (Vespula vulgaris) populations for conservation gains. New Zealand Journal of Ecology 22:55-63.

Brown, J. H. 1971. Mechanisms of competitive exclusion between two species of chipmunks. Ecology 52:305-311.

Brown, J. H. and D. W. Davidson. 1977. Competition between seed-eating rodents and ants in desert ecosystems. Science 196:880-882.

Chase, J. M., P. A. Abrams, J. P. Grover, S. Diehl, P. Chesson, R. D. Holt, S. A. Richards, R. M. Nisbet, and T. J. Case. 2002. The interaction between predation and competition: a review and synthesis. Ecology Letters 5.

Clapperton, B. K., J. A. V. Tilley, J. R. Beggs, and H. Moller. 1994. Changes in the distribution and proportions of Vespula vulgaris (L.) and Vespula germanica (Fab.) (Hymenoptera: Vespidae) between 1987 and 1990 in New Zealand New Zealand Journal of Zoology 21:295-303.

D'Adamo, P. and M. Lozada. 2005. Conspecific and food attraction in the wasp Vespula germanica (Hymenoptera: Vespidae), and their possible contributions to control. Annals of the Entomological Society of America 98:236-240.

Don, W. 2007. Ants of New Zealand. Otago University Press, Dunedin

Donovan, B. J. 1984. Occurrence of the common wasp, Vespula vulgaris (L.) (Hymenoptera: Vespidae) in New Zealand. . New Zealand Journal of Zoology 11:417-427. 
Giraldeau, L. 1984. Group foraging: the skill pool effect and frequency-dependant learning. The American Naturalist 124:72-79.

Harris, R. J. 1991. Diet of the wasps Vespula vulgaris and V. germanica in honeydew beech forest of the South Island, New Zealand. New Zealand Journal of Zoology 18:159-169.

Hendrichs, M. A. and J. Hendrichs. 1998. Perfumed to be killed: interception of Mediterranean fruit fly (Diptera: Tephritidae) sexual signalling by predatory foraging wasps (Hymenoptera: Vespidae). Annals of the Entomological Society of America 91:228-234.

Holway, D. A. 1999. Competitive mechanisms underlying the displacement of native ants by the invasive Argentine ant. Ecology 80:238-251.

Holway, D. A. and A. V. Suarez. 1999. Animal behaviour: an essential component of invasion biology. Trends in Ecology and Evolution 14:328-330.

Human, K. G. and D. M. Gordon. 1999. Behavioural interactions of the invasive Argentine ant with native ant species. Insectes Sociaux 46:159 - 163.

Kenis, M., M. Auger-Rozenberg, A. Roques, L. Timms, C. Péré, M. J. W. Cook, J. Settele, S. Augustin, and C. Lopez-Vaamonde. 2009. Ecological effects of invasive alien insects. Biological Invasions 11:21 - 45.

Lester, P. J., K. L. Abbott, M. Sarty, and K. C. Burns. 2009. Competitive assembly of South Pacific invasive ant communities. BMC Ecology 9.

Masciocchi, M., A. Farji-Brener, and P. Sackmann. 2009. Competition for food between the exotic wasp Vespula germanica and the native ant assemblage of NW Patagonia: evidence of biotic resistance? Biological Invasions DOI

\subsection{7/s10530-009-9469-5.}

Matthews, R. W., M. A. D. Goodisman, A. D. Austin, and R. Bashford. 2000. The introduced English wasp Vespula vulgaris (L.) (Hymenoptera: Vespidae) newly recorded invading forests in Tasmania. Australian Journal of Entomology 39:177179.

McColl, H. P. 1975. The invertebrate fauna of the litter surface of a Nothofagus truncata forest floor, and the effect of microclimate on activity. New Zealand Journal of Ecology 2:15-34.

McNatty, A., K. L. Abbott, and P. J. Lester. 2009. Invasive ants compete with and modify the trophic ecology of hermit crabs on tropical islands. Oecologia 160:187 - 194. 
Miner, B. G., S. E. Sultan, S. G. Morgan, D. K. Padilla, and R. A. Relyea. 2005. Ecological consequences of phenotypic plasticity. Trends in Ecology and Evolution 20:685692.

Moller, H. 1996. Lessons for invasion theory from social insects. Biological Conservation 78:125-142.

Moller, H. and J. A. V. Tilley. 1989. Beech honeydew: seasonal variation and use by wasps, honey bees, and other insects. New Zealand Journal of Zoology 16:289-302.

Mooney, H. A. and E. E. Cleland. 2001. The evolutionary impact of invasive species. Proceedings of the National Academy of Sciences 98:5446-5451.

Richter, M. R. and V. L. Tisch. 1999. Resource choice of social wasps: influence of presence, size and species of resident wasps. Insectes Sociaux 46:131-136.

Sagata, K. and P. J. Lester. 2009. Behavioural plasticity associated with propagule size, resources, and the invasion success of the Argentine ant Linepithema humile. Journal of Applied Ecology 46:190-027.

Sanders, N. J. and D. M. Gordon. 2003. Resource-dependent interactions and the organization of desert ant communities. Ecology 84:1024-1031.

Shuttack, S. O. 2000. Australian ants: their biology and identification. CSIRO Publishing, Collingwood, VIC.

SPSS. 2008. Release 16.0 Chicago SPSS inc.

Tanner, C. J. 2006. Numerical assessment affects aggression and competitive ability: a team-fighting strategy for the ant Formica xerophila. Proceedings of the Royal Society of London B 273:2737-2742.

Tanner, C. J. and F. R. Adler. 2009. To fight or not to fight: context-dependent interspecific aggression in competing ants. Animal Behaviour 77:297-305.

Thomas, C. D., H. Moller, G. M. Plunkett, and R. J. Harris. 1990. The prevalence of introduced Vespula vulgaris wasps in a New Zealand beech forest community. New Zealand Journal of Ecology 13:63-72. 


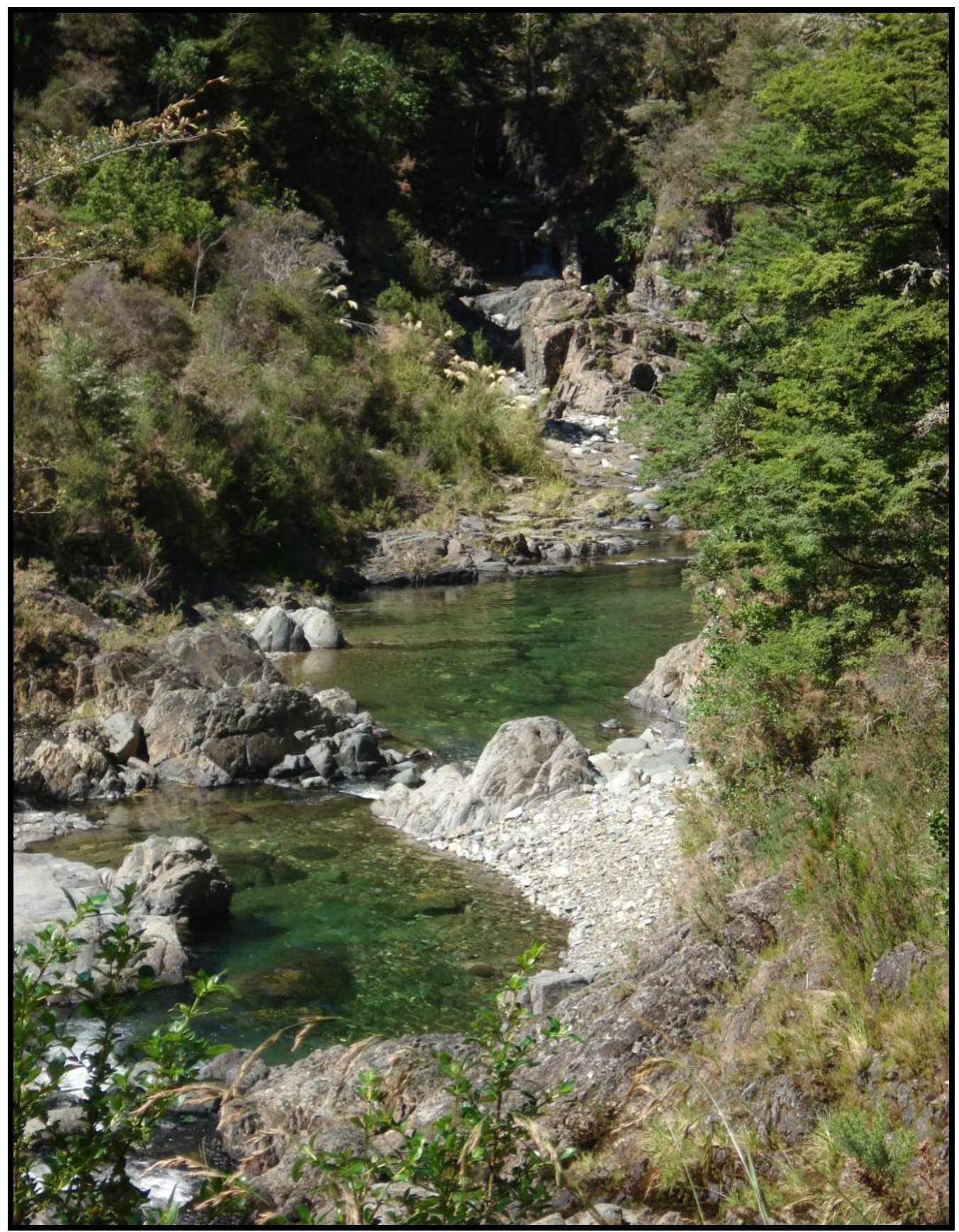

The Roding River 


\section{6}

\section{Chapter Six}

\section{General Discussion}

In this thesis I investigated the factors which may promote coexistence between endemic and invasive species which use a common resource. A summary of findings of this thesis are as follows: (1) the invertebrate community composition of the Nothofagus forest was significantly altered by the presence of the invasive common wasp Vespula vulgaris; (2) temporal separation of foraging, with distinct diurnal patterns, occurred between the native bush ant Prolasius advenus and Vespula vulgaris; (3) trophic levels of native bush ants changed in response to the removal of invasive common wasps; and (4) there was density dependant behavioural plasticity in competitive interactions between both the native ants Huberia brounii and Prolasius advenus, and the invasive common wasp Vespula vulgaris. Further, these findings have implications for the ecology of Nothofagus forests for our understanding of the considerable impact that invasive species may have on native ecosystems and particularly those species which have similar requirements. Additionally, this thesis provides important observations of the ecology and behaviour of two native ant species about which very little is known. 
Communities under pressure from predators may exhibit a decrease in the abundance and diversity of native species (Human and Gordon 1999, Snyder and Evans 2006, Rowles and O'Dowd 2007, Bøhn et al. 2008). The invasive common wasp Vespula vulgaris is a voracious predator, which is known to have significant impact on the native fauna of Nothofagus forests (Thomas et al. 1990, Beggs 2001, Beggs and Wardle 2006).

Because of the previously documented effects of common wasp predation I predicted that a reduction in common wasp numbers would result in a significant change in the community composition. After common wasp numbers were experimentally reduced I observed a substantial difference in the invertebrate community. The observed changes in community composition were as a result of differing abundances of families. I observed an overall decline in the numbers of many families over the summer period. This decline has implications for the trophic levels of other predacious species that co-occur with common wasps as protein resources become much more limited. The effect of resource limitation on isotope ratios and trophic levels is investigated in chapter four.

Under pressure from invasive omnivorous species, such as Vespula wasps, the abundance of prey species may decline as a result of increased predation (Harris 1991, Toft and Rees 1998). We may then see a consequent, indirect, decline in the number of other predacious species. Native ant species share many similar resource requirements with common wasps (Don 2007), and consequently may be particularly impacted by reduced prey availability due to common wasp predation and competition. Therefore, this study assessed the impact of common wasp reduction on two native ant species, The New Zealand bush ant, Prolasius advenus, and Huberia brounii.

There was a decline in ant numbers caught in traps between sampling periods. In particular, the decline in numbers of bush ants contributed most to the observed change in overall community structure. Conversely, Huberia brounii increased in number 
independently of the reduction in common wasp numbers. Common wasps alter their resource use seasonally depending on the nutritional needs of the colony (Harris 1991), so populations of competing species, such as native ants, which also use a variety of food resources, both protein and carbohydrate, may remain stable in number or even increase in abundance when pressure comes off some part of their normal diet. There are several explanations for the observed results. The most parsimonious explanation may be that we did not reduce common wasp numbers sufficiently to see a corresponding change in the invertebrate community. In order to more robustly determine the community effects of wasp removal it may be necessary to reduce common wasp numbers by up to $90 \%$ for many years (Beggs et al. 1998, Toft and Rees 1998, Beggs and Rees 1999). Even under these conditions species that are particularly vulnerable to common wasp predation or competition may have already been permanently excluded from this system.

In forests such as that at Nelson Lakes National park where an extensive annual poisoning program is in place, a seasonal reduction in the numbers of common wasps has the potential to lead to an increase in the abundance of food available to those common wasps that remain. This increase in food may lead to an increase in the quality of surviving queens, which in turn, may be able to establish more nests in the following year (Beggs et al. 1998). Therefore, it may be the case that repeated poisoning of an area to reduce common wasp numbers actually increases nest density in the early summer before the annual poisoning event. This increase in nest density may have the unintended consequence of increasing predation of native invertebrates, and thereby reducing, even further, the diversity and abundance of invertebrates in this system.

It would appear that as poisoning is not possible earlier in the season, and repeated poisoning may have the effect of increasing wasp numbers, there may be no solution to a long term reduction in wasp numbers. In order to be of benefit to the invertebrate 
community wasps need to be reduced by more than $90 \%$ therefore; more research needs to be done on how to achieve this. It may be that to cease the poisoning operation and allow wasps to persist in this environment is a realistic outcome in light of the difficulties in reducing common wasp numbers sufficiently. There will always be high numbers of common wasps present in these Nothofagus forests due to the abundant carbohydrate resource, and the area that is currently under poison control is a relatively small portion of total Nothofagus forest present in the South Island. Unfortunately the invertebrate community in these forests may have already suffered irretrievable losses.

Invasive species, when released from competition or predation, may increase in number rapidly and dominate niche space to the detriment of native species (Sakai et al. 2001, Amarasekare 2002, Tillman 2004). Native species affected by invasive organisms may continue to persist by altering the way in which they use shared resources (Amarasekare 2003, Ricklefs 2004). Additionally, spatial heterogeneity may provide opportunities for resource partitioning and promote coexistence (Shurin et al. 2004). Understanding resource partitioning is fundamental to understanding strategies of resource use, the effects of competition, and the mechanisms of coexistence (Abrams 1980).

In chapter three I investigated possible temporal niche shifts by bush ants in response to the presence of common wasps. In the face of a dominant invasive species, I hypothesised that the native ants in Nothofagus forests may have adjusted their pattern of resource use to avoid interspecific aggression or exclusion from resources. For example, bush ants and common wasps could potentially partition the honeydew resource spatially with bush ants concentrating their foraging lower on the tree trunks and common wasps foraging mainly in the canopy. The honeydew resource is concentrated in the canopy (Beggs et al. 2005, Wardhaugh et al. 2006). Common wasps are likely to be able to better access this resource than bush ants, which may be energetically confined to foraging lower 
on the tree. Bush ants are capable of climbing to the canopy, however the energy required to concentrate their foraging there makes this unlikely. Bush ants may therefore be limited to a less abundant resource lower on the trunks. I hypothesised that bush ants may compensate for this by continuing to forage throughout the night when common wasps are absent; however, this behaviour may not be as a direct result of competitive pressure. When there is direct competition for a food resource there may an advantage in some degree of behavioral plasticity I investigate the idea of density dependent behavioral plasticity in chapter five.

Because both bush ants and common wasps potentially compete for the same food resources, I predicted that I would see fewer bush ants foraging in areas of higher common wasp abundance. Additionally, bush ants and common wasps may partition the honeydew resource temporally to avoid direct competition. As bush ants have been observed foraging nocturnally I expected to see more bush ants foraging at night in areas of higher common wasp abundance. There was no evidence of temporal niche partitioning even though bush ants forage at night and common wasps do not. There were no more bush ants foraging nocturnally than there were foraging diurnally. Temporal separation is common amongst ants in hot climates where conditions may be lethal to some species, giving sole access to those species able to tolerate extreme temperatures (Vepsäläinen and Savolainen 1990, Cerdá et al. 1997, Andersen 2008, Lessard et al. 2009). A similar but opposite effect may be seen here, where common wasps are unable to tolerate colder temperatures at night and must confine their foraging to the day (Heinrich 1984).

In order to better understand patterns of resource use, I experimentally reduced numbers of common wasps. I predicted that this reduction of a dominant competitor may provoke an increase in the number of bush ants foraging during the day, and reduce any difference between the numbers of bush ants foraging both diurnally and nocturnally. I 
observed an increase in the numbers of bush ants foraging on honeydew when I experimentally reduced common wasp numbers. When common wasp numbers are at their peak they are capable of removing up to $99 \%$ of the standing honeydew crop, in addition with such high honeydew use the quality of the drops declines (Moller et al. 1991). Consequently, bush ants may have to forage more on the lesser quality honeydew for the same nutritional pay-off as higher quality honeydew in the absence of wasps. Therefore the observed increase in the numbers of bush ants foraging on honeydew may be due to a change in both the quantity and quality of the available honeydew. Given that wasps have both an effect on the invertebrate community composition in Nothofagus forests and on the foraging patterns of native bush ants it may be expected that the trophic levels of ants will change in response to competition from wasps.

Competition between species for a food resource can be a driving force structuring ecosystems (Brown and Davidson 1977). Niche adjustments by species with overlapping resource requirements may enable coexistence (Mooney and Cleland 2001, Gilbert et al. 2008). Stable isotopes can provide a sensitive indicator of environmental change to quantify the impacts of species invasions on natural food webs (Vander Zanden et al. 1999). Social hymenoptera such as bush ants and common wasps coexist on similar trophic levels; they both simultaneously fill multiple trophic roles as primary predators, secondary predators, and primary consumers (Mooney and Tillberg 2005). In chapter four I examined the effect of an invasive species on the trophic level of native competitors, using as a study system the native bush ant Prolasius advenus and the invasive common wasp Vespula vulgaris. I asked if the isotope ratios and trophic level of native competitors changed in response to the reduction in number of this invasive species.

In the pre-poisoning sampling period both native bush ants and invasive common wasps showed an increase in $\delta^{15} \mathrm{~N}$ enrichment in the wasps-controlled sites relative to the 
wasps-maintained sites. This relative increase may be related to the greater number of wasps in the wasps-maintained sites in this pre-poisoning period meaning that relatively more prey items were available in the wasps-controlled sites.

However, results showed that the overall trophic level of native ants was higher than that of the invasive common wasps, though both are well within the range of a secondary consumer (Vander Zanden et al. 1999). There was a significant effect of time, with the trophic level of both ants and common wasps increasing between sampling periods. The observed changes in the trophic levels of both bush ants and common wasps may be as a result of natural seasonal variation in food consumption related to the nutritional requirements of the colony. This change may be due to an increase in predation due to the nutritional requirements of new brood (Behmer 2009, Dussutour and Simpson 2009).

The trophic levels of bush ants appear not to be impacted significantly by competition from wasps, and yet common wasps have a detrimental and well documented effect on the invertebrate community. Therefore, it may be the case that bush ants are able to forage at night for protein resources that during the day they are excluded from. In chapter three I investigated temporal foraging patterns of bush ants on the honeydew resource and found no significant difference in honeydew use over a 24 hour period. I did not investigate predation by ants during this time. I did, however, observe ants attacking and killing several invertebrates during the night, so it might not be unreasonable to expect that bush ants may exploit this hunting opportunity without interference from common wasps.

As intense predation and competition pressure from an invasive species may impact populations of other predators, I asked if the trophic positions and isotope ratios of these other predators change in response to the reduction of an invasive species. Common wasps are known to consume an extraordinary amount of invertebrate prey during the summer months to the detriment of all other predators in these forests (Beggs et al. 1998, Beggs 
2001), however, my results showed no evidence that common wasps are having a deleterious effect on the diet of the other secondary predators tested, as there was no change in enrichment of $\delta^{15} \mathrm{~N}$ and $\delta^{13} \mathrm{C}$ of Carabidae as a result of the experimental reduction of common wasp numbers and only a small change in the enrichment of $\delta^{15} \mathrm{~N}$ of spiders. Elsewhere spiders and Carabidae have also remained abundant in areas subject to invasion by Argentine ants (Tillberg et al. 2007). Therefore, the observed changes in trophic levels of spiders and Carabidae may be as a result of natural seasonal variation in diet.

A more detailed comparison of the diets of common wasps, spiders and Carabidae would help determine the impact of increasing common wasp numbers on these other predators. The impacts of species invasions are complex, particularly among those species that fill multiple trophic roles. Native species that persist in the face of invasions may alter their resource use to enable coexistence. Further research is needed to determine if native competitors in my study sites have altered their diet in the face of this common wasp invasion. Native ants and common wasps manage to co-occur in the same environment using similar resources and yet there appears to be no reduction in number, trophic level, or foraging opportunity for these ants. It seems likely that the mechanism of co-occurrence may have a basis in behavioural adaptations.

Interspecific competition between species on the same trophic level often leads to a competitively dominant species displacing a subordinate species at food resources, and can result in competitive exclusion (Brown 1971, Holway 1999). However, competitive exclusion is not the only outcome and some competitors manage to coexist despite differences in dominance. It is possible that behavioural adaptations by native species to dominant invaders may enable species co-occurrence in the face of competition for resources (Mooney and Cleland 2001). The specific goal of chapter five was to determine 
whether the presence of exotic wasps influenced the foraging success of native ants, or conversely whether the presence of native ants influences the foraging success of invasive common wasps.

Wasps clearly compete with the native bush ants and Huberia brounii, as all species consume invertebrate prey and common wasps and bush ants use the same carbohydrate resources (honeydew from the sooty beech scale insect) (McColl 1975, Moller and Tilley 1989, Harris 1991, Don 2007). I observed that significantly more common wasps visited food stations with ants present than those without. Additionally, there were significantly more common wasps present on foods in the presence of $H$. brounii than were present on foods in the presence of bush ants. This study has suggested that wasps may find and access resources more readily when native ants are present. Common wasps may be picking up on visual or olfactory foraging signals from native ants. Common wasp conspecific attraction is density-dependent in some Vespula species and they will recruit more when there are already wasps present at a food source, some species even preferentially land on feeders occupied by heterospecifics (Richter and Tisch 1999, D'Adamo and Lozada 2005).

I tested if aggressive behaviour of wasps or ants is density-dependent. Additionally, I assessed whether numerical dominance corresponds to behavioural dominance at food resources. Bush ants were significantly more likely to attack common wasps when these ants were present in greater numbers. Bush ants seldom retreated from resources and this behavioural response decreased as the numbers of workers increased. However, the predominant behavioural response of Huberia brounii is to ignore common wasps. When common wasps foraged in the presence of bush ants they were more likely to ignore the ants, when ants were present in low numbers, and more likely to leave when there were 
more ants present. More bush ants were removed by common wasps when ants were at low abundances. Common wasps seldom showed any response to the presence of $H$. brounii.

Both bush ants and $H$. brounii may facilitate foraging by wasps, demonstrated by the increase in wasp numbers when foraging in the presence of ants. Masciocchi et al. (2009) concluded that aggressive behaviours of native ants in Patagonia combined with worker aggregation may confer a competitive advantage when faced with competition from the invasive wasps $V$. germanica. The behavioural response of common wasps removing ants seemed to serve the purpose of clearing space at the food station to allow common wasps to feed, and may be seen as a novel and extreme form of interference competition that requires further study.

The outcome of competition is not easy to predict and may vary in different communities and with different densities of competitors. The impact of competition occurring between common wasps and these two native ant species is likely to be density dependant. Additionally competitive responses vary depending on the species of ant and the type of food resource. Coexistence between endemic and invasive competitors is possible through two important mechanisms, niche separation and behavioural adaptations. I investigated temporal niche separation in chapter three and found that bush ants continue to forage throughout the night when common wasps are absent, this combined with the density-dependent behavioural adaptations displayed by bush ants towards common wasps may enable co-occurrence between native bush ants and invasive common wasps.

\subsection{Considerations for future research}

This thesis provides important observations of the ecology and behaviour of two native ant species, about which very little is known. In particular, this research focussed on the factors which may promote coexistence between an endemic and an invasive species. The 
invasive wasp Vespula vulgaris and the native ants Huberia brounii and Prolasius advenus not only coexist in the same environment but also utilise very similar, if not identical, resources. Wasps and both species of ants are predators of invertebrates and both wasps and bush ants collect honeydew from the scale insects that infest the bark of Nothofagus trees. Despite this similarity in resource use, wasps and both species of ant remain numerous in Nothofagus forests when theory would predict that the negative effects of intraspecific competition would limit numbers of the weaker competitors.

One of the major limiting factors of this study is the lack of a honeydew beech forest that has not been invaded by wasps. We simply have no knowledge of the invertebrate fauna prior to wasp invasion. Nor were we, in this study, able to control common wasp densities sufficiently to robustly detect an effect. It has been estimated that for the invertebrate community to recover from competition and predation pressure from common wasps it is necessary to reduce common wasp densities by more that $90 \%$ (Beggs et al. 1998, Toft and Rees 1998, Beggs and Rees 1999).

Any study conducted entirely in the field will have variation that is unable to be controlled, if indeed it is able to be identified. A clear example of this in evident in chapter three where because of an existing long term poisoning program at Nelson Lakes National Park we were confined to working in just two sites in the one location. Any result from this study needs to be interpreted in the light of potential peculiarities of this single location. Additionally, differences that may arise as a result of differences in elevation and microclimate between sites could be further investigated. Future direction on this research topic should involve laboratory studies to control for environmental effects.

Food preference trials of both ants and wasps would assist in understanding the possible impacts of predation in a natural environment. This would go some way to disentangling the effects of predation and natural seasonal variation in abundance. 
Additionally, the observations of increased numbers of common wasps present on foods with increased numbers of native ants provide a tantalising first taste of potential facilitation between these species. The mechanism, either visual or olfactory, which provokes this behaviour, deserves attention.

A more detailed investigation of the effects of the exclusion experiments used in chapter five should be undertaken in a controlled environment to investigate the effect of the exclosures on ant and wasp behaviour. It is possible that some of the results were confounded by a novel addition to the environment. Huberia brounii are not a particularly aggressive species and may have avoided the exclosures. Additionally behavioural interactions between these species could be tested in the more controlled environment of and artificial arena. This would remove any confounding factors due to environmental stimulus and concentrate solely on the interactions. This would also enable trials to be conducted to robustly investigate the density dependence of the aggressive response by bush ants.

This research provides the first experimental evidence of honeydew foraging by native ants in Nothofagus forests, and adds to the relatively small body of literature about the behaviour and ecology of two of our native ant species. It would appear that the native ants present in Nothofagus forests in my study sites, unlike most other invertebrates, are not adversely impacted by competition or predation from common wasps. 


\subsection{References}

Abrams, P. 1980. Some comments on measuring niche overlap. Ecology 61:44-49.

Amarasekare, P. 2002. Interference competition and species coexistence. Proceedings of the Royal Society of London B 269:2541-2550.

Amarasekare, P. 2003. Competitive coexistence in spatially structured environments: a synthesis. Ecology Letters 6:1109-1122.

Andersen, A. N. 2008. Not enough niches: non-equilibrial processes promoting species coexistence in diverse ant communities. Austral Ecology 33:211-220.

Beggs, J. 2001. The ecological consequences of social wasps (Vespula spp.) invading an ecosystem that has an abundant carbohydrate resource. Biological Conservation 99:17-28.

Beggs, J. R. and J. S. Rees. 1999. Restructuring of Lepidoptera communities by introduced Vespula wasps in a New Zealand beech forest. Oecologia 119:565-571.

Beggs, J., R. J. Toft, J. P. Malham, J. S. Rees, J. A. V. Tilley, H. Moller, and P. Alspach. 1998. The difficulty of reducing introduced wasp (Vespula vulgaris) populations for conservation gains. New Zealand Journal of Ecology 22:55-63.

Beggs, J. and D. A. Wardle. 2006. Keystone species: Competition for honeydew among exotic and indigenous species. Springer-Verlag, Berlin.

Beggs, J. R., B. J. Karl, D. A. Wardle, and K. I. Bonner. 2005. Soluble carbon production by honeydew scale insects in a New Zealand beech forest. New Zealand Journal of Ecology 29:105-115.

Behmer, S. T. 2009. Animal behaviour: Feeding the superorganism. Current Biology 19:R366 - R368.

Bøhn, T., P. Amundsen, and A. Sparrow. 2008. Competitive exclusion after invasion? Biological Invasions 10:359-368.

Brown, J. H. 1971. Mechanisms of competitive exclusion between two species of chipmunks. Ecology 52:305-311.

Brown, J. H. and D. W. Davidson. 1977. Competition between seed-eating rodents and ants in desert ecosystems. Science 196:880-882.

Cerdá, X., J. Retana, and S. Cros. 1997. Thermal disruption of transitive hierarchies in Mediterranean ant communities. Journal of Animal Ecology 66:363-374 
D'Adamo, P. and M. Lozada. 2005. Conspecific and food attraction in the wasp Vespula germanica (Hymenoptera: Vespidae), and their possible contributions to control. Annals of the Entomological Society of America 98:236-240.

Don, W. 2007. Ants of New Zealand. Otago University Press, Dunedin

Dussutour, A. and S. J. Simpson. 2009. Communal nutrition in ants. Current Biology 19:740 - 744.

Gilbert, B., D. S. Srivastava, and K. R. Kirby. 2008. Niche partitioning at multiple scales facilitates coexistence among mosquito larvae. Oikos 117:944-950.

Harris, R. J. 1991. Diet of the wasps Vespula vulgaris and V. germanica in honeydew beech forest of the South Island, New Zealand. New Zealand Journal of Zoology 18:159-169.

Heinrich, B. 1984. Strategies of thermoregulation and foraging in two vespid wasps, Dolichovespula maculata and Vespula vulgaris. Journal of Comparative Physiology B 154:175-180.

Holway, D. A. 1999. Competitive mechanisms underlying the displacement of native ants by the invasive Argentine ant. Ecology 80:238-251.

Human, K. G. and D. M. Gordon. 1999. Behavioural interactions of the invasive Argentine ant with native ant species. Insectes Sociaux 46:159 - 163.

Lessard, J.-P., R. R. Dunn, and N. J. Sanders. 2009. Temperature-mediated coexistence in temperate forest ant communities. Insectes Sociaux 56:149-156.

Masciocchi, M., A. Farji-Brener, and P. Sackmann. 2009. Competition for food between the exotic wasp Vespula germanica and the native ant assemblage of NW Patagonia: evidence of biotic resistance? Biological Invasions DOI

\subsection{7/s10530-009-9469-5.}

McColl, H. P. 1975. The invertebrate fauna of the litter surface of a Nothofagus truncata forest floor, and the effect of microclimate on activity. New Zealand Journal of Ecology 2:15-34.

Moller, H. and J. A. V. Tilley. 1989. Beech honeydew: seasonal variation and use by wasps, honey Bees, and other insects. New Zealand Journal of Zoology 16:289302.

Moller, H., J. A. V. Tilley, B. W. Thomas, and P. D. Gaze. 1991. Effect of introduced social wasps on the standing crop of honeydew in New Zealand beech forests. New Zealand Journal of Zoology 18:171-179. 
Mooney, H. A. and E. E. Cleland. 2001. The evolutionary impact of invasive species. Proceedings of the National Academy of Sciences 98:5446-5451.

Mooney, K. A. and C. V. Tillberg. 2005. Temporal and spatial variation to ant omnivory in pine forests. Ecology 86:1225-1235.

Richter, M. R. and V. L. Tisch. 1999. Resource choice of social wasps: influence of presence, size and species of resident wasps. Insectes Sociaux 46:131-136.

Ricklefs, R. E. 2004. A comprehensive framework for global patterns in biodiversity. Ecology Letters 7:1-15.

Rowles, A. D. and D. J. O'Dowd. 2007. Interference competition by Argentine ants displaces native ants: implications for biotic resistance to invasion. Biological Invasions 9:73-85.

Sakai, A. K., F. W. Allendorf, J. S. Holt, D. M. Lodge, J. Molofsky, K. A. With, S. Baughman, R. J. Cabin, J. E. Cohen, N. C. Ellstrand, D. E. McCauley, P. O'Neil, I. M. Parker, J. N. Thompson, and S. G. Weller. 2001. Population biology of invasive species. Annual Review of Ecology, Evolution, and Systematics 32:305-332.

Shurin, J. B., P. Amarasekare, J. M. Chase, R. D. Holt, M. F. Hoopes, and M. A. Leibold. 2004. Alternative stable states and regional community structure. Journal of Theoretical Biology 227:359-368.

Snyder, W. E. and E. W. Evans. 2006. Ecological effects of invasive arthropod generalist predators. Annual Review of Ecology, Evolution, and Systematics 37:95-122.

Thomas, C. D., H. Moller, G. M. Plunkett, and R. J. Harris. 1990. The prevalence of introduced Vespula vulgaris wasps in a New Zealand beech forest community. New Zealand Journal of Ecology 13:63-72.

Tillberg, C. V., D. A. Holway, E. G. LeBrun, and A. V. Suarez. 2007. Trophic ecology of invasive Argentine ants in their native and introduced ranges. Proceedings of the National Academy of Sciences 104:20856-20861.

Tillman, D. 2004. Niche tradeoffs, neutrality, and community structure: A stochastic theory of resource competition, invasion, and community assembly. Proceedings of the National Academy of Sciences 101:10854-10861.

Toft, R. J. and J. S. Rees. 1998. Reducing predation of orb-web spiders by controlling common wasps (Vespula vulgaris) in a New Zealand beech forest. Ecological Entomology 23:90-95. 
Vander Zanden, M. J., J. M. Casselman, and J. B. Rasmussen. 1999. Stable isotope evidence for the food web consequences of species invasions in lakes. Nature 401:464-467.

Vepsäläinen, K. and R. Savolainen. 1990. The effect of interference by formicine ants on the foraging of Myrmica. Journal of Animal Ecology 59:643-654.

Wardhaugh, C. W., T. J. Blakely, H. Greig, P. D. Morris, A. Barnden, S. Rickard, B. Atkinson, L. L. Fagan, R. M. Ewers, and R. K. Didham. 2006. Vertical stratification in the spatial distribution of the beech scale insect (Ultracoelostoma assimile) in Nothofagus tree canopies in New Zealand. Ecological Entomology 31:185-195. 